No.1734

Revised November 2021

(Replaced December 2020 version)

\title{
All aboard: the effects of port development
}

César Ducruet

Réka Juhász

Dávid Krisztián Nagy

Claudia Steinwender 


\begin{abstract}
Transport infrastructure facilitates the fast flow of goods and people across space, but it also occupies extensive amounts of land. This may drive up land rents and crowd out other economic activity. Using the introduction of containerized shipping - a relatively land-intensive technology - we find an important role for this crowding-out effect. At the local level, we find that seaport development increases city population by making a city more attractive, but this well-known market access effect is offset by the crowding-out mechanism. At the aggregate level, while we estimate overall welfare gains from containerization, our quantitative model featuring endogenous port development also implies i) sizeable welfare costs associated with the increased land-usage of ports, and ii) sizeable gains from cities' endogenous specialization across port- and non-port activities. These mechanisms are particularly important for targeted port development policies, which we illustrate by evaluating the effects of the Maritime Silk Road.
\end{abstract}

Key words: port development, containerization, quantitative economic geography JEL codes: R40; O33; F6

This paper was produced as part of the Centre's Trade Programme. The Centre for Economic Performance is financed by the Economic and Social Research Council.

\title{
Acknowledgements
}

We thank Treb Allen, David Atkin, Leah Brooks, Arnaud Costinot, Don Davis, Dave Donaldson, Joseph Doyle, Nicolas Gendron-Carrier, Matt Grant, Gordon Hanson, Tarek Hassan, Tom Holmes, David Hummels, Amit Khandelwal, Giampaolo Lecce, Nelson Lind, Nina Pavcnik, Giacomo Ponzetto, Jim Rauch, Steve Redding, Roberto Rigobon, Andrés Rodríguez-Clare, Esteban Rossi-Hansberg, Daniel Sturm, Tavneet Suri, Jaume Ventura, Jon Vogel and David Weinstein for helpful comments and discussions. We thank Bruce Blonigen, Mario Martín Antón and their co-authors for kindly sharing data. We thank staff at the Port Authorities of Houston, New Orleans, Long Beach, Los Angeles, Portland, San Francisco and Seattle for helping with our information requests. Olalekan Bello, Sabrina Chen, Naman Garg, Yi Jie Gwee, Hamza Husain, Felix Iglhaut, Rodrigo Martínez Mazza, Emanuela Migliaccio, Véronica Perez, Shuhua Si, Yue Yu, Howard Zihao Zhang and a team of Columbia University undergraduate students provided outstanding research assistance. César gratefully acknowledges financial support from the ERC (Starting Grant 'World Seastems' No. 313847). Réka is grateful for financial support from the Provost's Office at Columbia. Dávid acknowledges financial support from the Spanish Ministry of Economy and Competitiveness, through the Severo Ochoa Programme for Centres of Excellence in RD (CEX2019-000915-S and SEV-2015-0563) and through a Juan de la Cierva Grant (FJCI-2017-34728), the Spanish State Research Agency and the European Social Fund (RYC2019-027620-I / AEI / 10.13039/501100011033) and from the Generalitat de Catalunya, through CERCA and SGR Programme (2017SGR-1393).

César Ducruet, CNRS. Réka Juhasz, Columbia University, NBER and CEPR. Dávid Krisztián, CREI and CEPR. Claudia Steinwender, LMU Munich, NBER, CEPR and Centre for Economic Performance, London School of Economics.

Published by

Centre for Economic Performance

London School of Economics and Political Science

Houghton Street

London WC2A 2AE

All rights reserved. No part of this publication may be reproduced, stored in a retrieval system or transmitted in any form or by any means without the prior permission in writing of the publisher nor be issued to the public or circulated in any form other than that in which it is published.

Requests for permission to reproduce any article or part of the Working Paper should be sent to the editor at the above address.

(C) C. Ducruet, R. Juhász, D.K. Nagy and C. Steinwender, revised 2021. 


\section{Introduction}

Transport infrastructure is a ubiquitous feature of the modern landscape. Ports, roads, airports and railways facilitate trade in goods and the movement of people across space. However, they also occupy extensive amounts of land, particularly in cities (Manville and Shoup, 2005). For example, transport infrastructure occupies $18 \%$ of urban land within 5 kilometers of the center of Paris (Duranton and Puga, 2015). In Antwerpen and Rotterdam, the seaport alone occupies more than $30 \%$ of the city (OECD, 2014). By using locally scarce land resources intensively, transport infrastructure development has the potential to drive up land rents and crowd out other economic activity (Solow and Vickrey, 1971; Solow, 1972; Pines and Sadka, 1985). While the benefits of transport infrastructure development are well-understood, ${ }^{1}$ the cost side has not been quantified. ${ }^{2}$

In this paper, we provide evidence that the cost side matters both at the local and at the aggregate level using the example of seaport development. We use a major shock to maritime port technology, the containerization revolution that took place in the mid-20th century, to identify both the benefits and costs of port development. This setting is ideal, as rich historical evidence and systematic contemporary data show that containerization substantially increased the land intensity of port technology.

To isolate exogenous variation in a city's suitability for containerization, we build on a previous literature that has shown that access to deep water at the port is important for containerization (Brooks, Gendron-Carrier, and Rua, 2021; Altomonte, Colantone, and Bonacorsi, 2018). Using a novel measure of 'naturally endowed' depth (as distinct from depth attained by dredging) based on granular data on oceanic depths around a port, we find that cities exogenously more suited to this new technology witnessed a boom in shipping flows after the onset of containerization, but not before.

Combining a unique dataset of city populations and shipping flows worldwide for the period 1950-1990 with exogenous variation from naturally endowed depth, we provide several empirical results that point to the importance of the cost side for port development. We begin by estimating the causal effect of shipping on local, city-level population and fail to find a statistically significant effect. That is, cities that had higher shipping flows as a result of containerization did not experience inflows of population that are statistically distinguishable from zero. The IV point estimate is close to zero, and the implied economic magnitude is small. Given that increased trade through a city tends to have a positive effect on population by making the location more attractive for consumers and firms (the standard market access effect - Donaldson and Hornbeck, 2016; Redding and Turner, 2015), this finding suggests the presence of an offsetting negative force.

\footnotetext{
${ }^{1}$ See Redding and Turner (2015) for a recent survey of the literature.

${ }^{2}$ An exception is Brinkman and Lin (2019) who explore the disamenities associated with freeway construction in mid-20th century U.S. cities.
} 
To test for the presence of positive as well as negative forces, we decompose the effect of shipping on population guided by our structural model of port development. Our structural IV estimation shows that once the market access benefits of port development are accounted for, the effect of increased shipping on population is negative and statistically significant. This provides causal evidence for the local costs of containerization in the form of crowding out population.

We also show that this local cost influences the location of port development. First, to the extent that the land price mechanism is empirically important, we would expect low land-rent cities to be more attractive places for containerized ports. This is exactly what we find. Using the widely used Saiz measure (Saiz, 2010) as a proxy for land rents, we find that shipping increased disproportionately more in low land-rent cities. Second, we also find evidence consistent with the land price mechanism at work within cities. In particular, we show that ports moved towards the outskirts of the city, where land rents are typically lower (Duranton and Puga, 2019).

Of course, the land price mechanism is not the only force that can lead to the crowding out of population. We consider three alternative mechanisms that could potentially account for our findings; i) the lower labor intensity of containerized port technology, ii) pollution and other disamenities associated with port development, and iii) additional decreases in overland transportation costs caused by containerization. We show that these either do not stand up to more rigorous examination, or are quantitatively too small to explain our results.

Informed by the empirical evidence, we estimate the aggregate impact of the costs of port development in the second part of the paper. To this end, we develop an otherwise standard economic geography model of trading cities to which we add an endogenous port development decision. As such, the model incorporates not only the standard market access effect, but also allows for port development to crowd out other forms of economic activity. This is because in the model, developing the port (and hence reducing trade costs) requires scarce local land that can be used for other purposes. The effect of port development on city population is the outcome of the trade-off between the positive market access and negative crowding-out mechanisms, allowing for the endogenous specialization of cities into port activities.

We quantify the aggregate effects of port development by taking the model to the data. In particular, we use data on shipping flows, city GDP and population in 1990 to back out cities' unobserved model fundamentals. Armed with these fundamentals, we conduct two counterfactual simulations to shed light on the effect of accounting for the cost side of port development. In our first counterfactual, we simulate the pre-containerization equilibrium in the model by undoing the containerization shock. We show that the model-simulated data closely match our reduced form findings. The effect of shipping on population is not statistically significant and the point estimate is close to zero using the same IV strategy (based on depth) as in the reduced form. Furthermore, we show that containerization increased shipping more in low land-rent cities, as in the data. 
Our estimates suggest that containerization increased world welfare by $3.84 \%$. To measure the contribution of the cost side of port development to these welfare gains, we compare the aggregate welfare effects in our model to the predictions from a standard model in which transport cost reductions are exogenous and free (i.e., they do not use scarce resources). We find a quantitatively meaningful role for two mechanisms. First, we estimate the aggregate resource cost of containerization to be substantial: it reduces the welfare gains arising from a standard model by about $16 \%$. Second, we also find a role for additional welfare gains stemming from endogenous specialization in port- and non-port activities based on comparative advantage. In particular, these gains offset about $58 \%$ of the resource cost of containerization. In addition, we find that, unlike in our baseline model, the local population effects of shipping are positive, economically meaningful and statistically significant in the standard model. This result underscores the link between the zero local population effects identified using the model-simulated data and the endogenous crowding-out mechanism that is absent from standard models.

In our second counterfactual, we examine the effects of targeted port development policies. We focus on a setting similar to the 'Maritime Silk Road' project - a large set of port investments currently being undertaken by China in South Asian, African and European ports. Our findings suggest that targeted port development has the potential for large distributional effects triggered by the reallocation of shipping activity. Most strikingly, the model predicts a large decline in shipping in Singapore (a non-targeted port which we estimate to lose about 50\% of its shipping flows), which is driven by the fact that shipping activity reallocates to nearby, targeted ports. The initial shock is then amplified by less endogenous port development in Singapore as demand for port services falls, illustrating the increasing returns to scale at work in our model. However, despite losing a sizeable fraction of its shipping flows, Singapore gains $1 \%$ in GDP, as resources reallocate to Singapore's highly productive non-port activities. This illustrates that, because of the resource cost of port development, gains and losses in shipping do not translate directly into gains in real GDP. These findings highlight the importance of accounting for the endogenous port development mechanism when quantifying how the gains from targeted port development are distributed across space. More speculatively, they question the wisdom of highly productive, expensive cities such as Hong Kong and Singapore continuing to specialize heavily in port services.

Related literature. A recent, growing literature provides evidence that better trading opportunities lead to local benefits inducing city development (Bleakley and Lin, 2012; Armenter, Koren, and Nagy, 2014; Nagy, 2020). Some of these studies focus on city development at port locations in particular (Fujita and Mori, 1996; Coşar and Fajgelbaum, 2016; Fajgelbaum and Redding, 2018). We contribute to this literature by showing that trade-induced development can also have substantial local costs. While the potential for transport infrastructure to crowd out other economic activity in cities has long been recognized theoretically (Solow and Vickrey, 1971; Solow, 1972; Pines and 
Sadka, 1985), the effect has not been estimated empirically. The crowding-out mechanism also relates the paper to the 'Dutch disease' literature. This literature shows that booming industries can entail significant costs by putting a strain on scarce local resources and therefore crowding out other (tradable) sectors (Corden and Neary, 1982; Krugman, 1987; Allcott and Keniston, 2017). ${ }^{3}$ Relative to this literature, our setting contains the potential for not only costs but also gains, as booming port activities benefit local tradables through improving market access. Thus, one contribution of our paper is to generalize the predictions from the two, seemingly disparate literatures that have focused on either the costs or the benefits from booming sectors.

Our paper is also related to the quantitative international trade literature, which has developed tractable models of trade across multiple countries with various dimensions of heterogeneity (Anderson, 1979; Eaton and Kortum, 2002; Melitz, 2003). These seminal models characterize trade and the distribution of economic activity across countries as a function of exogenous trade costs. A standard prediction of these models is that the relationship between trade flows and costs follows a gravity equation, which has been documented as one of the strongest empirical regularities in the data (Head and Mayer, 2014). We complement this literature by developing a framework in which trade costs are endogenous, in a way that is both tractable and preserves the gravity structure of trade flows. This relates our paper to Fajgelbaum and Schaal (2020) and Santamaría (2020), who consider endogenous road construction in multi-location models of economic geography, as well as Brancaccio, Kalouptsidi, and Papageorgiou (2020), who endogenize trade costs in the noncontainerized shipping sector. Unlike these papers, we focus on port development as a source of endogenous shipping costs, and solve for the decentralized equilibrium as opposed to the optimal allocation to quantify the effect of port development on trade, the distribution of population, and welfare.

Finally, our paper is related to a large literature studying the effects of transport infrastructure improvements. ${ }^{4}$ Within this literature, Brinkman and Lin (2019) is the only other paper we are aware of that shows empirical evidence for the cost side of infrastructure development, focusing on disamenities associated with freeway construction in mid-20th century U.S. cities. Our paper also relates to the growing empirical literature studying the effects of containerization (Hummels, 2007; Bernhofen, El-Sahli, and Kneller, 2016; Gomtsyan, 2016; Coşar and Demir, 2018; Holmes and Singer, 2018; Altomonte et al., 2018; Brooks et al., 2021) or the role of container shipping networks in world trade (Wong, 2020; Heiland, Moxnes, Ulltveit-Moe, and Zi, 2021; Ganapati, Wong, and Ziv, 2020). Most closely related in this vein is Brooks et al. (2021), who study the reduced-form effects of containerization on local economic outcomes across U.S. counties. Our

\footnotetext{
${ }^{3}$ Relatedly, Falvey (1976) discusses how the transportation sector can draw away resources from tradables in particular.

${ }^{4}$ Redding and Turner (2015) provides an overview of recent developments in this literature.
} 
main contribution to this literature is twofold. First, motivated by the evidence that containerization dramatically increased land use in ports, our paper highlights the crowding-out effect of containerization and finds sizeable local and global costs stemming from this effect. ${ }^{5}$ Second, to the best of our knowledge, ours is the first paper seeking to quantify the aggregate effects of port development on global trade and welfare through the lens of a general equilibrium economic geography model.

The paper is structured as follows. In the next section, we describe the main features of containerized technology. Section 2 discusses the main data sources used in the analysis. Section 3 presents the reduced form empirical strategy and results, while Section 4 introduces the model. Section 5 revisits the empirics guided by the predictions of the model. Section 6 measures the aggregate effects of containerization, and Section 7 considers alternative explanations for the crowding-out mechanism. In Section 8, we illustrate the effects of targeted port development policies similar to the 'Maritime Silk Road.' Finally, Section 9 concludes.

\section{The increased land-intensity of containerization}

The introduction of steamships and railroads in the 19th century substantially reduced both water and overland transportation costs. However, transshipment remained slow and expensive through the middle of the 20th century (Krugman, 2011). As a report by McKinsey highlighted; "The bottleneck in freight transport has always been the interface between transport modes, especially the crucial land/sea interface" (1972, pp. 1-3). Containerization, that is, the handling of cargo in standardized boxes, was the breakthrough innovation that dramatically reduced transshipment times and costs (Hummels, 2007; Rodrigue, 2016). In this section, we show that while substantial transshipment cost reductions were achieved in shipping as a result of containerization, this came at the cost of needing to dedicate much more land to port activities, which was not feasible in many port cities.

\subsection{The cost - space trade-off in containerization}

As late as the mid-1950s, transshipment at seaports was a costly and slow procedure as it entailed handling cargo item-by-item - a process called breakbulk shipping. The reason for this was that cargo came in many different sizes and needed to be handled individually, despite the widespread use of machinery introduced pre-containerziation (see Panel A of Figure A.1). The San Francisco Port Commission (1971) estimated that it took 7 to 10 days to merely discharge cargo from a ship. According to Bernhofen et al. (2016), two-thirds of a ship's time was spent in port. This led to high costs as the capital utilization of ships was low, and the cost of capital tied up in inventory

\footnotetext{
${ }^{5}$ These results are consistent with Brooks et al. (2021) who find that containerization led to the highest population growth in U.S. counties with initially low land rents.
} 
was high. ${ }^{6}$

U.S. shippers first started placing cargo into containers in the late 1950s. Containerized shipping was initially introduced on domestic routes between U.S. ports, but the technology was rapidly adopted and standardized worldwide in 1967 (Rua, 2014). Containerized port technology can be seen in its mature form at the Port of Seattle in 1969 in Panel B of Figure A.1 (a mere 10 to 15 years after the photos shown in Panel A were taken). Cargo, packed in standardized containers, is loaded onto and off ships using large, purpose-built cranes situated on the wharf. Large, open areas beside the wharf are used to line up containers.

Containerization substantially reduced transshipment costs for a number of reasons. First, as containers could be handled in a uniform way, loading and unloading times were vastly reduced. The San Francisco Port Commission (1971) estimated that a container ship could be unloaded and loaded in 48 hours or less, a tenth of the previous time spent in port. Similarly, using detailed data on vessel turnaround times for one anonymized port, Kahveci (1999) estimates that the average time ships spent in port fell from 8 days to 11 hours as a result of containerization, a reduction of $94 \%$. Second, the reduction in turnaround time justified investment in much larger vessels (Gilman, 1983). The average size of newly-built container ships increased by $402 \%$ between 1960 and $1990 .^{7}$ Larger ship sizes made it possible to realize even larger cost reductions through increasing returns to scale in shipping and port handling. Rodrigue (2016, p. 118) estimates that moving from a 2,500 TEU capacity vessel to one with 5,000 TEU reduced costs per container by $50 \%$.

Adapting ports and their surroundings to containerized technology was not without costs, however. First, faster turnaround times could only be achieved at the cost of building much larger terminals. Rodrigue (2016, p. 118) names site constraints, and in particular, the large consumption of terminal space as the primary challenge associated with containerization. Containerized terminals need more space as the easy accessibility of containers allows for efficient on- and off-loading. Containers are lined up next to where the ships dock, and space is also needed to rapidly off-load cargo. Second, modern ports need a system of road and rail links to bring cargo in and out of the port (Bernhofen et al., 2016). While some of this complementary transport infrastructure is not located in the port, it also contributes to the extensive land usage of containerized port activities.

The increased space requirements of containerization were evident from the start. For example, in a 1971 report, alarm bells were rung about the inadequacy of San Francisco's finger piers to accommodate new types of cargo handling; "No pier facilities in the Bay Area today are capable

\footnotetext{
${ }^{6}$ Industry experts estimated that the handling of cargo at the port accounted for a major share of freight costs (Levinson, 2010). As an example, transshipment costs were estimated to account for $49 \%$ of the total transport cost on one route from the U.S. to Europe (Eyre, 1964).

${ }^{7}$ These calculations are based on data from the Miramar Ship Index (Haworth, 2020). See Appendix B.11 for details.
} 
of handling the new space requirements on this scale of new and larger container ships. (...) thus more berthing and backup area is needed" (1971, p. 13). Ports in densely built up areas such as Manhattan and San Francisco were almost certainly doomed to decline as one observer noted for San Francisco; "Rows of finger piers adjacent to a densely built up city could not adequately serve container shipping, which involved larger ships that required larger wharves and much larger areas of open space for loading and unloading" (Corbett, 2010, p. 164).

\subsection{Evidence for the increased land-intensity of containerization}

We present two pieces of evidence that point to a substantial increase in the land intensity of port technology with the introduction of containerization. First, for the Port of Seattle, we are able to measure the area of the port per volume of traffic handled around the time of containerization. ${ }^{8}$ Between 1961 and 1973, the port built a new containerized facilities, increasing the area of the port almost fourfold. Consistent with these investments, by 1973, containerized cargo accounted for $43 \%$ of total traffic. While the total volume of traffic handled more than doubled, we calculate that area relative to throughput increased by $90 \%$. Although these numbers do not include the land use of complementary transport facilities outside the port, they already suggest that containerized technology requires substantially more land per unit of cargo shipped.

Second, we examine the relationship between port area and containerized cargo volume across a large set of cities in our sample. We exploit the availability of high resolution remote sensing data that makes it possible to measure the area of ports in our sample today. ${ }^{9}$ We match this with data on the cargo composition handled by each port using data from Le Journal de la Marine Marchande (JMM) for 2008-09. Column (2) in Table A.1 shows that, controlling for the total volume of traffic, ports that handle more containerized cargo are typically larger. In columns (3)-(6), we control for additional potential confounders. The coefficient remains significant and very similar in magnitude when we add controls for the volume of non-liquid and solid bulk handled by the port (e.g., oil, coal or grain, the handling of which may be technologically very different), the GDP per capita of the country (to get at differences in the extent of automation), or even country fixed effects.

To get a better sense of magnitudes, in column (7) we use the share of containerized cargo (while continuing to control for the total volume of cargo). The binscatter (plotted in Figure A.2) visualizes the positive relationship between the area occupied by the port and the share of con-

\footnotetext{
${ }^{8}$ More precisely, we use engineering maps for all properties under the ownership of the Seattle Port Authority to calculate the area of the port and divide by the five-year moving-average of throughput to smooth out year-to-year fluctuations in capacity utilization. A more detailed discussion, including information on data sources, is included in Appendix B.6.

${ }^{9}$ In particular, for a random set of cities in our dataset, we hand-coded polygons from Google Earth that we identified as containing port activities. A more detailed description of data and methodology can be found in Appendix B.7. Unfortunately, the resolution of historical satellite images is not sufficiently high to replicate this exercise for our sample period.
} 
tainerized cargo. The coefficient of interest is large and statistically significant. Based on this specification, moving from a fully non-containerized port to a fully containerized port is associated with a $75 \%$ increase in port area (i.e., $\exp (0.5624)-1)$, holding the volume of traffic fixed.

Because of its land intensity, port development may entail significant opportunity costs. As a recent report highlights; "[L]and use impacts often become prevalent in case of port development projects, because they enter into competition for land with other uses of the city surface. (...) Agglomeration effects and high job density are generally considered to be factors of urban economic growth, and these agglomeration effects may be constrained by the presence of large port areas" (OECD, 2014, p. 51). In the following sections, we use the increased land-intensity of containerized technology to estimate these costs.

\section{Data}

Our analysis builds on a decadal city-level dataset of shipping flows, population, and other economic outcomes for the period 1950-1990. We complement this with GIS data that allows us to calculate geographic characteristics of the city. We review the main variables used in the analysis below and report summary statistics in Table A.2. Detailed documentation including sources and description of cleaning steps for all the data used in the paper can be found in the Data Appendix (Appendix B).

Shipping flows (Appendix B.1). Crucial to our analysis is a dataset of worldwide bilateral ship movements at the port level for the period 1950-1990 from Ducruet, Cuyala, and Hosni (2018). An observation is a ship moving from one port to another at a particular point in time. ${ }^{10}$ One week samples from the first week of May for each year were extracted from the Lloyd's Shipping Index, a unique source that provides a daily list of merchant vessels and their latest inter-port movements.

These data provide us with rich variation to study the geography of sea-borne trade through the second half of the 20th century. They cover both domestic and international shipping. Moreover, the data cover a long time period spanning the containerization revolution. We are thus able to compare the effects of port activity on cities both before and after the arrival of the new technology. We know of no other data source that has a similar coverage across time and space, especially at such a detailed level of disaggregation. An important limitation, however, is that we do not observe either the value or the volume of shipment but only bilateral ship movements. From these ship movements, we sum the total number of ships passing through each port, which we call shipping flows.

City population. As we are interested in the economic effects of containerization, we use data on

\footnotetext{
${ }^{10}$ As such, it is similar to contemporary satellite AIS (Automatic Identification System) data that tracks the precise movements of vessels around the globe. Such AIS data are used in Brancaccio et al. (2020) and Heiland et al. (2021).
} 
city population worldwide for locations with more than 100,000 inhabitants from Villes Géopolis (Moriconi-Ebrard, 1994) for each decade between 1950-1990 (Geopolis cities, henceforth). The advantage of these data relative to sources such as the more frequently used UN World Cities dataset is that a consistent and systematic effort was made to obtain populations for the urban agglomeration of cities (that is, the number of inhabitants living in a city's contiguous built-up area) as opposed to the administrative boundaries that are often reported in country-specific sources. For example, New York (New York) and Newark (New Jersey) form one 'city' according to this definition. We observe population for cities that reached 100,000 inhabitants in any year throughout this period. For most of these cities, we observe population even when the city had fewer than 100,000 inhabitants, potentially leading to sampling bias. To address this, we will show that our results are robust to using the subset of cities that had already attained 100,000 inhabitants in the first sample year, 1950.

Ports were hand-matched from the shipping data to cities based on whether the port was located within the urban agglomeration of a city in the Geopolis dataset, allowing for multiple ports to be assigned to one city (Ducruet et al., 2018). We define port cities in a time-invariant manner; a port city with positive shipping flows in at least one year will be classified as a port city for all years. Of the 2,636 cities in the Geopolis dataset, 553 have at least one port. We label these as port cities. The quantitative estimation covers the full set of 2,636 Geopolis cities (port and non-port cities).

Underwater elevation levels (Appendix B.2). We use gridded bathymetric data on underwater elevation levels at a detailed spatial resolution (30 arc seconds, or about 1 kilometer at the equator) from the General Bathymetric Chart of the Oceans (GEBCO) to measure sea depth around the city.

Saiz land rent proxy (Appendix B.3). While we are not aware of any dataset that covers land rents globally going back to the 1950s, Saiz (2010) proposes a geography-based measure that correlates well with land rents. This allows us to construct land rent proxies for all cities in our dataset. The 'Saiz-measure' is defined as follows: Take a 50 kilometer radius around the centroid of the city. Exclude all sea cells, all internal water bodies and wetland areas, as well as all cells with a gradient above $15 \%$. The remaining cells, as a share of the total cells, can be used as a proxy for land rents. We replicate the methodology in Saiz exactly, using GIS data that have global coverage.

City-level GDP per capita (Appendix B.4). Data on city-level income levels are needed for the quantitative estimation only. We are not aware of readily available sources of GDP per capita data for cities worldwide. For this reason, we estimate GDP per capita for the last year in our sample (1990) for the full sample of 2,636 worldwide cities in the following way. First, we use estimates of city GDP from the Canback Global Income Distribution Database for a subset of our sample (898 cities) for which data are reported for 1990. We extrapolate GDP per capita for 
the full sample of cities using the linear fit of the GDP per capita data on nightlight luminosity and country fixed effects, building on a growing body of evidence suggesting that income can be reasonably approximated using nightlight luminosity data (Donaldson and Storeygard, 2016).

\section{The reduced form effects of containerization}

In this section, we study the local effects of containerization on port cities. To isolate the causal effect, we first develop an exogenous measure of port suitability. Next, we discuss our main reduced form findings.

\subsection{An exogenous measure of port suitability}

Section 1 discussed the fact that containerization led to larger ship sizes. This, in turn, required greater depth at the port. Following the previous literature, we think of naturally endowed depth as an exogenous cost-shifter that makes it cheaper for a port to reach a desired depth through costly dredging (Brooks et al., 2021; Altomonte et al., 2018). The empirical challenge is that observed port depth is a combination of naturally endowed depth and depth attained by dredging. Our solution to this relies on using contemporary granular data on underwater elevation levels around the port to isolate the naturally endowed component of depth. In particular, we take all sea cells within buffer rings around the geocode of the port and sum the number of cells that are 'very deep,' which we define as depth greater than 30 feet following Brooks et al. (2021). These authors argue that given vessel sizes in the 1950s (pre-containerization), depth beyond 30 feet conferred no advantage to the port. Below, we will test how reasonable this assumption is by examining pre-trends in shipping.

To operationalize our measure, we need to take a stand on which set of cells around the port to consider. Our aim is to measure depth in areas around the port that are used by ships to navigate and wait for their docking time. We examine the location (using exact geocodes) of stationary ships around the port in a one hour window for 100 random ports in our sample using contemporary data. ${ }^{11}$ The majority of stationary ships are located within $5 \mathrm{~km}$, which justifies our baseline measure of port suitability: the log of the sum of 'very deep' cells in a buffer ring 3-5 km around the port. ${ }^{12}$ We examined the effect of depth measured at various buffers and confirmed that the effects are similar in nearby rings, suggesting that the variation we use from the $3-5 \mathrm{~km}$ buffer is a representative measure of depth at the port.

\footnotetext{
${ }^{11}$ These data are from marinetraffic.com and refer to stationary ships near the port captured between November 4 and 10, 2019, at 12:00-13:00 local time. Summary statistics and further details are provided in Appendix B.12. There is a concern that where ships are found around the port today is a poor proxy for where ships were located during our sample period. For this reason, we show that depth measured in the same way at different nearby buffers yields similar results.

${ }^{12}$ There are zeros in the data, that is, there are ports with no cells deeper than 30 feet in the $3-5 \mathrm{~km}$ buffer around the port. For this reason, in practice, we use $\ln \left(1+\sum_{i} \mathbb{1}\left(\right.\right.$ depth $\left.\left._{i} \geq 30 \mathrm{ft}\right)\right)$, where $i$ denotes a cell.
} 
Testing for endogenous dredging. The key assumption behind our ability to isolate naturally endowed depth (from depth attained by dredging) is that when ports need to invest in costly dredging, they typically do not dredge entire areas in our buffers, but narrow channels that ships use to navigate to the port. By calculating depth over many sea cells, the vast majority of depth measurements for each port should reflect naturally endowed depth. We test this assumption in the following way. For 100 random ports in our sample, we obtained access to nautical maps from marinetraffic.com which clearly demarcate the dredged channels that ships use to navigate to the port. ${ }^{13}$ We then construct a binary variable, 'Dredging', that takes the value of 1 if a port has a dredged channel in the $3-5 \mathrm{~km}$ buffer ring. Table A.3 shows the association between this measure and the depth measure. The unconditional association (column 1) is negative and statistically significant. That is, ports that we measure to be shallow are more likely to have a dredged channel. This is what we would expect to find if our measure captured naturally endowed depth. ${ }^{14}$

Balancing checks. We examine the extent to which our measure of exogenous port suitability is correlated with other observables pre-containerization in order to assess the types of confounders that may bias the results. Table A.4 shows the results. If greater depth would have led to more shipping even before containerization, we would expect to see a positive coefficient between depth and shipping flows. However, we see that the unconditional measure of depth is negatively correlated with both the level of shipping flows in 1950 (measured in logs) and population in 1950 (measured in logs), indicating that initially small cities have larger depth. In terms of growth rates pre-containerization, depth is weakly positively correlated with population growth between 1950 and 1960 (the coefficient is significant at 10\%). This suggests that our depth measure is correlated with small cities that were growing relatively fast, i.e., population convergence. In order to purge our depth measure of this variation, we residualize it on city population in 1950 (measured in $\operatorname{logs}) .{ }^{15}$ We re-examine how the part of the variation in depth that is uncorrelated with 1950 population, 'residualized depth,' correlates with the same observables. Reassuringly, residualized depth is correlated neither with the levels of shipping and population in 1950 (the latter by construction), nor with the change in shipping and population between 1950 and 1960. In the empirical analysis, we therefore use the residualized measure of depth as the baseline measure of exogenous port suitability.

Table A.4 also shows the correlation with other observables. Residualized depth is uncorrelated

\footnotetext{
${ }^{13}$ We provide more details on this exercise in Appendix B.13.

${ }^{14}$ Adding continent or coastline fixed effects (columns 2 and 3, respectively) reduces the size of the negative coefficient and we lose statistical significance in column (3), but the estimated coefficients remain negative.

${ }^{15}$ More precisely, we regress the log of depth on the log of population in 1950 and take the residuals from this regression. Population in 1950 is not observed for 21 out of 553 port cities. For these, we replace 1950 population with the first year in which population is observed, which is generally 1960.
} 
with all observables we consider, except the Saiz land rent proxy. This is unsurprising, as arguably similar geographic characteristics determine the overland (Saiz measure) and underwater (depth measure) geographic features around a city. For this reason, we show robustness of all our results to the inclusion of the Saiz land rent proxy interacted with year indicator variables. The final issue concerns potential spatial correlation in the depth measure. We tackle the issue of spatial correlation in the empirics by testing the robustness of our results to using only within-region variation, and to adjusting for spatial autocorrelation in the error term by reporting Conley standard errors (Conley, 1999).

\subsection{Dealing with land reclamation}

Both the depth and the Saiz measure are constructed using contemporary GIS data, which capture natural geography in combination with investments in reclaiming land from the sea. To investigate the extent to which reclamation may introduce systematic measurement error, we use data from Martín-Antón, Negro, López-Gutiérrez, and Esteban (2016) on coastal land reclamation conducted for any potential purpose. ${ }^{16}$ Table A.5 shows that there is somewhat more land reclamation in cities we measure to be more geographically constrained (and hence have higher land rents). This is what we would expect if the Saiz measure was mostly capturing natural geography. The reason for this seems to be that while land reclamation is fairly common (76 out of 553 ports report some land reclamation), it is typically small relative to the area over which the Saiz measure is constructed. ${ }^{17}$ Turning to the association between the depth measure and the binary indicator of land reclamation, the estimated coefficient is small and never statistically significant.

\subsection{Results}

Depth predicts shipping, but only after 1960. First, we examine whether depth predicts port activity during our sample period. We implement this using the following flexible specification that allows us to examine the timing of when depth started to matter for shipping.

$$
\begin{aligned}
& \ln \left(\text { Ship }_{i t}\right)=\sum_{j=1960}^{1990} \beta_{j} * \text { Depth }_{i} * \mathbb{1}(\text { Year }=j)+\sum_{j=1960}^{1990} \phi_{j} * \ln \left(\text { Pop }_{i, 1950}\right) * \mathbb{1}(\text { Year }=j) \\
& +\alpha_{i}+\delta_{t}+\epsilon_{i t}
\end{aligned}
$$

The outcome variable of interest, $\ln \left(S_{i i} p_{i t}\right)$, is the log of shipping flows observed in city $i$ at time $t$. We need to take a stand on the treatment of zeros in the shipping data. ${ }^{18}$ In the

\footnotetext{
${ }^{16}$ See Appendix B.8 for a discussion of the data.

${ }^{17}$ The median size of reclaimed area in the sample for the non-zero observations is 13 square kilometers, which pales in comparison to the 7850 square kilometers covered in the Saiz measure.

${ }^{18}$ The data contain zeros for two reasons. First, we may observe zeros because of measurement error:
} 
baseline measure, we annualize the weekly counts of ships from the raw data by multiplying the one-week sample of shipping flows we observe by 52. This is primarily so that our results are comparable to regressions we run using model-simulated data in the quantification exercise in Section 6. Finally, we replace the zeros in the data with ones and take the natural logarithm of this adjusted annualized count. ${ }^{19}$ Dept $_{i}$ is the cross-sectional measure of port suitability defined in the previous subsection. We interact this measure with binary indicators for the decades 1960 - 1990 to estimate the time path of how depth affected shipping flows. In addition, we include the full set of city and year fixed-effects (denoted $\alpha_{i}$ and $\delta_{t}$, respectively) as well as the log of population in 1950 interacted with year indicator variables across all specifications. This is equivalent to using the residualized depth measure in a panel setting. We cluster standard errors at the city level in the baseline to account for the serial correlation of shocks. We also report Conley standard errors (in curly brackets). ${ }^{20}$ Each $\beta_{j}$ in this specification estimates the increase in shipping caused by having a deeper port in a given year relative to 1950 .

Table 1 contains the estimated coefficients. Column (1) presents coefficients for the baseline specification. A number of points should be noted. First, deeper ports did not witness differential growth in shipping flows between 1950 and 1960, consistent with this being a decade in which containerization was just being developed in a few ports around the world. Second, we see an effect of depth in each of the following decades, as containerization was adopted worldwide. The coefficient of interest is much larger and significantly different from zero for the interaction of depth and each year indicator including and after 1970. This is consistent with containerization technology being rolled out in the early 1960s across US ports and worldwide later in the decade, as we discussed in Section 1.

A causal interpretation of the estimated effect of depth relies on the identifying assumption that the time-varying effect of depth is uncorrelated with the error term. The timing of when depth started to matter and the lack of pre-trends provide evidence that this assumption is plausible. Next, we turn to further testing this result with more demanding specifications. One concern is that many determinants of depth may be spatially correlated and if true, the estimates could be hard to

small ports with low shipping flows may not register an inter-port movement during the week in which we capture the data. Second, zeros may appear due to the time-invariant definition of port status that we use. We observe zero shipping flows in a particular year if a port was established in the city only after 1950, or if a port shut down in the city during our sample period. Overall, we observe zero shipping flows for $16 \%$ of the port-year observations. From examining the data, the zeros seem to be more likely driven by mismeasuring small shipping flows rather than the entry and exit of ports.

${ }^{19}$ In robustness checks discussed below, we show that all of the results presented in this section are robust to other standard ways of dealing with the zeros. In these, we do not annualize the data in order to verify that this transformation does not drive the results.

${ }^{20}$ As these are typically very close to the clustered standard errors, we only report them for the main results for easier readability of the tables. We allow for spatial correlation at distances up to $1,000 \mathrm{~km}$ and set the spatial decay function to be linear. 
disentangle from broader regional trends. To this end, column (2) adds the full set of 'coastline' by year-fixed effects to examine the extent to which our identifying variation relies on cross-regional variation. ${ }^{21}$ Note that this set of fixed effects subsumes continent by year fixed effects. Column (3) adds the Saiz land rent proxy interacted with year indicators to capture trends driven by the time-varying effect of land rents. Column (4) adds country GDP per capita (measured in 1960) interacted with year indicators to control for potentially differential growth trends across initially rich and poor countries. ${ }^{22}$ The coefficients are remarkably stable.

Based on these results, we introduce a 'containerization' treatment indicator that turns on in years including and after 1970. This yields a single coefficient that estimates the differential effect of depth on shipping after the onset of containerization. Column (5) shows the results. Cities endowed with more depth, and hence more suitable to containerized technologies witnessed disproportionate increases in their shipping flows after containerization. Panel A in Figure A.3 shows that the coefficient of interest remains fairly stable as we drop continents one at a time, underscoring that no single region appears to be driving the results. The coefficient becomes somewhat smaller when we drop North America, which is in line with the United States being the birthplace and an early adopter of containerization.

Panel A in Table A.6 contains further robustness checks. First, we test robustness to different data construction choices. In particular, we examine different ways of treating zero shipping values, different ways of defining the depth measure for the handful of ports that are located far inland from the coastline and restricting the sample to the subset of cities that had already attained 100,000 inhabitants by 1950 to examine sample selection bias. The coefficient of interest remains similar in magnitude and highly significant across all these checks. We now turn to examining how this containerization-induced boom in shipping affected city population.

The local causal effect of shipping on population. We are interested in the long-run effect of port activity on population. To this end, we estimate the following long-differenced specification;

$$
\Delta \ln \left(\text { Pop }_{i}\right)=\beta * \Delta \ln \left(\text { Ship }_{i}\right)+\phi * \ln \left(\text { Pop }_{i, 1950}\right)+\epsilon_{i}
$$

where $\Delta \ln \left(P o p_{i}\right)$ and $\Delta \ln \left(S h i p_{i}\right)$ are the change in the natural logarithm of population and shipping flows between 1950 and 1990, respectively. The identification challenge is that the shipping flows of a city are endogenous. Our main worry is reverse causality: fast growing cities will witness increases in their shipping flows. Our solution is to isolate exogenous variation in shipping

\footnotetext{
${ }^{21}$ We define coastlines in the following way. We assign each port to its nearest ocean (e.g., 'Pacific Ocean') or body of water (e.g., 'Great Lakes') and further disaggregate oceans by continent. This yields 22 coastlines worldwide. Examples are 'Mediterranean - Europe' and 'North America - Atlantic.'

${ }^{22}$ We use the 1960 (pre-containerization) measure of country GDP per capita as this is observed for a larger set of countries than for 1950 .
} 
using a city's suitability for containerization based on its natural depth.

Columns (1) - (4) in Table 2 contain the baseline regression results. Both the estimated OLS and 2SLS coefficients on shipping are small and statistically indistinguishable from zero (OLS coefficient 0.013 , s.e. $0.009 ; 2$ SLS coefficient 0.006 , s.e. 0.073 ). To assess magnitudes, we report the standardized 'beta' coefficients for our effects of interest in italics underneath the estimated regression coefficients. A one standard deviation increase in the growth of shipping flows between 1950 and 1990 leads to a 0.02 standard deviation increase in population growth over the same time horizon based on the 2SLS estimate. Columns (3) and (4) show the first stage and reduced form, respectively. These help illuminate what drives the small and insignificant effect. While the first stage coefficient is highly significant and the Kleibergen-Paap F-statistic is reasonable (9.98), there is no reduced form relationship between depth and population (the reduced form coefficient is 0.004 , s.e. 0.020$)$.

Table A.7 shows the panel specification allowing us to utilize the full decadal variation in the data. ${ }^{23}$ Two important points emerge. First, the results are very similar to the long-differenced specification. The 2SLS coefficient remains small in magnitude and statistically indistinguishable from zero. The first stage is strong (the Kleibergen-Paap F-statistic is 21.13), and the reduced form is small and statistically insignificant. Second, column (5) shows the full time path of effects for the reduced form. These make clear that the statistically insignificant coefficient in the 2SLS estimate does not stem from the fact that population is sluggish to adjust. The time path of the coefficients shows no discernible trend, and there is no clear difference in population growth postcontainerization for deeper ports. All of the coefficients are estimated to be very close to zero (the one 'furthest' away from zero is 0.007 ), the coefficients are never close to statistical significance, and in two of the five decades, the estimated effect is negative, suggesting that, if anything, deeper ports were growing at a slower rate than shallower ones some of the time.

We subject the 2SLS panel specification to the same set of robustness checks conducted above: we include coastline by year fixed effects, as well as control for the time varying-effects of the the Saiz land-rent proxy and GDP per capita (Table A.8). Despite the demanding nature of these specifications, the first stage remains sufficiently strong (the Kleibergen-Paap F-statistic is always above 10) and the estimated 2SLS coefficient is never statistically different from zero. In fact, in two out of three cases, the estimated coefficient is negative. No single continent drives this result (Figure A.3, panel B, plots the estimated coefficient dropping continents one at a time). ${ }^{24}$ Table

\footnotetext{
${ }^{23}$ The specification is $\ln \left(\right.$ Pop $\left._{i t}\right)=\beta * \ln \left(\right.$ Ship $\left._{i t}\right)+\sum_{j=1960}^{1990} \phi_{j} * \ln \left(\right.$ Pop $\left._{i, 1950}\right) * \mathbb{1}($ Year $=j)+\alpha_{i}+$ $\delta_{t}+\epsilon_{i t}$, where $\ln \left(P_{o p} p_{i t}\right)$ is the natural logarithm of population in city $i$ at time $t$, and all other variables are as previously defined.

${ }^{24}$ This exercise also helps reconcile the results presented here with Brooks et al. (2021) who find a positive effect of containerization on county population growth in the United States. A direct comparison is not possible as our sample only contains 40 U.S. cities and the 2SLS estimate on this subsample yields a
} 
A.6, panel B, shows that the results are robust to the same set of additional robustness checks to data choices performed in panel A.

In summary, these results show that we cannot reject that the effect of increased port activity on population was zero. Given that increased trade through a city tends to increase population through the standard market access effect (Donaldson and Hornbeck, 2016; Redding and Turner, 2015), this finding suggests a role for a countervailing force. The large standard errors typical of 2SLS estimation do not allow for a definitive answer based on this evidence alone. However, guided by the model, we will be able to formally test for the presence of negative as well as positive forces in Section 5. In the last part of this section, we examine two pieces of evidence consistent with one offsetting force: crowding out due to the land-price mechanism.

Land prices affect the location of port development. Do land prices affect where port development takes place after containerization? If the land intensity of containerized port development is as important as the literature discussed in Section 1 suggests, we should find an empirically important role for it. We test for this in two ways. First, we examine whether low land-rent cities disproportionately attracted port development by estimating heterogeneity in land rents in the depth shipping relationship using the following specification;

$$
\begin{aligned}
\ln \left(\text { Ship }_{i t}\right)= & \beta * \text { Depth }_{i} * \mathbb{1}(\text { Year } \geq 1970)+\gamma * \text { Depth }_{i} * \text { Rent }_{i} * \mathbb{1}(\text { Year } \geq 1970) \\
& +\eta * \text { Rent }_{i} * \mathbb{1}(\text { Year } \geq 1970)+\sum_{j=1960}^{1990} \phi_{j} * \ln \left(\text { Pop }_{i, 1950}\right) * \mathbb{1}(\text { Year }=j) \\
& +\alpha_{i}+\delta_{t}+\epsilon_{i t}
\end{aligned}
$$

where Rent $_{i}$ is the Saiz land rent proxy for city $i$, and all other variables are as defined above. ${ }^{25}$ We have defined the Saiz measure such that higher values correspond to less area that can be developed, implying high land rents. The coefficient of interest is $\gamma-$ the interaction between our depth measure and the Saiz land rent proxy (interacted with the 'containerization' treatment variable that turns on in 1970). Note that this is a fully saturated specification. We allow both depth and the Saiz measure to have their own time trend break in 1970. We plot the marginal effect of depth at different values of the Saiz measure in Figure 1a (the corresponding estimates are presented in Table A.9). Consistent with an important role for land rents in determining the location of port development, the coefficient of interest, $\gamma$, is negative, large and statistically different from zero

Kleibergen-Paap F-statistic below 1. However, dropping North America leads to a negative (though statistically insignificant) point estimate (Figure A.3), suggesting that on average North American cities may have had a larger than average population response to containerization.

${ }^{25}$ We view the Saiz measure as a proxy for land rents (Saiz, 2010), rather than simply capturing supplyside constraints. 
(coefficient -0.707, se. 0.323). Cities with exogenously deeper ports witnessed increased shipping flows after 1970, but disproportionately more so in low land rent cities.

Panel C in Figure A.3 explores the heterogeneity of the result by dropping continents one at a time. The effect is consistently negative. We perform the same set of robustness checks for this result as for previous ones (see Tables A.6, panel C, and A.9). The results are largely robust to these specifications, as our coefficient of interest, $\gamma$, remains negative and economically large throughout all these checks, though in two especially demanding specifications the level of significance drops slightly below $10 \%$.

Second, we test for the importance of land in port development by examining within-city port moves. In Figure A.4, we plot the kernel density for the distance of ports from the city center before and after containerization (in 1953 and 2017, respectively). During this period, ports moved further from the centroid of the city towards the outskirts, where land prices are typically lower (Duranton and Puga, 2019). This is particularly striking for the subset of cities in which a new port was built (right panel). In these cases, the new port was located on average $9 \mathrm{~km}$ further from the centroid of the city than the old port.

Together, these two pieces of evidence underscore that the land-intensive nature of containerized technology is an empirically important determinant of where containerized port infrastructure was developed. Armed with this evidence, we now turn to writing down a quantitative spatial model that captures many realistic features of port infrastructure development including the land price mechanism. We note that, of course, there are mechanisms other than the land-intensity of containerization that could account for the crowd-out of population. We explore three prominent ones in Section 7.

\section{A model of cities and endogenous port development}

To measure the aggregate effects of port development, we develop a flexible quantitative general equilibrium model of trade across cities that captures both the benefits and costs of port development.

\subsection{Setup}

The world consists of $S>0$ cities, indexed by $r$ or $s$. An exogenously given subset of cities are port cities, while the rest are non-port cities. We make the Armington assumption that each city produces one variety of a differentiated final good that we also index by $r$ or $s$ (Anderson, 1979). Each city belongs to one country, and each country is inhabited by an exogenous mass of workers who choose the city in which they want to live. We do not allow for mobility across countries but allow for mobility across cities within a country, subject to frictions. 


\subsubsection{Workers}

Each worker owns one unit of labor that she supplies in her city of residence. The utility of a worker $j$ who chooses to live in city $r$ is given by

$$
u_{j}(r)=\left[\sum_{s=1}^{S} q_{j}(r, s)^{\frac{\sigma-1}{\sigma}}\right]^{\frac{\sigma}{\sigma-1}} a(r) b_{j}(r)
$$

where $q_{j}(r, s)$ is the worker's consumption of the good made in city $s, a(r)$ is the level of amenities in city $r$, and $b_{j}(r)$ is an idiosyncratic city taste shifter. $\sigma>1$ is the elasticity of substitution across goods.

The dispersion of $b_{j}(r)$ represents the severity of cross-city mobility frictions that workers face, similar to Kennan and Walker (2011) and Monte, Redding, and Rossi-Hansberg (2018). For tractability, we assume that $b_{j}(r)$ is drawn from a Fréchet distribution with shape parameter $1 / \eta$ and a scale parameter normalized to one. Hence, a larger value of $\eta$ corresponds to more severe frictions to mobility.

\subsubsection{Landlords}

Each city $r$ is also inhabited by a positive mass of immobile landlords who own the exogenously given stock of land available in the city. ${ }^{26}$ We normalize the stock of land available in each city to one. ${ }^{27}$ Landlords have the same preferences over goods as workers. They do not work but finance their consumption from the revenues they collect from their stock of land.

Each landlord is small relative to the total mass of landlords in the city and hence thinks that she cannot influence prices. Yet the mass of landlords is small enough that the population of each city can be approximated well with the mass of workers who choose to reside in the city.

In non-port cities, landlords rent out their land to firms that produce the city-specific good. In port cities, landlords can also use part of their land to provide transshipment services. The more land they use for transshipment services, the more the cost of transshipping a unit of a good de-

\footnotetext{
${ }^{26}$ The assumption about the elasticity of land supply merits further discussion. A perfectly elastic land supply would not yield a crowding-out mechanism as cities would respond to containerization by expanding their stock of land. As we find empirical evidence in support of a sizeable crowding out effect (see Section 5), we need to move away from the case of perfectly elastic land supply. To retain the tractability of the model, we assume that land supply is perfectly inelastic and leave the case of imperfectly elastic supply for future research.

${ }^{27}$ We could allow the stock of available land to vary across cities. This more general setup is isomorphic to our current model, except that, instead of productivity in the city-specific good sector, a combination of the stock of land and productivity enters the model's equilibrium conditions. In other words, the city productivity levels we identify from our current model reflect not only productivity per se, but also the stock of available land. This fact, however, does not affect our quantitative results as we keep productivity levels fixed in our model simulations.
} 
creases. The landlord can charge a price for the transshipment service she provides. Competition among port city landlords drives down this price to marginal cost. Hence, profits from transshipment services are zero in equilibrium. ${ }^{28}$

\subsubsection{Production}

Firms can freely enter the production of the city-specific good. Hence, they take all prices as given and make zero profits. Production requires labor and land. The representative firm operating in city $r$ faces the production function

$$
q(r)=\tilde{A}(r) n(r)^{\gamma}(1-F(r))^{1-\gamma}
$$

where $q(r)$ denotes the firm's output, $\tilde{A}(r)$ is total factor productivity in the city, $n(r)$ is the amount of labor employed by the firm, and $F(r)$ is the share of land that landlords in the city use for transshipment services (thus, $F(r)=0$ in non-port cities). Hence, $1-F(r)$ is the remainder of land that landlords rent out to firms for production, and $\gamma$ and $1-\gamma$ correspond to the expenditure shares on labor and land, respectively.

We incorporate agglomeration economies by allowing total factor productivity to depend on the population of the city, $N(r)$ :

$$
\tilde{A}(r)=A(r) N(r)^{\alpha}
$$

where $A(r)$ is the exogenous fundamental productivity of the city, and $\alpha \in[0,1-\gamma]$ is a parameter that captures the strength of agglomeration economies. ${ }^{29}$ The representative firm does not internalize the effect that its employment decision has on local population. Hence, it takes $N(r)$ as given.

\subsubsection{Shipping and port development}

Firms in city $r$ can ship their product to any destination $s \in S$. Shipping is, however, subject to iceberg costs: if a firm $i$ from city $r$ wants to ship its product over a route $\rho$ that connects $r$ with $s$, then it needs to ship $T(\rho, i)$ units of the product such that one unit arrives at $s$. Shipping costs consist of a component common across firms $\bar{T}(\rho)$, as well as a firm-specific idiosyncratic

\footnotetext{
${ }^{28}$ In Section 6, we show that the effects of containerization remain similar in an alternative framework in which landlords have market power and thus can make profits. We provide a detailed description of this alternative framework in Appendix A.7.

${ }^{29}$ We make the assumption $\alpha \leq 1-\gamma$ to guarantee that agglomeration forces are not overwhelmingly strong in the model. Estimates of the land share, $1-\gamma$, tend to be substantially above estimates of agglomeration externalities $\alpha$. In particular, our calibration involves setting $\alpha$ to 0.06 (a standard value used in the literature) and $1-\gamma$ to 0.16 based on Desmet and Rappaport (2017).
} 
component $\epsilon(\rho, i)$ that is distributed i.i.d. across firms and shipping routes: ${ }^{30}$

$$
T(\rho, i)=\bar{T}(\rho) \epsilon(\rho, i)
$$

For tractability, we assume that $\epsilon(\rho, i)$ is drawn from a Weibull distribution with shape parameter $\theta$ and a scale parameter normalized to one. Firms only learn the realizations of their idiosyncratic cost shifters after making their production decisions. Therefore, they make these decisions based on the expected value of shipping costs,

$$
\mathbf{E}[T(\rho, i)]=\bar{T}(\rho) \mathbf{E}[\epsilon(\rho, i)]=\bar{T}(\rho) \Gamma\left(\frac{\theta+1}{\theta}\right) .
$$

After learning $\epsilon(\rho, i)$, they choose the route that minimizes their total shipping costs.

Certain shipping routes involve land shipping only (land-only), while others involve a combination of land and sea shipping through a set of ports (land-and-sea). Land-only shipping is only available between cities that are directly connected by land. The common cost of land-only shipping between cities $r$ and $s$ is an increasing function of the minimum overland distance between the two cities, $d(r, s)$ :

$$
\bar{T}(\rho)=1+\phi_{\varsigma}(d(r, s))
$$

The cost of land-and-sea shipping depends on the set of ports en route. In particular, the common cost of shipping from $r$ to $s$ through port cities $p_{0}, \ldots, p_{M}$ takes the form

$$
\bar{T}(\rho)=\left[1+\phi_{\varsigma}\left(d\left(r, p_{0}\right)\right)\right]\left[1+\phi_{\varsigma}\left(d\left(p_{M}, s\right)\right)\right] \prod_{m=0}^{M-1}\left[1+\phi_{\tau}\left(d\left(p_{m}, p_{m+1}\right)\right)\right] \prod_{m=0}^{M}\left[1+O\left(p_{m}\right)\right]
$$

where $\phi_{\varsigma}\left(d\left(r, p_{0}\right)\right)$ corresponds to the overland shipping cost between the origin and the first port en route $p_{0}$, and $\phi_{\varsigma}\left(d\left(p_{M}, s\right)\right)$ corresponds to the overland shipping cost between the last port en route $p_{M}$ and the destination. $\phi_{\tau}\left(d\left(p_{m}, p_{m+1}\right)\right)$ denotes the sea shipping cost between ports $p_{m}$ and $p_{m+1}$, a function of the minimum sea distance between the two ports, $d\left(p_{m}, p_{m+1}\right)$. Finally, $O\left(p_{m}\right)$ denotes the price that the firm needs to pay for transshipment services in port city $p_{m} \cdot{ }^{31}$

Transshipment costs are central to our analysis as these are the costs that port city landlords can lower by developing the port, that is, by allocating more land to the port. In particular, we assume

\footnotetext{
${ }^{30}$ The assumption of idiosyncratic shipping cost shifters follows Allen and Atkin (2016) and Allen and Arkolakis (2019), and allows us to tractably characterize shipping flows with a large number of cities. In the alternative case with no idiosyncratic shifters, applied in Allen and Arkolakis (2014) and Nagy (2020), finding optimal shipping flows is computationally more demanding.

${ }^{31}$ Note that this formulation does not allow for land shipping between two subsequent ports along the route. In practice, this is extremely unlikely to arise as land shipping is substantially more expensive than sea shipping.
} 
that the landlord's cost of handling one unit of a good at port $p_{m}$ equals

$$
\left[\nu\left(p_{m}\right)+\psi\left(F\left(p_{m}\right)\right)\right] \text { Shipping }\left(p_{m}\right)^{\lambda}
$$

where $\nu\left(p_{m}\right)$ is an exogenous cost shifter capturing the fundamental efficiency of port $p_{m}, \psi\left(F\left(p_{m}\right)\right)$ is a non-negative, strictly decreasing and strictly convex function of $F\left(p_{m}\right)$, the share of land allocated to the port, and Shipping $\left(p_{m}\right)^{\lambda}$ captures congestion externalities arising from the fact that handling one unit of cargo becomes more costly as the total amount of shipping, Shipping $\left(p_{m}\right)$, increases for a given port size. ${ }^{32}$ As each port city landlord is atomistic, she takes the price of transshipment services $O\left(p_{m}\right)$ and the total port-level shipping Shipping $\left(p_{m}\right)$ as given when choosing $F\left(p_{m}\right)$. Moreover, perfect competition among port city landlords ensures that the price of transshipment services is driven down to marginal cost and therefore

$$
O\left(p_{m}\right)=\left[\nu\left(p_{m}\right)+\psi\left(F\left(p_{m}\right)\right)\right] \text { Shipping }\left(p_{m}\right)^{\lambda}
$$

in equilibrium.

One concern is that, according to our formulation, land is required for transshipment services while labor is not. In reality, ports employ labor. To address this concern, Appendix A.6 presents an extension of our model in which a combination of land and labor must be employed in transshipment. This appendix also shows that the model with transshipment labor, although more complex in its structure, delivers qualitative predictions that are extremely similar to the predictions of our baseline model.

\subsubsection{Equilibrium}

In equilibrium, workers choose their consumption of goods and residence to maximize their utility, taking prices and wages as given. Landlords choose their consumption and land use to maximize their utility, taking prices, land rents and shipping flows as given. Firms choose their production of goods, employment and land use to maximize their profits, taking prices, land rents and wages as given. Competition drives profits from production and profits from transshipment services down to zero. Markets for goods, land and labor clear in each city, and markets for transshipment services clear in each port city. Appendix A.1 provides a formal definition and characterization of the equilibrium.

\footnotetext{
${ }^{32}$ To be precise, Shipping $\left(p_{m}\right)$ is defined as the dollar amount of shipping flowing through port $p_{m}$, excluding the price of transshipment services at $p_{m}$. We exclude the price of transshipment services from the definition of Shipping $\left(p_{m}\right)$ as it simplifies the procedure of taking the model to the data.
} 


\subsection{Predictions of the model}

In equilibrium, the share of land allocated to the port in port city $r$ is the solution to the equation

$$
-\psi^{\prime}(F(r))=\frac{R(r)}{\text { Shipping }(r)^{1+\lambda}}
$$

where $R(r)$ denotes land rents in city $r$, given by

$$
R(r)=\frac{1-\gamma}{\gamma} \frac{w(r) N(r)}{1-F(r)}
$$

such that $w(r)$ is the wage in city $r .{ }^{33}$ As the left-hand side of equation (5) is decreasing in $F(r)$ by the convexity of $\psi$, we have the following two propositions.

Proposition 1. Land allocated to the port is increasing in the amount of shipping flows (keeping land rents fixed).

Proposition 1 is the consequence of two forces in the model. The first is increasing returns to scale in transshipment technology: as shipping flows increase, it becomes profitable to lower unit costs by allocating more land to the port. The second force is congestion: an increase in shipping flows makes landlords allocate more land to the port to palliate congestion.

Proposition 2. Land allocated to the port is decreasing in land rents (keeping the amount of shipping flows fixed).

Proposition 2 highlights that the cost of port development differs across cities. Cities that have high land rents do not allocate much land to the port as the opportunity cost of land is very high. As a result, everything else fixed, port development primarily takes place in low-rent cities, consistent with what we document in the data. ${ }^{34}$

Finally, the model delivers the spatial distribution of population $N(r)$ as the solution to the following equation:

$$
N(r)^{[1+\eta \sigma+(1-\gamma-\alpha)(\sigma-1)] \frac{\sigma-1}{2 \sigma-1}}=\gamma^{\sigma-1} \tilde{a}(r)^{\frac{\sigma(\sigma-1)}{2 \sigma-1}} A(r)^{\frac{(\sigma-1)^{2}}{2 \sigma-1}}(1-F(r))^{(1-\gamma) \frac{(\sigma-1)^{2}}{2 \sigma-1}} M A(r)
$$

\footnotetext{
${ }^{33}$ The derivation of all equations presented here can be found in Appendix A.2.

${ }^{34}$ Equation (6) makes clear that equilibrium rents depend on a number of endogenous variables: the share of land allocated to the port, population and wages. These different forces might lead to either an increase or a decrease in local land rents in response to port development. For this reason, the evolution of land rents following port development cannot be used to test the model.
} 
where $M A(r)$ is the market access of city $r$, given by

$$
M A(r)=\sum_{s=1}^{S} \frac{\tilde{a}(s)^{\frac{(\sigma-1)^{2}}{2 \sigma-1}} A(s)^{\frac{\sigma(\sigma-1)}{2 \sigma-1}}(1-F(s))^{(1-\gamma) \frac{\sigma(\sigma-1)}{2 \sigma-1}} N(s)^{[1-\eta(\sigma-1)-(1-\gamma-\alpha) \sigma] \frac{\sigma-1}{2 \sigma-1}}}{\mathbf{E}[T(r, s)]^{\sigma-1}}
$$

and $\tilde{a}(r)$ can be obtained by scaling amenities $a(r)$ according to

$$
\tilde{a}(r)=\aleph_{c} a(r)
$$

where the endogenous country-specific scaling factor $\aleph_{c}$ adjusts such that the exogenously given population of country $c$ equals the sum of the populations of its cities.

How is the population of a port city affected by the development of its port? Our last proposition shows that the net effect on population is the outcome of two opposing forces: the market access effect that increases the population of the city, and the crowding-out effect that leads to a decrease in the city's population.

Proposition 3. An increase in the share of land allocated to the port in city $r, F(r)$, decreases shipping costs $\mathbf{E}[T(r, s)]$, thus increasing $M A(r)$. Everything else fixed, an increase in $M A(r)$ increases the population of the city (market access effect). At the same time, holding $M A(r)$ fixed, an increase in $F(r)$ decreases the share of land that can be used for production, $1-F(r)$, thus decreasing the population of the city (crowding-out effect).

Proof. These results follow directly from equation (7).

Proposition 3 sheds light on the fact that, to measure the net effect of port development, it is essential to consider both its benefits and its costs. On the one hand, port development lowers shipping costs. On the other hand, it requires scarce local land that needs to be reallocated from other productive uses. On net, one of these two forces may dominate the other, or they may offset each other exactly. The model, and equation (7) in particular, provide a structure that allows us to capture these opposing forces.

\section{Empirical evidence for the model's mechanisms}

Building on the model, we revisit the empirics in order to test the positive and negative effects of port development predicted by the model. We estimate the following panel specification, referred to as the model-inspired empirical specification: ${ }^{35}$

$$
\ln \left(\text { Pop }_{i t}\right)=\phi_{1} * \ln (\text { Ship })_{i t}+\phi_{2} * \ln (M A)_{i t}+\alpha_{i}+\delta_{t}+\epsilon_{i t}
$$

\footnotetext{
${ }^{35}$ Due to the lack of time-varying data on ports' land use, we cannot directly take equation (7) to the data.
} 
where $\ln (M A)_{i t}=\ln \left(\sum_{s=1}^{S} \frac{P o p_{s t}^{[1-\eta(\sigma-1)-(1-\gamma-\alpha) \sigma]} \frac{\sigma-1}{2 \sigma-1}}{T_{t}(i, s)^{\sigma-1}}\right)$ is the empirical equivalent of the modelbased market access term, and all other variables are as previously defined in Section 3. According to the mechanism described in the model, we expect $\phi_{1}$ to be negative and $\phi_{2}$ to be positive. We describe how each component of the market access term is calculated below.

$\underline{\text { Trade costs. }}$. We estimate time-varying bilateral trade costs $T_{t}(i, s)$ between origin and destination in the following way. As in the model, we assume that these bilateral costs consist of a combination of three possible components: first, the cost of shipping overland; second, the cost of sea shipping; and third, the cost of transshipment at seaports. We use the fast marching algorithm to calculate the lowest overall shipping cost between any given pair of cities. Following Allen and Arkolakis (2014), we assume that overland shipping costs $\phi_{\varsigma}$ and sea shipping costs $\phi_{\tau}$ take the form

$$
\phi_{\varsigma}(d)=e^{t_{\varsigma} d} \quad \phi_{\tau}(d)=e^{t_{\tau} d}
$$

where $d$ is (point-to-point) distance traveled. We take the values of $t_{\varsigma}$ and $t_{\tau}$ from the road and sea shipping cost elasticities estimated by Allen and Arkolakis (2014). ${ }^{36}$

Transshipment costs. There are no readily available measures of transshipment costs that we are aware of. To construct these, we use the following approach. Both the model and the transportation literature on ports argue that there are important increasing returns to scale in port technologies, rendering larger ports more cost-efficient (Rodrigue, 2016). We use estimates of port costs, available for a subset of our ports from Blonigen and Wilson (2008), to estimate the empirical relationship between port costs and shipping flows at the port level in our data, using a simple linear OLS specification. ${ }^{37}$ Consistent with increasing returns to scale in shipping, we find a negative and statistically significant association between port costs and the size of shipping flows. We use the estimated coefficient from this regression to predict port efficiency for all the ports in our data for each decade. Note that changing transshipment costs are the only source of time series variation in our estimated trade costs.

Parameters of the market access term. The model-based measure of market access requires taking a stand on the values of the parameters $\eta, \sigma, \gamma$ and $\alpha$. Table A.10 contains the parameter values we use and their source. We use the same values of these parameters when taking the full model to the data. Section 6.1.2 discusses the calibration of all structural parameters in detail.

Both regressors in the model-inspired specification (9) are potentially endogenous, requiring

\footnotetext{
${ }^{36}$ Allen and Arkolakis (2014) also allow for costs of inland and sea shipping that are fixed with respect to distance. However, they set the fixed costs of road shipping to zero. In the case of sea shipping, our aim is to define transshipment costs incurred at the seaport in a broad sense, such that they include any cost that is not a function of shipping distance, such as the fixed costs of sea transportation.

${ }^{37}$ Appendix B.14 provides the full details and results of the estimation.
} 
two sources of exogenous variation. We use depth as an instrument for shipping, as explained in Section 3. In addition, we use an exogenous population-growth shifter based on regional climate to construct an instrument for market access. This IV is based on insights from the urban economics literature, which has found that people have moved to places with warm winters over the course of the 20th century (e.g., Oi (1996); Rappaport (2007)).

We use the average number of frost free days, frost free ${ }_{i}$, during the years between 1961-1990 in each city to predict population growth during our time period. ${ }^{38}$ In order to predict population, we estimate the following specification:

$$
\ln \left(\text { Pop }_{i t}=\sum_{k=1960}^{1990} \beta_{k} * \text { frostfree }_{i} * \mathbb{1}(\text { Year }=k)+\alpha_{i}+\delta_{c t}+\epsilon_{i t}\right.
$$

where $\beta_{k}$ estimates the effect of warmer winters on population in each decade, $\alpha_{i}$ denotes cityspecific fixed effects, and $\delta_{c t}$ allows for the full set of country by year fixed effects. Inclusion of these implies that we only use within-country variation in climatic conditions when estimating the effect of frost-free days on population growth. We do this to address the concern that climatic conditions vary across regions in ways that may correlate with unobserved drivers of population growth, confounding our estimates of interest. Table A.11 shows the result of this estimation and presents some robustness checks. To construct our second instrument, we predict population for each city-year pair based on the estimated effects of frost free days and the estimated city fixed effect (we do not use the estimated country-year fixed effects to predict population). Using these predictions for city-level population, we define our second instrument as follows:

$$
\ln \left(M A I V_{i t}\right)=\ln \left(\sum_{s} \frac{\left.\exp (\ln \widehat{(P o p})_{i t}\right)}{\left(T_{1950}(i, s)\right)^{\sigma-1}}\right)
$$

where $T_{1950}(i, s)$ is the trade cost between cities $i$ and $s$ in 1950. We hold bilateral trade costs fixed throughout all years in order to make sure that potentially endogenous changes in trade costs over time are not used in the instrument. The specifications are estimated on the set of port cities in our dataset. Importantly, however, the market access of port cities is calculated using the full set of (port and non-port) cities.

Table 3 presents the estimation results. The OLS estimate in column (1) shows a very small negative effect of shipping on population that is not distinguishable from zero. Column (2) shows the 2SLS specification. Consistent with the predictions of the model, once we control for market

\footnotetext{
${ }^{38}$ Appendix B.15 contains a description of the data on the number of frost free days. This second instrument uses a source of exogenous variation that is orthogonal to port depth, as the number of frost free days and port depth (both residualized and un-residualized) are uncorrelated with each other. The correlation between the number of frost free days and unresidualized depth is 0.04 (p-val: 0.40 ), and the correlation between the number of frost free days and residualized depth is -0.02 (p-val: 0.68 ).
} 
access, shipping has a negative, statistically significant effect on population. ${ }^{39}$ The instruments yield a combined Kleibergen-Paap F-statistic of 9.63 which is just below the often recommended value of 10; however, it is larger than the critical value of 7.03 that the Stock-Yogo weak ID test suggests for $10 \%$ maximum bias (Stock and Yogo, 2002). ${ }^{40}$ Columns (3) and (4) report the first stages of the regression. Reassuringly, depth is a strong predictor of shipping, while the market access IV predicts market access strongly. Table A.12 shows that the pre-trends check with respect to depth holds (for both first stages) in this more complex specification that adds market access. ${ }^{41}$

We test the robustness of this result in a number of ways in Table A.13. First, we show that the results are remarkably robust to dropping cities in the close vicinity of the city in the market access IV, suggesting that much of the identifying variation is coming from population movements further away from the city itself. Moreover, the signs of the effects are robust to the same set of controls used in Section 3, though in the case of these demanding specifications, we don't always retain statistical significance at $10 \%$. Finally, we show that the coefficients are robust to applying the Borusyak and Hull (2020) correction to potential non-random shock exposure in the market access IV by constructing counterfactual shocks that could have been realized. ${ }^{42}$ We conclude that this lends well-identified evidence for the model mechanism. In the next section, we therefore turn to taking the full model to the data.

\section{The aggregate effects of containerization}

We use our model to measure the aggregate effects of containerization. To this end, we first take the model to post-containerization data, then roll back containerization in a counterfactual exercise. The difference between the counterfactual and the post-containerization equilibrium captures the aggregate effects of containerization. We also test whether the model can replicate the reducedform findings of Section 3.

\footnotetext{
${ }^{39}$ As expected, market access has a significant positive effect on population. It is difficult to compare the size of the market access effect to existing estimates (Donaldson and Hornbeck, 2016; Jedwab and Storeygard, 2021; Maurer and Rauch, 2021) because different papers construct market access in different ways. Jedwab and Storeygard (2021) are the only paper we are aware of that report standardized coefficients that allow for a comparison. They estimate that a one standard deviation increase in market access leads to a $0.43-0.85$ standard deviation increase in population. Relative to that paper, our estimate is slightly larger (1.13), but within the same ballpark.

${ }^{40}$ With the usual caveat that Stock and Yogo (2002) values have been derived only for i.i.d. errors, whereas we allow for autocorrelated or spatially correlated standard errors.

${ }^{41}$ As there is no similar 'pre-treatment period' for the market access IV, it is not possible to conduct a similar exercise for this IV.

${ }^{42}$ To construct these counterfactual shocks, we reshuffle frost-free days across the world (column 7) or within 30 degree latitude bands (column 8).
} 


\subsection{Taking the model to the data}

Taking the model to the data consists of three steps. First, we calculate inland and sea shipping costs across cities and choose a functional form for endogenous transshipment costs. Second, we choose the values of the model's seven structural parameters. Finally, we back out the values of unobserved city fundamentals that rationalize the post-containerization data.

\subsubsection{Calculating shipping costs}

To calculate inland and sea shipping costs across cities ${ }^{43}$ as a function of distance $d$, we follow our strategy outlined in Section 5 and assume

$$
\phi_{\varsigma}(d)=e^{t_{\varsigma} d} \quad \phi_{\tau}(d)=e^{t_{\tau} d}
$$

and set the elasticities $t_{\varsigma}$ and $t_{\tau}$ to the corresponding estimates in Allen and Arkolakis (2014).

Next, we choose endogenous transshipment costs as a function of the share of land allocated to transshipment services (port share, $F$ ), $\psi(F)$. The existing literature provides us with little guidance on this, as ours is the first paper that argues for the relevance of this relationship in a quantitative trade and geography framework. Hence, our goal is to keep the functional form of $\psi$ as simple as possible. That said, the functional form needs to satisfy our theoretical restrictions $(\psi \geq$ $\left.0, \psi^{\prime}<0, \psi^{\prime \prime}>0\right)$ and needs to be numerically tractable in the model inversion and simulations. In particular, the range of $\psi^{\prime}$ should ideally span the entire $(-\infty, 0)$ interval over its domain $(0,1)$, as otherwise it could become impossible to obtain port shares that rationalize the GDP and shipping data in every port city from equations (5) and (6). One simple function that satisfies all these restrictions is

$$
\psi^{\prime}(F)=1-F^{-\beta}
$$

where we restrict $\beta>0$ to guarantee $\psi^{\prime}<0 .{ }^{44}$

Finally, we capture the additional costs of cross-country trade, such as tariffs, quotas and redtape barriers, by multiplying the overall shipping cost between any two cities that are not in the same country by a constant $B>1$. We choose the value of $B$ such that the model replicates the ratio of international trade to world GDP in 1990. This procedure yields $B=2.1$.

\footnotetext{
${ }^{43}$ We have 553 port and 2,083 non-port cities in our data. For details, see Section 2.

${ }^{44}$ We can then obtain $\psi$ by integrating equation $(10)$ as $\psi(F)=\frac{F^{\beta}+(\beta-1)^{-1}}{F^{\beta-1}}+\kappa$, where we restrict $\kappa \geq \bar{\kappa}=-\left[1+(\beta-1)^{-1}\right]$ to guarantee $\psi \geq 0$. As total transshipment costs in city $r$ equal $[\nu(r)+\psi(F(r))]$ Shipping $(r)^{\lambda}, \kappa$ is isomorphic to a uniform shifter in exogenous port costs $\nu(r)$ and therefore cannot be identified separately from them. Thus, we set $\kappa$ to its theoretical lower bound $\bar{\kappa}$ without loss of generality.
} 


\subsubsection{Choosing the values of structural parameters}

On the production side, we take the estimate of the strength of agglomeration externalities, $\alpha=$ 0.06, from Ciccone and Hall (1993). This estimate has performed well in the literature for various countries and time periods. $\alpha=0.06$ implies that doubling city size increases city productivity by $6 \%$. Still on the production side, the expenditure shares on labor and land equal $\gamma$ and $1-\gamma$, respectively. Unfortunately, we are not aware of any study that measures the land share for the entire world. Thus, we base our benchmark value of $\gamma$ on Desmet and Rappaport (2017), who estimate a value of 0.10 for the difference between the land share and the agglomeration elasticity in the United States between 1960 and 2000, a period that corresponds to our sample period. Given we set $\alpha=0.06$, this suggests choosing $\gamma=0.84 .^{45}$

On the consumption side, we have two structural parameters: the migration elasticity, which we set to $\eta=0.15$ based on Kennan and Walker (2011), and the elasticity of substitution across tradable final goods, which we set to $\sigma=4$ based on Bernard, Eaton, Jensen, and Kortum (2003).

Finally, there are three structural parameters that influence shipping costs. One is the dispersion of idiosyncratic shipping costs, which - together with the functional form of these costs - we take from Allen and Arkolakis (2019), setting $\theta=203$. Another is the elasticity of transshipment costs to total shipping at the port (congestion externalities), which we take from the empirical estimates of Abe and Wilson (2009), setting $\lambda=0.074$. Table A.10 summarizes the calibration of these six structural parameters.

The last structural parameter to choose is $\beta$ from the endogenous transshipment function. Given that $\beta$ drives the relationship between the value of shipping flows and the port share in equation (5), we calibrate it to match the correlation between these two variables in the data. ${ }^{46} \mathrm{We}$ have been able to find high-quality, consistent data for the land area occupied by ports for only 7 port cities in 1990. We define the port share as the ratio of the land area occupied by the port and the total land area of the city. We find that the correlation between shipping and port share for these seven cities is 0.474 in the data. ${ }^{47}$

In the model, we compute the correlation between shipping and port share in the following way. First, for each port city, we numerically solve equations (5) and (6) for the port share that rationalizes shipping flows, Shipping $(r)$, and city GDP, $\gamma^{-1} w(r) N(r)$. As we explain in Ap-

\footnotetext{
${ }^{45}$ Another advantage of using this land share estimate is that it also accounts for the share of land embedded in housing, which is absent from our model but could matter for the quantitative results.

${ }^{46}$ To calculate this correlation, we first transform the number of ships, which is what we directly observe in the data, into the value of shipments, which is what enters equation (5). This procedure is described in detail in Section 6.1.3.

${ }^{47}$ Data sources are documented in Appendix B.5. Our port area data do not include the space occupied by complementary transport infrastructure outside the port, such as railroad and road links. As long as the land area occupied by these pieces of infrastructure is proportional to port area, accounting for them would not change the correlation between shipping flows and the port share.
} 
pendix A.3, our theoretical restrictions on $\psi^{\prime}$ guarantee that this procedure identifies a unique port share $F(r) \in(0,1)$ for each port city. Next, we calculate the correlation between Shipping $(r)$ and $F(r)$ for our set of port cities.

Under higher values of $\beta$, the endogenous port development mechanism plays a stronger role in the model. This is because, under higher $\beta$, the endogenous transshipment cost function is more responsive to changes in the port share:

$$
\frac{d\left|\psi^{\prime}(F)\right|}{d \beta}=-F^{-\beta} \log (F)>0
$$

Hence, everything else fixed, landlords have an incentive to increase the port share further if $\beta$ is high. Thus, we expect a stronger correlation between shipping and port share under higher values of $\beta$. This is precisely what we find. Figure A.5a plots the values of the correlation for a range of $\beta$ between 0.020 and 0.046 . Within this range, $\beta=0.031$ is the one that implies the correlation found in the data, $0.474 .^{48}$ Hence, we use this value of $\beta$ in our baseline calibration.

\subsubsection{Recovering post-containerization fundamentals}

We use observed data on city populations, shipping flows and city-level GDP per capita together with the structure of the model to find the set of city amenities $a(r)$, productivities $A(r)$ and exogenous transshipment $\operatorname{costs} \nu(r)$ that rationalize the data.

As city-level GDP data are only available for 1990, we choose to back out the model fundamentals based on the 1990 distribution of population, shipping and GDP. Since this year is after the advent of containerization, our counterfactual will involve rolling back, or undoing, the containerization shock. Hence, the aggregate effect of containerization can be assessed by comparing the counterfactual equilibrium (pre-containerization) to our 1990 equilibrium (post-containerization).

We transform the number of ships observed in the data in port city $r$ in 1990, Ship $(r)$, into the value of shipments, Shipping $(r)$, according to

$$
\text { Shipping }(r)=V \cdot \operatorname{Ship}(r)
$$

where we choose $V$ to match the ratio of shipping to world GDP. The rationale behind choosing this particular moment is that it can be calculated as a simple linear function of $V$ :

$$
\frac{\sum_{r} \text { Shipping }(r)}{\sum_{r} G D P(r)}=V \cdot \frac{\sum_{r} \operatorname{Ship}(r)}{\sum_{r} G D P(r)}
$$

\footnotetext{
${ }^{48}$ Instead of calculating the model-implied correlation over the entire set of port cities, we can compute it for the same set of seven port cities where we observe the port share. Reassuringly, for $\beta=0.031$, this gives us a correlation of 0.463 , essentially identical to the one found for the whole set of port cities.
} 
where Ship $(r)$ and $G D P(r)$ are both observable in the data. This procedure gives us a value of $V=364 .^{49}$

Using city-level GDP data, we can obtain wages as

$$
w(r)=\gamma \frac{G D P(r)}{N(r)}
$$

according to the model, where the structural parameter $\gamma$ is calibrated to 0.84 .

Once population $N(r)$ and wages $w(r)$ are available for each city and the value of shipments, Shipping $(r)$, is available for each port city, the equilibrium conditions of the model can be inverted to back out city amenities up to a country-level scale, $\tilde{a}(r)$, fundamental city productivities $A(r)$, and each port city's exogenous transshipment costs $\nu(r)$. We provide the details of this inversion procedure in Appendix A.3. ${ }^{50}$

\subsection{Counterfactual: rolling back containerization}

In our counterfactual, we account for the technological aspects of containerization documented in Section 1: lower costs, particularly in deep ports, and the increased land-intensity of transshipment. This requires us to change the values of three model fundamentals relative to the postcontainerization equilibrium. ${ }^{51}$

First, we capture the lower land intensity of port technology before containerization by decreasing the shape parameter of transshipment technology, $\beta$. As we argued in Section 6.1.2, a decrease in $\beta$ makes the endogenous transshipment cost function less responsive to changes in the port share, $F(r)$. Hence, under lower values of $\beta$, port city landlords have less incentive to increase $F(r)$, and port sizes will be generally smaller. To choose the value of the parameter in the counterfactual, $\beta_{C F}$, we use the empirical evidence of Section 1. In particular, we argued in Section 1 that containerized ports occupy on average $75 \%$ larger area if we hold the volume of traffic fixed. In our model, this means that the average port share would have increased by $75 \%$ if we held the non-technological determinants of the port share, i.e., shipping and land rents, fixed:

$$
\frac{\sum_{r \in P} F(r)}{\sum_{r \in P} \hat{F}(r)}-1=0.75
$$

\footnotetext{
${ }^{49}$ As not all our port cities have positive shipping flows in 1990 but the model cannot rationalize zero shipping flows under finite positive values of city-specific fundamentals, we change Ship $(r)$ from zero to one in these cities.

${ }^{50}$ The complex structure of the model does not allow us to prove that the inversion procedure identifies a unique set of $\tilde{a}(r), A(r)$ and $\nu(r)$. Nonetheless, we have experimented with various different initial guesses, and the inversion algorithm converges to the same fixed point, suggesting that the vector of cityspecific fundamentals that rationalize the data is likely unique.

${ }^{51}$ Appendix A.4 provides details on how we solve for counterfactual equilibria in the model.
} 
where $P$ is the set of port cities, $F(r)$ is the port share of port city $r$ in 1990 , given by

$$
-\left[1-F(r)^{-\beta}\right]=\frac{R(r)}{\text { Shipping }(r)^{1+\lambda}}
$$

which we obtain by combining equations (5) and (10), and $\hat{F}(r)$ is the port share implied by the same rents and shipping but shape parameter $\beta_{C F}$ :

$$
-\left[1-\hat{F}(r)^{-\beta_{C F}}\right]=\frac{R(r)}{\text { Shipping }(r)^{1+\lambda}}
$$

To back out $\beta_{C F}$, we first solve equation (12) for $F(r)$. Next, we solve equation (13) for $\hat{F}(r)$ for a range of $\beta_{C F}$. Finally, we pick the $\beta_{C F}$ under which equation (11) holds. Figure A.5b shows that the increase in mean port share is monotonic in $\beta_{C F}$ and hence the parameter is identified. The value at which mean port share increases by $75 \%$ is $\beta_{C F}=0.018$.

Second, we capture the fact that depth was not relevant for transshipment prior to containerization. To this end, we offset the relationship between exogenous transshipment costs and depth in the counterfactual. We first run the regression

$$
\log \nu(r)=\omega_{0}-\omega_{1} * \operatorname{Depth}(r)+\varepsilon(r)
$$

on our sample of port cities, where $\nu(r)$ is the exogenous transshipment cost of city $r$ recovered in Section 6.1.3, and Depth $(r)$ is our residualized depth measure, defined in Section 3. In line with the fact that depth lowers transshipment costs after containerization, we find $\widehat{\omega_{1}}=0.048$ (se. 0.025, p-value 0.053). Next, we undo this dependence of exogenous transshipment costs on depth by adding $\widehat{\omega_{1}} *$ Depth $(r)$ to $\log \nu(r) .{ }^{52}$

Finally, we incorporate the overall reduction in transshipment costs due to containerization by increasing exogenous transshipment costs $\nu(r)$ uniformly across ports. More precisely, we increase $\log \nu(r)$ by the same number $\nu_{C F}$ at each port to match the estimated $25 \%$ average change in the sum of exogenous and endogenous transshipment costs as a result of containerization. ${ }^{53}$

\footnotetext{
${ }^{52}$ To avoid outliers influencing the results of this step, we trim the values of $\nu(r)$ at 0.01 before estimating $\omega_{1}$. The inversion algorithm assigns very small $\nu$ 's to some cities. Due to lack of machine precision in the inversion algorithm for very small values of $\nu$ 's, very small differences in $\nu$ 's may be exaggerated greatly when taking logs of $\nu$ 's in the estimation. This affects 19 port cities, for which we identify $\nu(r)$ below 0.01. As these 19 port cities are deeper than average, we obtain a slightly higher regression coefficient, $\widehat{\omega_{1}}=0.056$, without the trimming.

${ }^{53}$ Rodrigue (2016, p. 117) estimates that containerization led to an overall $70 \%$ to $85 \%$ reduction in maritime transport costs by 2010; "While before containerization maritime transport costs could account for between 5 and 10 percent of the retail price, this share has been reduced to about 1.5 percent, depending on the goods being transported." A reduction from $5 \%$ to $1.5 \%$ of retail price equals a $70 \%$ cost reduction
} 
Naturally, higher values of $\nu_{C F}$ yield a larger change in transshipment costs, suggesting that there should be a unique $\nu_{C F}$ at which we meet our $25 \%$ target. This procedure identifies $\nu_{C F}=0.280$.

Overall, according to our simulation, these changes in transshipment technology lead to an increase in the international trade to world GDP ratio by 4.7 percentage points from the counterfactual to the 1990 equilibrium. As a reference point, the trade to world GDP ratio increased by 15 percentage points between 1960 and 1990. This suggests that containerization was responsible for about one-third of the overall increase in trade to world GDP during these three decades.

The fraction of land occupied by ports (i.e., the port share) increases in most port cities from the counterfactual to the 1990 equilibrium. Port shares become larger for two reasons. First, the increase in $\beta$ increases the incentive to invest more land in port development, mimicking the changing land-intensity of port technologies caused by containerization. Second, the reduction in trade costs leads to increased demand for shipping, encouraging yet more investment in port development. Figure A.6 presents the full distribution of port share changes across cities. The median change is 3 percentage points, while the 5 th percentile is zero pp and the 95th percentile is 35 pp. ${ }^{54}$

\subsection{Test of the model: the reduced-form effects of containerization}

In this section, we examine whether our quantified model can replicate the two key reduced-form facts related to containerization estimated in Section 3. First, to examine the local population effects of shipping in the model, we consider equation (1). Following the same identification strategy, we instrument the change in shipping with residualized port depth. Column (5) of Table 2 presents the results of this exercise. The model-simulated data have a strikingly similar estimated coefficient (0.006 in the data and 0.008 in the model-simulated data). The coefficient is neither statistically, nor economically significant. The results from column (5) confirm that the crowdingout effect of increased land use caused by port development is sufficient to offset the positive local population effect of increased shipping due to the market access effect. ${ }^{55}$

Second, we examine whether containerization induces shipping activity to reallocate toward low-rent cities in the model. To this end, we consider the long-differenced version of the rent

$(=1-1.5 / 5)$; similarly, a reduction from $10 \%$ to $1.5 \%$ equals an $85 \%$ cost reduction. We estimate that $36 \%$ of the total cost reduction took place up to 1990, by assuming that cost reductions are proportionate to ship size increases. These calculations are based on data from the Miramar Ship Index (Haworth, 2020). More details on these data are provided in Appendix B.11. Using the more conservative estimate of 70\%, this gives us a $25 \%$ decrease in average transshipment costs.

${ }^{54} \mathrm{~A}$ natural question is whether we can use the predicted port shares (an untargeted moment) to test the model fit. Data limitations preclude us from doing this. First, we only have data on the area of the port for 7 cities. Second, even for these cities, we do not observe the land occupied by complementary transport infrastructure outside the port, which is a potentially important contributor to the increased land usage of port activities. Instead, we test the model's fit to the data along other dimensions in Section 6.3.

${ }^{55}$ We discuss columns (6) and (7) in Section 6.4. 
heterogeneity result (specification 2). Depth $h_{i}$ is our depth measure residualized on population in 1950, as in the data. The difference is that, while we had to rely on a proxy of city-level rents in specification (2), we can use model-implied (pre-containerization) rents $R_{i, C F}$ here. We evaluate the coefficient of interest, $\gamma$, at different values of $\log$ rents $\ln \left(R_{i, C F}\right)$ in Figure $1 \mathrm{~b} .{ }^{56}$ As the figure shows, the effect of land rents on shipping is negative, large and statistically significant, as in the data. This provides further evidence that the land price mechanism is present in the model not only in a qualitative sense (as we showed in Section 4.2), but it is a significant driver of where port development takes place.

\subsection{The aggregate welfare effects of containerization}

We estimate that aggregate world welfare increased by $3.84 \%$ as a result of containerization. ${ }^{57}$ The welfare gains from containerization stem from a combination of three factors in the model: lower shipping costs, which increase welfare; the increased cost of land use, i.e., the resource costs of containerization, which lower the gains; and the gains from increased specialization of cities in port or non-port activities, i.e., the specialization gains from containerization.

To assess the quantitative importance of each of these margins, we develop two simple benchmark models that will allow us to isolate the three mechanisms at work. 'Benchmark 1' is closest to a standard model, as it assumes that transshipment costs are exogenous and free - that is, land is solely used for the production of the city-specific good. Thus, the welfare gains from containerization only stem from shipping cost reductions in this benchmark model. 'Benchmark 2,' on the other hand, requires land to be used to reduce transshipment costs. However, we restrict land use to be identical across port cities (and equal to the mean port share in our baseline). ${ }^{58}$

As Benchmark 2 only differs from Benchmark 1 in land being used for port activities, a comparison between these two models reveals the resource costs of increased land use due to containerization. As our baseline model only differs from Benchmark 2 in the potential specialization of port cities in port or non-port activities (through each city choosing the allocation of land between the two), a comparison between these two models reveals the endogenous specialization gains from containerization.

To implement the decomposition of the aggregate welfare effects, we first take Benchmark 1 and Benchmark 2 to our 1990 data. Next, we conduct the containerization counterfactual in each benchmark model. In particular, we conduct the counterfactual such that the world trade to GDP ratio changes to the same extent $(+4.7 \mathrm{pp})$ in each benchmark as in our baseline model. Hence,

\footnotetext{
${ }^{56}$ Table A.14 shows the corresponding estimates.

${ }^{57}$ We define the change in aggregate world welfare as the average of changes in country-level welfare between the counterfactual and the 1990 equilibrium, weighted by country population. Within each country, labor mobility equalizes welfare across cities, as in Redding (2016). However, we do not allow for mobility across countries, hence different countries experience different welfare effects.

${ }^{58}$ We provide a description of each benchmark model and their quantitative estimation in Appendix A.5.
} 
differences in the welfare effects across the models do not stem from trade changing to a different extent.

We find that containerization leads to welfare gains of $4.12 \%$ in Benchmark 1. In Benchmark 2 , the gains from containerization reduce to $3.45 \%$. The difference between Benchmark 1 and Benchmark 2, 0.67 percentage points, captures the resource costs of containerization. These costs are sizeable: they eat up as much as $16 \%$ of the gains from the shipping cost reduction. Finally, the difference between Benchmark 2 and our baseline model, 0.39 percentage points, captures the specialization gains from containerization. Note that these gains are able to offset about $58 \%$ of the resource costs of containerization, but they do not fully compensate for all the costs. Based on this exercise, relative to a standard model in which transport cost reductions are exogenous and free, both model mechanisms - the resource cost and the endogenous specialization effect - lead to quantitatively meaningful effects on welfare.

We can also use the benchmark models to provide another test of whether it is indeed our endogenous crowding-out mechanism that leads to the null effect of shipping on population in the model. To this end, we estimate the causal effect of shipping on population in the two benchmarks (columns 6 and 7 of Table 2, respectively). Unlike in our baseline model, shipping leads to a significant increase in city population in both benchmarks. This is intuitive: while better market access draws people into the city in all three models, increased land use in transshipment does not have a differential impact on city population in the benchmarks. ${ }^{59}$ The standardized coefficients demonstrate that a one standard deviation increase in shipping translates into a larger $(0.166$ and 0.181 standard deviation) increase in population in the benchmarks than in the baseline model (0.064) or in the data (0.022). This underscores that the crowding-out effect is driving the zero local population effect of shipping in the model. It also suggests that the crowding-out effect is sizeable - not just in terms of the effect it has at the aggregate level, but also in terms of its local effect.

In Appendix A.8, we show that the aggregate and local effects of containerization implied by the model are robust to different values of the containerization shock and some alternative modeling choices. These alternative specifications include different values of transshipment cost shape parameter $\beta$ in 1990 or in the counterfactual, different changes in exogenous transshipment costs, and a model in which landlords make profits from the provision of transshipment services.

\section{Alternative explanations for the crowding-out effect}

Thus far, we have shown both reduced form and structural evidence that the land price mechanism can account for the crowding out of population that we observe in the data. Of course, there are

\footnotetext{
${ }^{59}$ In Benchmark 2, land used for transshipment increases equally across port cities. Hence, land used for transshipment does not react endogenously to shipping, leading to no differential impact on the population of cities with different changes in shipping. In Benchmark 1, no land is used for transshipment by assumption.
} 
other explanations that could also explain these findings. In this section, we consider a number of them.

Declining labor-intensity of port technology. Containerization is a labor-saving technology as the standardization of cargo-handling allows for more extensive automation (Bridgman, 2014). If the job destruction that occurred in port-related activities was sufficiently large, it could account for a substantial part of the population crowding-out identified in our empirics. We assess the magnitude of this channel using readily available historical data on U.S. employment in water transportation (the industry to which longshoremen belong) from the Bureau of Economic Analysis (BEA). ${ }^{60}$

There were approximately 222,000 full-time equivalent employees in water transportation in the U.S., accounting for $0.12 \%$ of the population in $1960 .{ }^{61}$ Between 1960 and 1987 (the last year in the series), employment fell by $23 \%$. We conduct a back-of-the envelope calculation to assess the magnitude of population crowding out that this channel could account for. We make the following conservative assumptions: i) we assign all U.S. water-transportation workers precontainerization to our sample of U.S. cities; ii) we assume all of these jobs were made redundant by containerization (when in fact, only $23 \%$ of jobs disappeared); and iii) we assume all workers moved out of the port city. This would result in a reduction of the population in port cities by $0.34 \%$ relative to 1960 population levels. ${ }^{62}$

The implied population losses are about an order of magnitude too small relative to i) the causally estimated average crowding-out effect, which is $3.8 \%,{ }^{63}$ or ii) the average crowding out implied by the quantitative model, which is $2.25 \% .{ }^{64}$ Both of these numbers are about an order of magnitude larger than the entire size of the water transport sector in 1960. Based on this, we conclude that the declining labor intensity of port technology can at most account for a very small fraction of the crowding-out effect.

Inland transport cost reductions. While we focus on estimating what effects containerization had by reducing transshipment costs at seaports, in reality, containerization had broader effects on transport costs. Most importantly, it arguably also reduced overland transport costs as intermodal

\footnotetext{
${ }^{60}$ We use 'Water Transportation' employees from the BEA's 'Full-Time Equivalent Employees by Industry' series (Table 6.5). Accessed February, 2021 at https://apps.bea.gov/iTable/iTable.cfm?reqid=19\&step= $2 \&$ isuri $=1 \& 1921=$ survey.

${ }^{61}$ Source: https://en.wikipedia.org/wiki/1960_United_States_census. Employees in water transportation accounted for $0.34 \%$ of all full-time equivalent employees.

${ }^{62}$ The population of the sample of U.S. Geopolis cities was 64,951,000 in 1960.

${ }^{63}$ Shipping increased on average by $24 \%$ between 1960 and 1990 . Multiplying this by the elasticity of population w.r.t. shipping estimated in Table 3, column $2(-0.159)$ yields a $3.8 \%$ population loss.

${ }^{64}$ In the quantitative estimation, the size of the non-shipping sector decreases on average by $8.98 \%$ across port cities with the introduction of containerization. The log-linearized equation determining equilibrium city population (equation 7 ) implies a population loss of $8.98 \% * 0.25=2.25 \%$, where the elasticity of 0.25 is based on the parameter values used in the quantitative estimation (and reported in Table A.10).
} 
transshipping between trucks and railways became cheaper. This raises the concern that the population outflows estimated in port cities are driven by the fact that these overland transport cost reductions made inland cities more attractive, leading to population outflows from port cities that counteract the standard market access effect.

We investigate this channel by using our quantitative model to examine how adding an inland cost increase to our counterfactual simulation (i.e., the rolling back of containerization) changes the results. Rows (10) and (11) of Table A.15 show that adding this additional shock does not meaningfully alter i) the estimated aggregate resource costs and specialization gains from containerization, ii) the zero local population effects, iii) the reallocation of shipping toward low-rent cities. ${ }^{65}$ The reason for this is that the overland cost reduction has two opposing effects of roughly similar magnitude. On the one hand, overland transport cost reductions make these routes more attractive relative to sea routes, leading to less endogenous port development. However, they also increase the overall volume of shipping, which increases port development. ${ }^{66}$ Put differently, we find no evidence of missing interaction effects between the aspect of containerization we are interested in, and the overland transport cost reductions, which we do not account for in the main analysis of this paper.

Pollution and other negative amenities associated with port development. A different explanation relies on the argument that port development is a 'dirty' activity that leads to population outflows as people flee the disamenities of port activities. While it is undeniable that ports generate pollution and other disamenities, this in and of itself is not sufficient to confound our results. As we are using exogenous variation in port development caused by depth and variation in the Saiz (2010) land rent proxy, it must be the case that the disamenities associated with port development are correlated with both containerization and with the Saiz proxy. We have not found any evidence pointing in this direction.

To study whether disamenities associated with ports became stronger in response to containerization, we examined historical annual reports from multiple U.S. ports. ${ }^{67}$ While we found evidence of environmental concerns related to dredging and the (noise) pollution associated with airport operations (but not seaport operations), we found no paper trail for concerns regarding air quality or pollution more generally from containerized port activities. On the contrary, we found one example of air quality issues related to non-containerized cargo. ${ }^{68}$ That is, while there are

\footnotetext{
${ }^{65}$ Adding the inland cost reduction obviously changes the overall welfare gains. We provide further details on this robustness exercise in Appendix A.8.

${ }^{66}$ The canceling out of these two forces is also reflected in the fact that mean port size changes are very similar with and without overland cost changes; in both cases, the increase is about 8.6 percentage points.

${ }^{67}$ Appendix B.16 contains a detailed list of all ports examined and the sources.

${ }^{68}$ In the 1970 s, the Port of Seattle undertook efforts to mitigate dust emitted by its grain terminal operations, serving as a model for EPA guidelines on dust control.
} 
obvious disamenities associated with seaports, it is less clear that these amenities are correlated with the containerization shock and the Saiz land rent proxy.

\section{The effects of targeted port development}

We use our estimated model to illustrate the effects of targeted port development policy in this section. Our model is particularly well-suited to such an exercise, as it allows the development of both targeted and non-targeted ports to endogenously respond to port development policy, highlighting rich distributional impacts. We study a large-scale port development policy similar to the Chinese government's 'Maritime Silk Road' project, which is part of the 'Belt and Road Initiative.' 69 In particular, we study the effects of a $10 \%$ reduction in exogenous transshipment costs in 24 port cities in Asia, Africa and Europe targeted by Chinese investment (see Figure A.7 for the set of targeted ports). ${ }^{70}$

Table 4 examines the effects of this policy on treated and untreated port cities, and inland cities. We compare the effects generated by our model ('Baseline') to those of a more standard model ('Benchmark 1' - introduced in Section 6.4). As column (1) demonstrates, targeted port cities see a significant and large increase in shipping activities, primarily at the expense of nontargeted port cities in the same country. This local reallocation of shipping is more pronounced in the baseline model than in Benchmark 1 (column 5). To see why this is the case, in columns (2) and (6) we examine the effect on port costs (the sum of exogenous and endogenous transshipment costs, $\nu(r)+\psi(F(r))$ ). In Benchmark 1, endogenous transshipment costs are absent, implying that targeted port cities see an exact 10\% (0.105 log point) decline in their transshipment costs, while non-targeted cities see no effect. By contrast, in the baseline model, the direct effect of the policy is amplified by an endogenous reallocation of land within the city. This results in a decline in endogenous transshipment costs in targeted ports (where more land is allocated to the port) and an increase in endogenous transshipment costs in non-targeted ports (where less land is allocated to the port). This endogenous port development response to the policy is precisely what draws additional shipping into targeted cities and away from non-targeted ones. ${ }^{71}$

We also study the effects on cities' market access (as defined by equation 8) and population across both models. The effect on market access is similar in both simulations, as we would expect: all cities gain on average, particularly targeted port cities and inland cities located in the same country. In terms of population responses, however, the similar improvement in market access

\footnotetext{
${ }^{69}$ The simulation we conduct is similar to the Maritime Silk Road project, as we analyze effects relative to the 1990 equilibrium, not today. Moreover, the absence of specific details on the size of the actual investments precludes us from matching exactly what the project entails.

${ }^{70}$ We take the targeted ports from OECD (2018) and choose the decrease in $\nu(r)$ to be $10 \%$ to illustrate the effects of a sizeable, but not dramatic decrease in transshipment costs. We keep all other fundamentals of the model fixed at their levels recovered in Section 6.1.

${ }^{71}$ As presented in Table A.16, the results remain similar if we include country fixed effects.
} 
results in strikingly different population responses - highlighting the crowding out mechanism at work in our model. In the baseline (column 4), endogenous port development in targeted port cities moves people out of the city through increased land use, primarily to non-targeted port cities. In contrast, in Benchmark 1 (column 8), targeted ports gain population at the expense of non-targeted ones. These findings highlight the importance of accounting for the crowding-out effect when evaluating how targeted port development affects the spatial distribution of population.

We examine how targeted port development redistributes shipping and real GDP across regions of the world in Figure 2. We find the most dramatic distributional effects in Asia. Strikingly, we see a dramatic reallocation of shipping to China and away from Singapore (which we estimate loses $50 \%$ of its shipping flows). ${ }^{72}$ Neither countries have targeted ports in this simulation. While these effects are also present in the benchmark model, they are far more muted. In our model, the initial reallocation of shipping is amplified by increasing returns to scale. As shipping moves away from Singapore towards targeted ports, incentives to develop the port of Singapore decrease, which ultimately leads the city to cut back substantially on its port activities by reallocating land away form the port. However, Singapore sees a more than $1 \%$ gain in real GDP in our baseline model, as the city's declining port frees up land that can be used profitably outside the shipping sector. This is particularly true in the case of Singapore, where the non-port sector is very productive. ${ }^{73}$

As the example of Singapore illustrates, increasing returns have the potential to substantially amplify changes in shipping and real GDP in our baseline model relative to a standard trade model such as Benchmark 1. This is also evident from the fact that changes in shipping and real GDP vary to a much larger degree across regions in the baseline model than in the benchmark. In Benchmark 1 , changes in shipping range from $-0.25 \%$ to $2.88 \%$ across our nine regions; in the baseline model, the corresponding numbers are $-47.93 \%$ and $19.68 \%$. In Benchmark 1, changes in real GDP range between $-0.02 \%$ and $0.23 \%$, while they vary between $-0.02 \%$ and $1.24 \%$ in the baseline. These results underscore that modeling endogenous port development is essential to correctly assess the magnitude of the distributional effects of port development policies.

\section{Conclusion}

The containerization shock studied in this paper allows us to shed light on the economic effects of port development. We have shown that the land-intensive nature of port development is an empirically strong force that has the potential to matter for the local, aggregate and distributional

\footnotetext{
${ }^{72}$ It must be noted, however, that China's percentage change in shipping does not correspond to a dramatic absolute change, as China had relatively little shipping back in 1990.

${ }^{73}$ According to our model, Singapore is at the 98th percentile in the world productivity distribution. Of course, the economic benefits from dismantling a port may be not the only factor considered by decisionmakers in reality. Governments' objective functions may include geopolitical advantages from maintaining a central position in the global shipping network. In our analysis, we focus on the economic effects and do not consider these additional factors.
} 
economic effects of port development. Though the analysis in this paper is positive, it offers some tentative implications for where port development is likely to have the biggest beneficial impact. On the one hand, the recent aggressive port development strategy followed by some developing country cities such as Colombo, Sri Lanka seems promising. These are cities where the opportunity cost of land remains relatively low given the low productivity of non-port activities. On the other hand, our findings cast some doubt on the wisdom of continuing to specialize in port services for some of the world's most productive and expensive cities such as Hong-Kong and Singapore. While these cities arguably benefited enormously from their position as important ports historically (at a time when they were also far poorer relative to the rest of the world), subsequent productivity growth outside the port sector has made the opportunity cost of the land occupied by the port extremely high. Our findings suggest that the 'Hong-Kongs' and 'Singapores' of the world may benefit from following the path of cities such as London (United Kingdom) - a city at the center of world trade for many decades, but one that now houses Canary Wharf, an important second financial district, on redeveloped land once occupied by the port.

\section{References}

Abe, K. and J. Wilson (2009). Weathering the Storm: Investing in Port Infrastructure to Lower Trade Costs in East Asia. World Bank.

Allcott, H. and D. Keniston (2017). Dutch Disease or Agglomeration? The Local Economic Effects of Natural Resource Booms in Modern America. Review of Economic Studies 85(2), 695-731.

Allen, T. and C. Arkolakis (2014). Trade and the Topography of the Spatial Economy. Quarterly Journal of Economics 129(3), 1085-1140.

Allen, T. and C. Arkolakis (2019). The Welfare Effects of Transportation Infrastructure Improvements.

Allen, T. and D. Atkin (2016). Volatility and the Gains from Trade.

Altomonte, C., I. Colantone, and L. Bonacorsi (2018). Trade and Growth in the Age of Global Value Chains. Technical report, BAFFI CAREFIN Centre Research Paper.

Anderson, J. (1979). A Theoretical Foundation for the Gravity Equation. American Economic Review 69(1), 106-116.

Armenter, R., M. Koren, and D. Nagy (2014). Bridges.

Bernard, A., J. Eaton, J. Jensen, and S. Kortum (2003). Plants and Productivity in International Trade. American Economic Review 93(4), 1268-1290.

Bernhofen, D., Z. El-Sahli, and R. Kneller (2016). Estimating the Effects of the Container Revolution on World Trade. Journal of International Economics 98, 36-50.

Bleakley, H. and J. Lin (2012). Portage and Path Dependence. Quarterly Journal of Economics 127, 587-644.

Blonigen, B. and W. Wilson (2008). Port Efficiency and Trade Flows. Review of International Economics 16(1), 21-36.

Borusyak, K. and P. Hull (2020). Non-Random Exposure to Exogenous Shocks: Theory and Applications. National Bureau of Economic Research (Working Paper 27845). 
Brancaccio, G., M. Kalouptsidi, and T. Papageorgiou (2020). Geography, transportation, and endogenous trade costs. Econometrica 88(2), 657-691.

Bridgman, B. (2014). Why Containerization Did Not Reduce Ocean Trade Shipping Costs.

Brinkman, J. and J. Lin (2019). Freeway revolts! the quality of life effects of highways. Mimeo.

Brooks, L., N. Gendron-Carrier, and G. Rua (2021). The Local Impact of Containerization.

Ciccone, A. and R. Hall (1993). Productivity and the Density of Economic Activity. National Bureau of Economic Research (Working Paper 4313).

Coşar, A. and P. Fajgelbaum (2016). Internal Geography, International Trade, and Regional Specialization. American Economic Journal: Microeconomics 1(8), 24-56.

Conley, T. (1999). Gmm Estimation with Cross Sectional Dependence. Journal of Econometrics 92(1), 1-45.

Corbett, M. (2010). The History and Transformation of the Port of San Francisco, 1848-2010. San Francisco Architectural Heritage.

Corden, W. and J. Neary (1982). Booming sector and de-industrialisation in a small open economy. Economic Journal 92(368), 825-848.

Coşar, A. and B. Demir (2018). Shipping Inside the Box: Containerization and Trade. Journal of International Economics 114, 331-345.

Desmet, K. and J. Rappaport (2017). The Settlement of the United States, 1800-2000: The Long Transition Towards Gibrat's Law. Journal of Urban Economics 98, 50-68.

Donaldson, D. and R. Hornbeck (2016). Railroads and American Economic Growth: A "market access" Approach. Quarterly Journal of Economics 131(2), 799-858.

Donaldson, D. and A. Storeygard (2016). The View from Above: Applications of Satellite Data in Economics. Journal of Economic Perspectives 30(4), 171-98.

Ducruet, C., S. Cuyala, and A. E. Hosni (2018). Maritime Networks as Systems of Cities: The Long-term Interdependencies Between Global Shipping Flows and Urban Development. Journal of Transport Geography 66, 340-355.

Duranton, G. and D. Puga (2015). Urban Land Use. In Handbook of Regional and Urban Economics. Elsevier.

Duranton, G. and D. Puga (2019). Urban Growth and its Aggregate Implications.

Eaton, J. and S. Kortum (2002). Technology, Geography, and Trade. Econometrica 70(5), 17411779.

Eyre, J. (1964). Shipping Containers in the Americas. In Pan American Union: Recent Developments in the Use and Handling of Unitized Cargoes, pp. 38-42.

Fajgelbaum, P. and S. Redding (2018). Trade, Structural Transformation and Development: Evidence from Argentina, 1869-1914.

Fajgelbaum, P. D. and E. Schaal (2020). Optimal transport networks in spatial equilibrium. Econometrica 88(4), 1411-1452.

Falvey, R. E. (1976). Transport Costs in the Pure Theory of International Trade. The Economic Journal 86(343), 536-550.

Fujita, M. and T. Mori (1996). The Role of Ports in the Making of Major Cities: Self-agglomeration and Hub-Effect. Journal of Development Economics 49, 93-120.

Ganapati, S., W. F. Wong, and O. Ziv (2020). Entrepôt: Hubs, Scale, and Trade Costs.

Gilman, S. (1983). The Competitive Dynamics of Container Shipping. Gower Publishing Company.

Gomtsyan, D. (2016). Rise of the Machines: Evidence from the Container Revolution. 
Haworth, R. B. (2020). Miramar ship index.

Head, K. and T. Mayer (2014). Gravity Equations: Workhorse, Toolkit, and Cookbook, Volume 4 of Handbook of international economics. Elsevier.

Heiland, I., A. Moxnes, K. H. Ulltveit-Moe, and Y. Zi (2021). Trade From Space: Shipping Networks and The Global Implications of Local Shocks.

Holmes, T. and E. Singer (2018). Indivisibilities in Distribution. National Bureau of Economic Research (Working Paper 24525).

Hummels, D. (2007). Transportation Costs and International Trade in the Second Era of Globalization. Journal of Economic Perspectives 21(3), 131-154.

Jedwab, R. and A. Storeygard (2021). The Average and Heterogeneous Effects of Transportation Investments: Evidence from Sub-Saharan Africa 1960-2010. National Bureau of Economic Reserach (Working Paper 27670).

Kahveci, E. (1999). Fast Turnaround Ships and Their Impact on Crews.

Kennan, J. and J. Walker (2011). The Effect of Expected Income on Individual Migration Decisions. Econometrica 79(1), 211-251.

Krugman, P. (1987). The Narrow Moving Band, the Dutch Disease, and the Competitive Consequences of Mrs. Thatcher: Notes on Trade in the Presence of Dynamic Scale Economies. Journal of Development Economics 27(1-2), 41-55.

Krugman, P. (2011). Comparative Advantage, Growth, And The Gains From Trade And Globalization: A Festschrift in Honor of Alan V Deardorff. Technical report, Citigroup Foundation Special Lecture.

Levinson, M. (2010). The Box: How the Shipping Container Made the World Smaller and the World Economy Bigger. Princeton University Press.

Manville, M. and D. Shoup (2005). Parking, people and cities. Journal of Urban Planning and Development 131(4), 233-245.

Martín-Antón, M., d. C. J. M. Negro, V., J. S. López-Gutiérrez, and M. D. Esteban (2016). Review of coastal land reclamation situation in the world. Journal of Coastal Research 75, 667 - 671.

Maurer, S. and F. Rauch (2021). Economic Geography Aspects of the Panama Canal.

McKinsey \& Company (1972). Containerization: A Five-Year Balance Sheet. Technical report, McKinsey \& Company.

Melitz, M. J. (2003). The Impact of Trade on Intra-Industry Reallocations and Aggregate Industry Productivity. Econometrica 71(6), 1695-1725.

Monte, F., S. Redding, and E. Rossi-Hansberg (2018). Commuting, Migration, and Local Employment Elasticities. American Economic Review 108(12), 3855-90.

Moriconi-Ebrard, F. (1994). Geopolis.

Nagy, D. (2020). Hinterlands, City Formation and Growth: Evidence from the U.S. Westward Expansion.

OECD (2014). The Competitiveness of Global Port Cities. Technical report, OECD Publishing.

OECD (2018). The Belt and Road Initiative in the Global Trade, Investment, and Finance Landscape. Technical report, OECD Publishing Paris.

Oi, W. (1996). The Economics of New Goods. In The Welfare Implications of Invention. University of Chicago Press.

Pines, D. and E. Sadka (1985). Zoning, First-best, Second-best, and Third-best Criteria for Allocating Land for Roads. Journal of Urban Economics 17(2), 161-173.

Port of San Francisco (1971). San Francisco Port Needs, Shipping and Area Requirements. Tech- 
nical report, Port of San Francisco.

Rappaport, J. (2007). Moving to Nice Weather. Regional Science and Urban Economics 37(3), 375-398.

Redding, S. (2016). Goods Trade, Factor Mobility and Welfare. Journal of International Economics 101, 148-167.

Redding, S. and M. Turner (2015). Transportation Costs and the Spatial Organization of Economic Activity, Volume 5 of Handbook of regional and urban economics, pp. 1339-1398. Elsevier.

Rodrigue, J. (2016). The Geography of Transport Systems. Taylor Francis.

Rua, G. (2014). Diffusion of Containerization.

Saiz, A. (2010). The Geographic Determinants of Housing Supply. Quarterly Journal of Economics 125(3), 1253-1296.

Santamaría, M. (2020). The Gains from Reshaping Infrastructure: Evidence from the division of Germany.

Solow, R. (1972). Congestion, Density and the Use of Land in Transportation. The Swedish Journal of Economics 74(1), 161-173.

Solow, R. and W. Vickrey (1971). Land Use in a Long Narrow City. Journal of Economic Theory 3(4), 430-447.

Stock, J. and M. Yogo (2002). Testing for Weak Instruments in Linear IV Regression. In Essays in Honor of Thomas Rothenberg. Cambridge University Press.

Wong, W. F. (2020). The Round Trip Effect: Endogenous Transport Costs and International Trade. 


\section{A Tables}

Table 1: Depth predicts shipping flows, but only after 1960

\begin{tabular}{lccccc}
\hline \hline & \multicolumn{5}{c}{ Dependent variable: $\ln$ (Shipment) } \\
\cline { 2 - 6 } Independent variables & $(1)$ & $(2)$ & $(3)$ & $(4)$ & $(5)$ \\
\hline Depth $\times$ post 1970 & & & & & $0.247 * * *$ \\
& & & & & $(0.059)$ \\
& & & & & $\{0.052\}$ \\
Depth $\times 1960$ & -0.051 & 0.029 & 0.050 & -0.055 & \\
& $(0.063)$ & $(0.069)$ & $(0.066)$ & $(0.068)$ & \\
Depth $\times 1970$ & $0.222^{* * *}$ & $0.233^{* * *}$ & $0.278^{* * *}$ & $0.213^{* * *}$ & \\
& $(0.069)$ & $(0.077)$ & $(0.082)$ & $(0.071)$ & \\
Depth $\times 1980$ & $0.188^{* *}$ & $0.212^{* * *}$ & $0.291^{* * *}$ & $0.192^{* * *}$ & \\
& $(0.079)$ & $(0.085)$ & $(0.090)$ & $(0.081)$ & \\
Depth $\times 1990$ & $0.255^{* * *}$ & $0.222^{* * *}$ & $0.312^{* * *}$ & $0.283^{* * *}$ & \\
& $(0.086)$ & $(0.087)$ & $(0.099)$ & $(0.087)$ & \\
\hline Observations & 2765 & 2765 & 2765 & 2360 & 2765 \\
R-squared & 0.126 & 0.248 & 0.131 & 0.142 & 0.126 \\
Number of cities & 553 & 553 & 553 & 472 & 553 \\
Year FE & $\checkmark$ & $\checkmark$ & $\checkmark$ & $\checkmark$ & $\checkmark$ \\
City FE & $\checkmark$ & $\checkmark$ & $\checkmark$ & $\checkmark$ & $\checkmark$ \\
Population 1950 $\times$ Year & $\checkmark$ & $\checkmark$ & $\checkmark$ & $\checkmark$ & $\checkmark$ \\
Coastline $\times$ Year FE & $\times$ & $\checkmark$ & $\times$ & $\times$ & $\times$ \\
Saiz $\times$ Year & $\times$ & $\times$ & $\checkmark$ & $\times$ & $\times$ \\
GDP pc $($ country) $\times$ Year & $\times$ & $\times$ & $\times$ & $\checkmark$ & $\times$ \\
\hline \hline
\end{tabular}

Notes: 'Depth' indicates the port suitability measure. It is interacted with decade dummies or an indicator variable for decades including and after 1970, as indicated. Standard errors clustered at the city level in parentheses, Conley standard errors to adjust for spatial correlation in curly brackets. ${ }^{* * *} \mathrm{p}<0.01, * * \mathrm{p}<0.05, * \mathrm{p}<0.1$ (significance refers to clustered standard errors). 
Table 2: The local causal effect of shipping on population: reduced form and model-simulated data

\begin{tabular}{|c|c|c|c|c|c|c|c|}
\hline \multirow[b]{2}{*}{ Independent variables } & \multicolumn{4}{|c|}{ Reduced form } & \multicolumn{3}{|c|}{$\begin{array}{c}\text { Model-simulated data } \\
\text { Dependent Variable: } \Delta \ln (\text { Pop })\end{array}$} \\
\hline & $\begin{array}{c}\Delta \ln (\text { Pop }) \\
(1)\end{array}$ & $\begin{array}{c}\Delta \ln (\text { Pop }) \\
(2)\end{array}$ & $\begin{array}{c}\Delta \ln (\text { Ship) } \\
\text { (3) }\end{array}$ & $\begin{array}{c}\Delta \ln (\text { Pop }) \\
(4)\end{array}$ & $\begin{array}{l}\text { Model } \\
(5)\end{array}$ & $\begin{array}{c}\text { Benchmark } 1 \\
\text { (6) }\end{array}$ & $\begin{array}{c}\text { Benchmark } 2 \\
\text { (7) }\end{array}$ \\
\hline \multirow[t]{4}{*}{$\Delta \ln ($ Ship$)$} & 0.013 & 0.006 & & & 0.008 & $0.019 * * *$ & $0.021 * * *$ \\
\hline & 0.052 & 0.022 & & & 0.064 & $0.166 * * *$ & $0.181 * * *$ \\
\hline & $(0.009)$ & $(0.073)$ & & & $(0.006)$ & $(0.006)$ & $(0.006)$ \\
\hline & $\{0.014\}$ & $\{0.115\}$ & & & & & \\
\hline \multirow[t]{3}{*}{ Depth } & & & $0.272 * * *$ & 0.002 & & & \\
\hline & & & $0.134 * * *$ & 0.003 & & & \\
\hline & & & $(0.086)$ & $(0.020)$ & & & \\
\hline Observations & 531 & 531 & 531 & 531 & 531 & 531 & 531 \\
\hline Specification & OLS & 2 SLS & FS & $\mathrm{RF}$ & 2 SLS & $2 \mathrm{SLS}$ & 2 SLS \\
\hline KP F-stat & & 9.98 & & & 560.52 & 643.19 & 623.71 \\
\hline
\end{tabular}

Notes: 'Depth' indicates the port suitability measure. Standardized coefficients in italics underneath the baseline coefficients. All 2SLS specifications purge the depth instrument of variation correlated with initial population. Column (2) uses depth as IV for shipping, controlling for population in 1950, which is equivalent to using residualized depth as an IV. Columns (5) to (7) use residualized depth as IV, which is the variation that we feed into the model to simulate the counterfactual. Notation for specification as follows: 'FS' refers to the first stage, 'RF' to the reduced form. Standard errors clustered at the city level in parentheses, Conley standard errors to adjust for spatial correlation in curly brackets. $* * * \mathrm{p}<0.01, * * \mathrm{p}<0.05$, * $\mathrm{p}<0.1$ (significance refers to clustered standard errors). 
Table 3: Model-inspired specification: Disentangling market access effect and crowding out effect

\begin{tabular}{|c|c|c|c|c|}
\hline Independent variables & $\begin{array}{c}(1) \\
\ln (\text { Population })\end{array}$ & $\begin{array}{c}(2) \\
\ln (\text { Population })\end{array}$ & $\begin{array}{c}\text { (3) } \\
\ln \text { (Shipment) }\end{array}$ & $\begin{array}{c}(4) \\
\ln \text { (Market Access) }\end{array}$ \\
\hline \multirow[t]{3}{*}{$\ln$ (Ship) } & -0.001 & $-0.159 * *$ & & \\
\hline & $(0.006)$ & $(0.065)$ & & \\
\hline & $\{0.005\}$ & $\{0.051\}$ & & \\
\hline \multirow[t]{3}{*}{$\ln$ (Market Access) } & $1.512 * * *$ & $7.103 * * *$ & & \\
\hline & $(0.536)$ & $(0.795)$ & & \\
\hline & $\{0.317\}$ & $\{0.854\}$ & & \\
\hline \multirow[t]{3}{*}{ Depth $\times$ post 1970} & & & $0.275^{* * *}$ & $0.007 * * *$ \\
\hline & & & $(0.058)$ & $(0.001)$ \\
\hline & & & $\{0.051\}$ & $\{0.001\}$ \\
\hline \multirow[t]{3}{*}{ Market Access IV } & & & 7.188 & $1.927 * * *$ \\
\hline & & & (5.428) & $(0.140)$ \\
\hline & & & $\{5.748\}$ & $\{0.188\}$ \\
\hline Observations & 2696 & 2696 & 2696 & 2696 \\
\hline Number of cities & 544 & 544 & 544 & 544 \\
\hline Year FE & $\checkmark$ & $\sqrt{ }$ & $\checkmark$ & $\checkmark$ \\
\hline City FE & $\checkmark$ & $\checkmark$ & $\checkmark$ & $\checkmark$ \\
\hline Population $1950 \times$ Year & $\checkmark$ & $\checkmark$ & $\checkmark$ & $\checkmark$ \\
\hline Specification & OLS & 2 SLS & FS & FS \\
\hline KP F-stat 22.07 & & 9.63 & & \\
\hline
\end{tabular}

Notes: 'Depth' indicates the port suitability measure. It is interacted with an indicator variable for decades including and after 1970. 'In(Market Access)' is the empirical counterpart of the market access term, defined in Section 5. 'Market access IV' is the instrument for the market access term, defined in Section 5. 'FS' refers to the first stage. Standard errors clustered at the city level in parentheses, Conley standard errors to adjust for spatial correlation in curly brackets. *** $\mathrm{p}<0.01$, $* * \mathrm{p}<0.05, * \mathrm{p}<0.1$ (significance refers to clustered standard errors). 


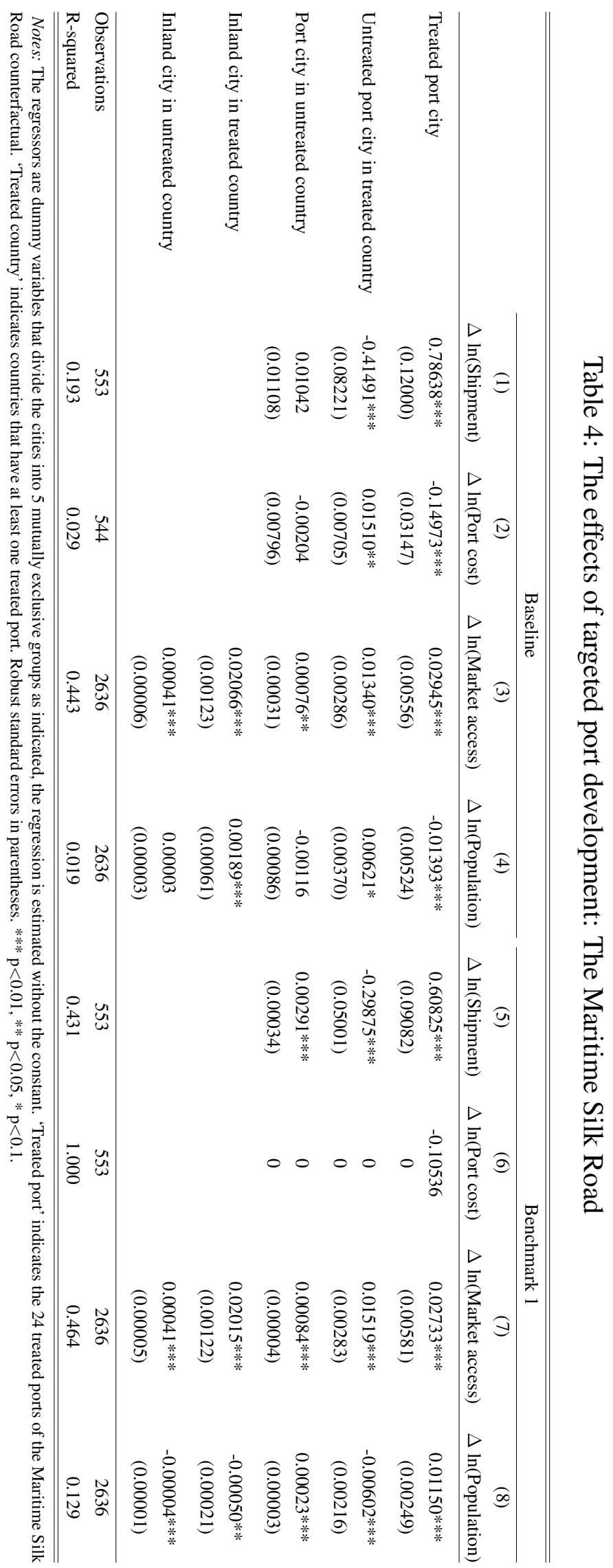




\section{B Figures}

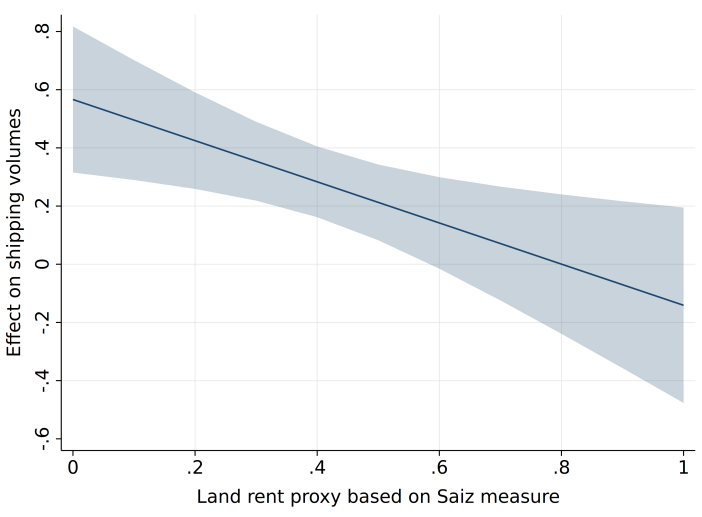

(a) Data

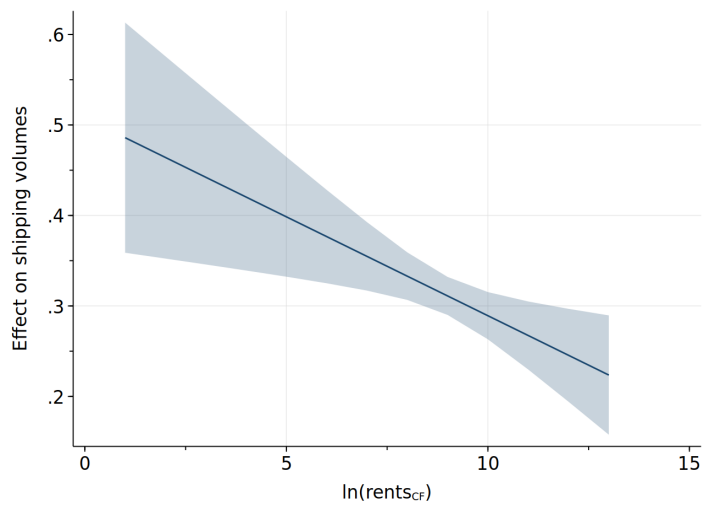

(b) Model-simulated data

Figure 1: Containerization increased shipping more in low land-rent cities

Notes: Panel A shows the estimated $\gamma$ coefficient from equation (2) evaluated at different values of the Saiz land rent proxy. Panel B shows the same estimated coefficient using model-simulated data evaluated at different values of the counterfactual land rents.

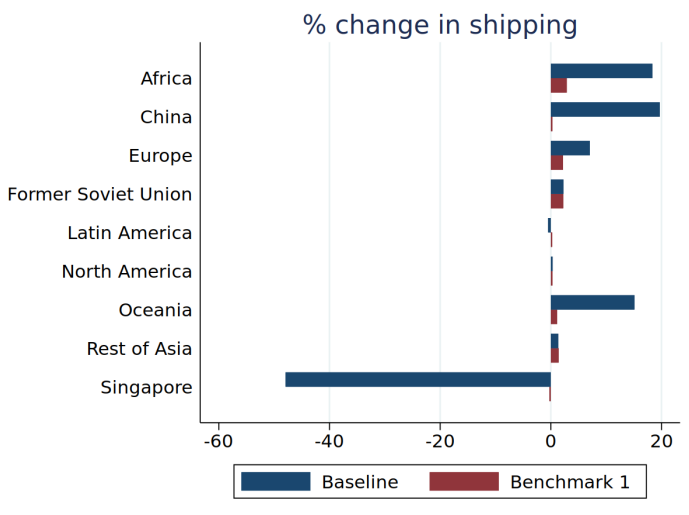

(a) Change in shipping, percent

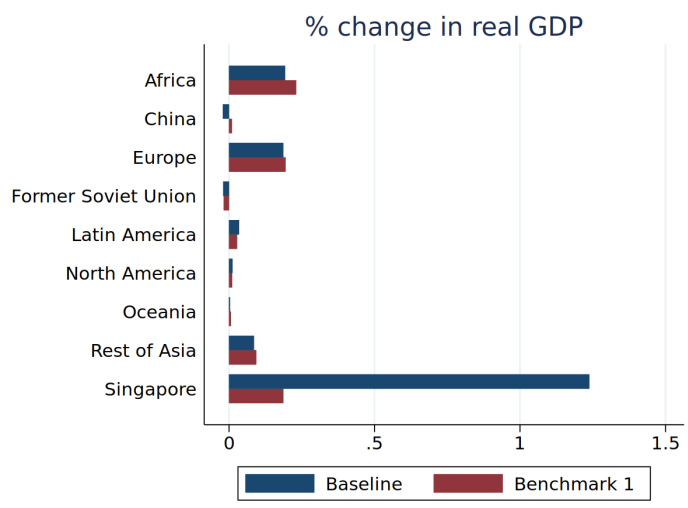

(b) Change in real GDP, percent

Figure 2: Simulated changes across regions, Maritime Silk Road

Notes: Panel A (B) shows the change in total shipping (total real GDP) of each region between the model inversion and the Maritime Silk Road counterfactual. When delineating these regions, we roughly follow the world's continents. An exception is 'Rest of Asia,' which is Asia except China, Singapore, and the former Soviet Union. We treat China separately as we are naturally interested in the effects that this Chinese government policy has on China itself. We treat Singapore separately as we find strikingly large effects on this port city, which we discuss in the text. 


\section{Online Appendix}

\section{All aboard: The effects of port development}

\section{César Ducruet Réka Juhász Dávid Krisztián Nagy Claudia Steinwender}

\section{A Theory}

\section{A.1 Equilibrium of the model}

We define the equilibrium of the model as follows.

Definition 1. Given structural parameters $\alpha, \gamma, \eta, \sigma, \theta, \lambda$, the number of cities $S$ and the subset of port cities $P \subseteq\{1, \ldots, S\}$, country populations $N_{c}$, city amenities $a:\{1, \ldots, S\} \rightarrow \mathbb{R}$, productivities $A:\{1, \ldots, S\} \rightarrow \mathbb{R}$, exogenous transshipment costs $\nu: P \rightarrow \mathbb{R}$, inland and sea shipping costs as a function of distance $\phi_{\varsigma}, \phi_{\tau}: \mathbb{R} \rightarrow \mathbb{R}$ and endogenous transshipment costs as a function of port share $\psi:(0,1) \rightarrow \mathbb{R}$, an equilibrium of the model is a set of city populations $N: S \rightarrow \mathbb{R}$, nominal wages $w: S \rightarrow \mathbb{R}$, land rents $R: S \rightarrow \mathbb{R}$, employment levels $n: S \rightarrow \mathbb{R}$, port shares $F: S \rightarrow[0,1)$, port-level shipping flows Shipping $P \rightarrow \mathbb{R}$, the prices of transshipment services $O: P \rightarrow \mathbb{R}$, the prices of goods $p: S^{2} \rightarrow \mathbb{R}$ and the quantities of goods $q: S^{2} \rightarrow \mathbb{R}$ such that

1. workers choose their consumption of goods and city of residence within their country to maximize their utility (3), taking prices and wages as given;

2. landlords in each city $r$ choose their consumption of goods and land use to maximize their utility

$$
u_{L}(r)=\left[\sum_{s=1}^{S} q_{L}(s, r)^{\frac{\sigma-1}{\sigma}}\right]^{\frac{\sigma}{\sigma-1}}
$$

taking prices, land rents and shipping flows as given; ${ }^{1}$

3. competition among landlords drives the price of transshipment services down to marginal cost, (4), and landlords' profits from transshipment down to zero; ${ }^{2}$

4. firms in each city $r$ choose their production, employment and land use to maximize their profits,

$$
\max _{n(r), 1-F(r)} p(r, r) \tilde{A}(r) n(r)^{\gamma}(1-F(r))^{1-\gamma}-w(r) n(r)-R(r)(1-F(r))
$$

\footnotetext{
${ }^{1}$ We assume that landlords do not enjoy city amenities and do not have idiosyncratic tastes for cities. As landlords are immobile, this assumption does not have any consequence on their optimal choices and is therefore without loss of generality.

${ }^{2}$ We relax this assumption in the monopolistic competition version of the model, presented in Appendix A.7.
} 
taking prices, land rents and wages as given, where $p(r, r)$ is the factory gate price of the good produced by the firm, and choose the shipping route to each destination to maximize their profits;

5. competition among firms drives their profits down to zero;

6. there is no possibility of arbitrage, implying that the price of good $r$ at s equals the expected iceberg cost over the factory gate price,

$$
p(r, s)=p(r, r) \mathbf{E}[T(r, s)]
$$

7. the market for labor clears in each city $r$, implying $n(r)=N(r)$;

8. national labor markets clear, implying $\sum_{r \in c} N(r)=N_{c}$ in each country c;

9. the market for land clears in each city;

10. the market for transshipment services clears in each port city;

11. the market for each good clears worldwide.

Note that this equilibrium definition implies that we do not give landlords the right to choose the amount of transshipment they conduct. In other words, landlords cannot refuse the provision of transshipment services to anyone at the market price. This assumption is needed for computational tractability, as it allows us to abstract from a corner solution in which the supply of transshipment services is zero. In line with this logic, we can relax the assumption and allow landlords to choose any positive amount of transshipment, but not zero transshipment. Generalizing the model this way does not change the equilibrium as landlords' profits are linear in the amount of transshipment and zero in equilibrium, hence landlords are indifferent between transshipping any two amounts as long as they are both positive. ${ }^{3}$

\section{A.2 Equilibrium land use, wages, city populations and shipping flows}

This section uses the equilibrium conditions of Appendix A.1 to characterize cities' equilibrium land use, wages, populations and shipping flows. To obtain these, we proceed as follows. Appendix A.2.1 solves for workers' optimal location choices. Appendix A.2.2 solves the landlords' problem for the optimal allocation of land between production and transshipment. Appendix A.2.3 solves the firms' problem, while Appendix A.2.4 uses equilibrium prices, the price index and market

\footnotetext{
${ }^{3}$ In the monopolistic competition version of the model (Appendix A.7), we do not need to make this assumption. In that model, landlords have market power and therefore choose both the price and the quantity of transshipment in a way that maximizes their profits.
} 
clearing to obtain the equations characterizing cities' equilibrium wages and population. Finally, Appendix A.2.5 derives the value of shipments flowing through any port in equilibrium.

\section{A.2.1 Workers' optimal location choices}

The utility function of workers, (3), implies that the indirect utility of a worker living in city $r$ equals

$$
u_{j}(r)=\frac{w(r)}{P(r)} a(r) b_{j}(r)
$$

where $w(r)$ is the nominal wage and $P(r)$ is the CES price index of consumption goods in the city.

We assume that $b_{j}(r)$ is distributed Fréchet with scale parameter one and shape parameter $1 / \eta$ :

$$
\operatorname{Pr}\left(b_{j}(r) \leq b\right)=e^{-b^{-1 / \eta}}
$$

from which we obtain that the worker's indirect utility is also distributed Fréchet with scale parameter $\left[\frac{w(r)}{P(r)} a(r)\right]^{1 / \eta}$ :

$$
\operatorname{Pr}\left(u_{j}(r) \leq u\right)=e^{-\left[\frac{w(r)}{P(r)} a(r)\right]^{1 / \eta} u^{-1 / \eta}}
$$

and hence, by the properties of the Fréchet distribution, the probability with which a worker chooses to live in city $r$ is given by

$$
\operatorname{Pr}\left(u_{j}(r) \geq u_{j}(s) \forall s \neq r\right)=\frac{\left[\frac{w(r)}{P(r)} a(r)\right]^{1 / \eta}}{\sum_{s \in c}\left[\frac{w(s)}{P(s)} a(s)\right]^{1 / \eta}}
$$

In equilibrium, the fraction of workers choosing to live in city $r$ coincides with this probability, implying

$$
\frac{N(r)}{\sum_{s \in c} N(s)}=\frac{\left[\frac{w(r)}{P(r)} a(r)\right]^{1 / \eta}}{\sum_{s \in c}\left[\frac{w(s)}{P(s)} a(s)\right]^{1 / \eta}} .
$$

\section{A.2.2 Landlords' optimal land use}

Landlords earn income from providing transshipment services and from renting out land to firms that produce the city-specific good. Their utility function, (A.1), implies that the indirect utility of a landlord in city $r$ equals her nominal income divided by the price index,

$$
u_{L}(r)=\frac{\left[O(r)-(\nu(r)+\psi(F(r))) \text { Shipping }(r)^{\lambda}\right] \text { Shipping }(r)+R(r)(1-F(r))}{P(r)}
$$


where $O(r)$ is the price of transshipment services in city $r$ (taken as given by the landlord), $\nu(r)$ is the exogenous part of transshipment costs, $F(r)$ is the share of land allocated to the port, Shipping $(r)$ is the value of shipments flowing through the port, excluding the price of transshipment services (hence, total demand for transshipment services, again taken as given by the landlord), $R(r)$ is the land rent prevailing in the city, and $1-F(r)$ is the share of land rented out to firms. That is, the first term in the numerator corresponds to the landlord's net nominal income from providing transshipment services, while the second term corresponds to her nominal income from renting out land to firms.

The landlord decides on the allocation of land, captured by the single variable $F(r)$, to maximize her utility. As she cannot influence the price index $P(r)$, this is equivalent to maximizing her nominal income:

$$
\max _{F(r)}\left[O(r)-(\nu(r)+\psi(F(r))) \text { Shipping }(r)^{\lambda}\right] \text { Shipping }(r)+R(r)(1-F(r))
$$

The first-order condition to this maximization problem is

$$
-\psi^{\prime}(F(r)) \text { Shipping }(r)^{1+\lambda}-R(r)=0
$$

from which, by rearranging,

$$
-\psi^{\prime}(F(r))=\frac{R(r)}{\text { Shipping }(r)^{1+\lambda}} .
$$

\section{A.2.3 Firms' problem}

Recall that the representative firm operating in city $r$ faces the production function

$$
q(r)=\tilde{A}(r) n(r)^{\gamma}(1-F(r))^{1-\gamma}
$$

and maximizes its profits, (A.2), by choosing its employment and land use. The first-order conditions to the firm's profit-maximization problem imply

$$
R(r)=\frac{1-\gamma}{\gamma} \frac{w(r) N(r)}{1-F(r)}
$$

where we have used labor market clearing, which implies $n(r)=N(r)$. Plugging this back into the firm's cost function and production function, we obtain that the firm's marginal cost of production is equal to

$$
\gamma^{-\gamma}(1-\gamma)^{-(1-\gamma)} \tilde{A}(r)^{-1} w(r)^{\gamma} R(r)^{1-\gamma}
$$


which, by perfect competition among firms, equals the factory gate price in equilibrium:

$$
p(r, r)=\gamma^{-1} A(r)^{-1}(1-F(r))^{-(1-\gamma)} N(r)^{1-\gamma-\alpha} w(r)
$$

where we have used (A.6) again, together with the fact that $\tilde{A}(r)=A(r) N(r)^{\alpha}$.

Finally, equation (A.6) also implies that total factor payments in city $r$ equal

$$
Y(r)=w(r) N(r)+R(r)(1-F(r))=w(r) N(r)+\frac{1-\gamma}{\gamma} w(r) N(r)=\frac{1}{\gamma} w(r) N(r) .
$$

\section{A.2.4 Equilibrium wages and populations}

From the workers' and landlords' problems, we can derive the constant-elasticity demand for the city- $r$ good in city $s$ as

$$
q(r, s)=p(r, s)^{-\sigma} P(s)^{\sigma-1} Y(s)
$$

where $p(r, s)$ is the price paid by the consumer, which includes the shipping cost between $r$ and $s$. Demand in value terms is equal to

$$
p(r, s) q(r, s)=p(r, r)^{1-\sigma} P(s)^{\sigma-1} Y(s) \mathbf{E}[T(r, s)]^{1-\sigma}
$$

where we have used equation (A.3).

Market clearing for the good produced in city $r$ implies that total factor payments in $r$ equal worldwide demand for the good (in value terms):

$$
\frac{1}{\gamma} w(r) N(r)=\sum_{s=1}^{S} p(r, r)^{1-\sigma} P(s)^{\sigma-1} \frac{1}{\gamma} w(s) N(s) \mathbf{E}[T(r, s)]
$$

where we have used equation (A.8) to substitute for total factor payments on both sides. Plugging (A.7) into this equation yields

$$
\begin{gathered}
w(r) N(r)=\gamma^{\sigma-1} A(r)^{\sigma-1}(1-F(r))^{(1-\gamma)(\sigma-1)} N(r)^{-(1-\gamma-\alpha)(\sigma-1)} . \\
w(r)^{1-\sigma} \sum_{s=1}^{S} P(s)^{\sigma-1} w(s) N(s) \mathbf{E}[T(r, s)]^{1-\sigma}
\end{gathered}
$$

The CES price index in city $r$ takes the form

$$
P(r)^{1-\sigma}=\sum_{s=1}^{S} p(s, r)^{1-\sigma}=\sum_{s=1}^{S} p(s, s)^{1-\sigma} \mathbf{E}[T(s, r)]^{1-\sigma}
$$


Plugging factory gate prices (A.7) into this equation yields

$$
P(r)^{1-\sigma}=\gamma^{\sigma-1} \sum_{s=1}^{S} A(s)^{\sigma-1}(1-F(s))^{(1-\gamma)(\sigma-1)} w(s)^{1-\sigma} N(s)^{-(1-\gamma-\alpha)(\sigma-1)} \mathbf{E}[T(s, r)]^{1-\sigma} .
$$

Rearranging equation (A.4) yields the following expression for the price index:

$$
P(r)=\tilde{a}(r) w(r) N(r)^{-\eta}
$$

where $\tilde{a}(r)$ can be obtained by scaling amenities $a(r)$ according to

$$
\tilde{a}(r)=\aleph_{c} a(r)=\left[\frac{\sum_{s \in c} N(s)}{\sum_{s \in c}\left[\frac{w(s)}{P(s)} a(s)\right]^{1 / \eta}}\right]^{\eta} a(r) .
$$

Plugging equation (A.11) into (A.9) yields

$$
\begin{aligned}
& A(r)^{1-\sigma}(1-F(r))^{-(1-\gamma)(\sigma-1)} w(r)^{\sigma} N(r)^{1+(1-\gamma-\alpha)(\sigma-1)}= \\
& \gamma^{\sigma-1} \sum_{s=1}^{S} \tilde{a}(s)^{\sigma-1} w(s)^{\sigma} N(s)^{1-\eta(\sigma-1)} \mathbf{E}[T(r, s)]^{1-\sigma}
\end{aligned}
$$

while plugging equation (A.11) into (A.10) yields

$$
\begin{aligned}
& \tilde{a}(r)^{1-\sigma} w(r)^{1-\sigma} N(r)^{\eta(\sigma-1)}=\gamma^{\sigma-1} . \\
& \sum_{s=1}^{S} A(s)^{\sigma-1}(1-F(s))^{(1-\gamma)(\sigma-1)} w(s)^{1-\sigma} N(s)^{-(1-\gamma-\alpha)(\sigma-1)} \mathbf{E}[T(s, r)]^{1-\sigma} .
\end{aligned}
$$

Note that our assumptions on trade costs guarantee symmetry and hence $\mathbf{E}[T(r, s)]^{1-\sigma}=$ $\mathrm{E}[T(s, r)]^{1-\sigma}$. Given this, we can show that equations (A.12) and (A.13) can be simplified further. To see that this is the case, guess that wages take the form

$$
w(r)=\tilde{a}(r)^{\iota_{1}} A(r)^{\iota_{2}}(1-F(r))^{\iota_{3}} N(r)^{\iota_{4}}
$$

That is, they only depend on local amenities, productivity, land available for production, and population. Inspecting equations (A.12) and (A.13), one can verify that this guess is indeed correct if

$$
\begin{gathered}
\iota_{1}=-\frac{\sigma-1}{2 \sigma-1} \\
\iota_{2}=\iota_{3}=(1-\gamma) \frac{\sigma-1}{2 \sigma-1}
\end{gathered}
$$

Appendix p.6 
and

$$
\iota_{4}=[\eta-(1-\gamma)(1-\alpha)(\sigma-1)-1] \frac{1}{2 \sigma-1}
$$

as (A.12) and (A.13) reduce to the same equation if the guess is correct with these values of $\iota_{1}, \iota_{2}$, $\iota_{3}$ and $\iota_{4}$. Thus, wages in city $r$ are given by

$$
w(r)=\tilde{a}(r)^{-\frac{\sigma-1}{2 \sigma-1}} A(r)^{\frac{\sigma-1}{2 \sigma-1}}(1-F(r))^{(1-\gamma) \frac{\sigma-1}{2 \sigma-1}} N(r)^{[\eta-(1-\gamma-\alpha)(\sigma-1)-1] \frac{1}{2 \sigma-1}} \cdot 4
$$

Finally, plugging (A.14) back into either (A.12) or (A.13) gives us an equation that determines the distribution of population across cities:

$$
N(r)^{[1+\eta \sigma+(1-\gamma-\alpha)(\sigma-1)] \frac{\sigma-1}{2 \sigma-1}}=\gamma^{\sigma-1} \tilde{a}(r)^{\frac{\sigma(\sigma-1)}{2 \sigma-1}} A(r)^{\frac{(\sigma-1)^{2}}{2 \sigma-1}}(1-F(r))^{(1-\gamma) \frac{(\sigma-1)^{2}}{2 \sigma-1}} M A(r)
$$

where

$$
M A(r)=\sum_{s=1}^{S} \frac{\tilde{a}(s)^{\frac{(\sigma-1)^{2}}{2 \sigma-1}} A(s)^{\frac{\sigma(\sigma-1)}{2 \sigma-1}}(1-F(s))^{(1-\gamma) \frac{\sigma(\sigma-1)}{2 \sigma-1}} N(s)^{[1-\eta(\sigma-1)-(1-\gamma-\alpha) \sigma] \frac{\sigma-1}{2 \sigma-1}}}{\mathbf{E}[T(r, s)]^{\sigma-1}}
$$

is the market access of city $r$.

\section{A.2.5 Equilibrium shipping flows}

This section derives the equilibrium value of shipping flows through any port. To obtain these, we first need to introduce further notation. Let $Z$ be an $S+P$ by $S+P$ matrix, where $P$ denotes both the set and the number of ports in the model. ${ }^{5}$ Each of the first $S$ rows and columns of $Z$ corresponds to a city, while each of the last $P$ rows and columns of $Z$ corresponds to a port. Let us call a city or a port a location; that is, each row and column in $Z$ corresponds to one location. We assume that an entry $z(i, \ell)$ of $Z$ is zero if locations $i$ and $\ell$ are not directly connected, or if $i=\ell$. Otherwise, $z(i, \ell)$ is defined as

$$
z(i, \ell)=[\bar{T}(i, \ell)[1+O(\ell)]]^{-\theta}
$$

where $\bar{T}(i, \ell)$ is the common cost of shipping from $i$ to $\ell$ directly, and $O(\ell)$ is the price of transshipment services at $\ell$. If $\ell$ is a port belonging to port city $r$, then this price is given by equation (4). If $\ell$ is not a port but a (port or non-port) city, then we define $O(\ell)=0 .^{6}$

\footnotetext{
${ }^{4}$ We can freely choose the intercept of this equation as we have not normalized any price yet. We choose it to be equal to one.

${ }^{5}$ Recall that $S$ is the total number of (port or non-port) cities.

${ }^{6}$ For computational reasons, we need to add a small iceberg cost of shipping between each port and its own city. This cost equals 1.03 in both the inversion and the model simulations.
} 
Following Allen and Arkolakis (2019), we can show that the expected cost of shipping from city $r$ to $s$ can be written as

$$
\mathbf{E}[T(r, s)]=\Gamma\left(\frac{\theta+1}{\theta}\right) x(r, s)^{-1 / \theta}
$$

where $x(r, s)$ is the $(r, s)$ entry of the matrix

$$
X=(I-Z)^{-1}
$$

and $I$ is the $S+P$ by $S+P$ identity matrix.

Similarly, we can show that, if a good is shipped from city $r$ to $s$, the probability that it is shipped through port $k$ is given by

$$
\pi(k \mid r, s)=\frac{x(r, k) x(k, s)}{x(r, s)}
$$

and therefore the total value of goods shipped through port $k$ from city $r$ to city $s$ (excluding the price paid for transshipment services at $k$ ) equals

$$
\text { Shipping }(k \mid r, s)=[1+O(k)]^{-1} p(r, s)^{1-\sigma} P(s)^{\sigma-1} \frac{1}{\gamma} w(s) N(s) \pi(k \mid r, s) .
$$

Combining this with equations (A.3), (A.7), (A.11) and (A.16) yields

$$
\begin{gathered}
\text { Shipping }(k \mid r, s)=\gamma^{\sigma-2}[1+O(k)]^{-1} A(r)^{\sigma-1}(1-F(r))^{(1-\gamma)(\sigma-1)} N(r)^{-(1-\alpha-\gamma)(\sigma-1)} . \\
w(r)^{1-\sigma} \tilde{a}(s)^{\sigma-1} N(s)^{1-\eta(\sigma-1)} w(s)^{\sigma} \mathbf{E}[T(r, s)]^{1-\sigma} \frac{x(r, k) x(k, s)}{x(r, s)}
\end{gathered}
$$

and therefore the total value of shipping through port $k$ is given by

$$
\text { Shipping }(k)=\gamma^{\sigma-2}[1+O(k)]^{-1} \sum_{r} D_{1}(r) x(r, k) \sum_{s} D_{2}(s) \frac{\mathbf{E}[T(r, s)]^{1-\sigma}}{x(r, s)} x(k, s)
$$

where

$$
D_{1}(r)=A(r)^{\sigma-1}(1-F(r))^{(1-\gamma)(\sigma-1)} N(r)^{-(1-\alpha-\gamma)(\sigma-1)} w(r)^{1-\sigma}
$$

and

$$
D_{2}(s)=\tilde{a}(s)^{\sigma-1} N(s)^{1-\eta(\sigma-1)} w(s)^{\sigma} .
$$




\section{A.3 Inverting the model}

This section describes how we invert the equilibrium conditions of the model to back out amenities, productivities and exogenous transshipment costs as a function of observed population, wages and the value of shipments. As a first step, we use the observed data to back out port shares in the model. To this end, we combine equations (A.5) and (A.6) to obtain port shares as a function of wages $w(r)$, population $N(r)$ and the value of shipments Shipping $(r)$ in each port city $r$ :

$$
-\psi^{\prime}(F(r))(1-F(r))=\frac{1-\gamma}{\gamma} \frac{w(r) N(r)}{\text { Shipping }(r)^{1+\lambda}}
$$

Given the assumptions we made on $\psi^{\prime}$, the left-hand side of equation (A.18) is strictly decreasing in $F(r)$. Moreover, the left-hand side takes every real value between zero and infinity as $\psi^{\prime}$ is continuous, $\lim _{F \rightarrow 1} \psi^{\prime}(F)=0$ and $\lim _{F \rightarrow 0} \psi^{\prime}(F)=-\infty$. This guarantees that solving equation (A.18) identifies a unique value of $F(r) \in(0,1)$ for every port city.

The second step consists of solving for $\tilde{a}(r), A(r)$ and $\nu(r)$ for the observed $N(r), w(r)$ and Shipping $(r)$, as well as the $F(r)$ recovered in the previous step. This is done using an algorithm that consists of an outer loop and an inner loop. In the inner loop, we obtain the values of $\tilde{a}(r)$ that solve the system of equations

$$
\tilde{a}(r)^{1-\sigma} w(r)^{1-\sigma} N(r)^{\eta(\sigma-1)}=\gamma^{\sigma-1} \sum_{s=1}^{S} \tilde{a}(s)^{\sigma-1} w(s)^{\sigma} N(s)^{1-\eta(\sigma-1)} \mathbf{E}[T(r, s)]^{1-\sigma}
$$

derived from equations (A.12) and (A.13) for a fixed set of exogenous transshipment costs $\nu(r)$, and hence for fixed $\mathbf{E}[T(r, s)]$. For any $\mathbf{E}[T(r, s)]$, this system yields a unique solution for $\tilde{a}(r)$. Rearranging equation (A.14), we can then uniquely express productivity $A(r)$ as a function of the recovered $\tilde{a}(r)$ :

$$
A(r)=\tilde{a}(r)(1-F(r))^{\gamma-1} w(r)^{\frac{2 \sigma-1}{\sigma-1}} N(r)^{-[\eta-(1-\gamma-\alpha)(\sigma-1)-1] \frac{1}{\sigma-1}}
$$

In the outer loop, we search for the set of $\nu(r)$ for which the value of shipments implied by equation (A.17) - hence, by $N(r), w(r), F(r)$ and the recovered $\tilde{a}(r)$ and $A(r)$ - rationalize the shipping flows observed in the data. In practice, we start from a uniform guess of $\nu(r)=\bar{\nu}$, then perform a large number of iterations in which we update $\nu(r)$ gradually to get closer to satisfying equation (A.17). We also update $\mathbf{E}[T(r, s)]$ in every iteration step. Even though we cannot prove that this procedure identifies a unique set of $\nu(r)$, the algorithm has been converging to the same fixed point for various different initial guesses on $\nu(r)$, even when guessing nonuniform distributions of $\nu(r)$ initially. 


\section{A.4 Counterfactual simulation}

This section describes how we perform counterfactual simulations in the model. First, we need to choose the absolute level of amenities $a(r)$ in each city $r$, as the inversion only identifies amenities up to a country-level scale, $\tilde{a}(r)=\aleph_{c} a(r)$. Unfortunately, nothing in the data guides us with this choice. Hence, we make the simplest possible assumption by assuming that average amenities are the same across countries and are equal to one:

$$
\frac{1}{C_{c}} \sum_{r \in c} a(r)=\frac{1}{C_{c}} \sum_{r \in c} \frac{\tilde{a}(r)}{\aleph_{c}}=1
$$

where $C_{c}$ denotes the number of cities in country $c$. Rearranging yields

$$
\aleph_{c}=\frac{1}{C_{c}} \sum_{r \in c} \tilde{a}(r)
$$

and hence we can obtain the absolute level of amenities in each city $r$ as

$$
a(r)=\frac{\tilde{a}(r)}{\aleph_{c}}=\frac{C_{c}}{\sum_{s \in c} \tilde{a}(s)} \tilde{a}(r) .
$$

Second, we solve for the counterfactual equilibrium of the model using an algorithm that consists of three loops embedded in each other. In the innermost loop, we obtain the distribution of population $N(r)$ that solves equation (A.15) for a fixed set of $\aleph_{c}, F(r)$ and Shipping $(r)$ (implying that $\mathbf{E}[T(r, s)]$ are also fixed). For any $\aleph_{c}, F(r)$ and Shipping $(r)$, equation (A.15) can be shown to have a unique positive solution if

$$
\alpha<1-\gamma+\eta
$$

which holds under the assumptions made in Section 4.1. Moreover, the solution can be obtained by simply iterating on equation (A.15), starting from any initial guess on $N(r)$. The proof of these results follows directly from the proof of equilibrium uniqueness in Allen and Arkolakis (2014).

In the middle loop, we solve for the set of country-specific $\aleph_{c}$ that guarantee that the sum of city populations equals total country population in each country:

$$
\sum_{r \in c} N(r)=N_{c}
$$

where $N_{c}$ denotes the exogenously given population of country $c$. We also solve for wages using equation (A.14) and for rents using equation (A.6).

In the outermost loop, we iterate on the distribution of port shares and shipping flows that 
satisfy both equations (A.5) and (A.17), also updating $\mathbf{E}[T(r, s)]$ in every step. We use the distributions of port share and shipping obtained in the inversion as our initial guesses. Even though we cannot prove that this procedure yields a unique equilibrium, we have been converging to the same distribution of endogenous variables for different initial guesses.

\section{A.5 Benchmark models used to decompose the aggregate welfare effects of containerization}

This section provides a description of the two benchmark models (Benchmark 1 and Benchmark 2) used to decompose the aggregate welfare effects of containerization.

\section{A.5.1 Benchmark 1: No land use in transshipment}

In Benchmark 1, we abstract from endogenous (land-dependent) transshipment costs. Thus, the cost of handling one unit of a good at port $p_{m}$ is given by

$$
\nu\left(p_{m}\right) \text { Shipping }\left(p_{m}\right)^{\lambda}
$$

and, by perfect competition, the price of transshipment services equals this cost:

$$
O\left(p_{m}\right)=\nu\left(p_{m}\right) \text { Shipping }\left(p_{m}\right)^{\lambda}
$$

As production is the only sector in which land can be productively used in this model, landlords optimally set the fraction of production land to one: $1-F(r)=1$. The remaining assumptions are the same as in the baseline model. Naturally, equation (A.5) does not hold in Benchmark 1, since all port shares are equal to zero.

Taking Benchmark 1 to the data. Taking Benchmark 1 to 1990 data follows similar steps as taking our baseline model to the data. We keep the structural parameters and the inland and sea shipping costs unchanged relative to the baseline model. To back out amenities, productivities and exogenous transshipment costs after containerization, we invert Benchmark 1 using 1990 data on population, wages and the value of shipments. This inversion procedure differs from the inversion of the baseline model in that we do not need to solve equation (A.5) for equilibrium port shares. As a result, we can skip the first step of the inversion procedure and immediately start with what we labeled as the second step in Appendix A.3.

In particular, we solve an algorithm that consists of an outer loop and an inner loop. In the inner loop, we obtain the values of city amenities $\tilde{a}(r)$ that solve equation (A.19), which holds in Benchmark 1 as well, for a fixed set of $\nu(r)$, hence for fixed $\mathbf{E}[T(r, s)]$. Once we have $\tilde{a}(r)$, we can obtain city productivities $A(r)$ from equation (A.20), which also holds in Benchmark 1, such that we set $1-F(r)=1$.

In the outer loop, we search for the set of $\nu(r)$ such that shipments implied by equation (A.17) equal the shipping flows observed in the data. Equation (A.17) also holds in Benchmark 1, except 
that we need to use $1-F(r)=1$ and equation (A.21) instead of equation (4) to calculate transshipment prices. In practice, we start from a uniform guess of $\nu(r)=\bar{\nu}$, then perform a large number of iterations in which we update $\nu(r)$ gradually to get closer to satisfying equation (A.17). We also update $\mathbf{E}[T(r, s)]$ in every iteration step.

Counterfactual simulation of Benchmark 1. When conducting the no-containerization counterfactual in Benchmark 1, we again stay as close as possible to our baseline model. We offset the relationship between $\log \nu(r)$ and port depth, and increase all $\log \nu(r)$ by a constant $\nu_{C F}$ such that we have the same increase in international trade to world GDP (4.7 pp) as in the baseline model (Section 6.2). We also use the same procedure to obtain $a(r)$ from $\tilde{a}(r)$ (Appendix A.4). When conducting the targeted port development counterfactual, we decrease exogenous transshipment costs in the 24 targeted ports by $10 \%$, as in the baseline model.

We solve for counterfactual equilibria using an algorithm that consists of three loops embedded in each other. In the innermost loop, we obtain the distribution of population $N(r)$ that solves equation (A.15) for a fixed set of $\aleph_{c}$ and Shipping $(r)$ (implying that $\mathbf{E}[T(r, s)]$ are also fixed). Equation (A.15) is unchanged relative to the baseline model, except that we need to use $1-F(r)=$ 1. We follow the same iterative procedure as in Appendix A.4 to solve equation (A.15).

In the middle loop, we solve for the set of country-specific $\aleph_{c}$ such that the sum of city populations equals total country population in each country. We also solve for wages using equation (A.14), which is the same as in the baseline model, except that $1-F(r)=1$.

In the outermost loop, we iterate on equation (A.17) to obtain equilibrium shipping flows, also updating $\mathbf{E}[T(r, s)]$ in every step. In contrast to the baseline model, we use $1-F(r)=1$ and equation (A.21) instead of equation (4) in this process. We use the 1990 shipping flows as our initial guess.

\section{A.5.2 Benchmark 2: Land use in transshipment identical across port cities}

In Benchmark 2, we allow for endogenous (land-dependent) transshipment costs. This implies that transshipment prices are given by equation (4), just like in our baseline model. However, we restrict transshipment land use to be identical across port cities. More precisely, we set the 1990 port share of each port city equal to the average 1990 port share in the baseline model. Similarly, we set the counterfactual port share equal to the average port share in the counterfactual of our baseline model. The remaining assumptions are the same as in the baseline model. Similar to Benchmark 1, equation (A.5) does not hold in this model since port shares are set exogenously through the above procedure, rather than optimally by port city landlords.

Taking Benchmark 2 to the data. We keep the structural parameters and the inland and sea shipping costs unchanged relative to the baseline model. To back out amenities, productivities and exogenous transshipment costs after containerization, we invert Benchmark 2 using 1990 data on 
population, wages and the value of shipments. Just like in Benchmark 1, we do not need to solve equation (A.5) for equilibrium port shares. As a result, we can skip the first step of the inversion procedure and immediately start from the second step. This second step, in turn, is conducted exactly as in the baseline model (see Appendix A.3 for details), except that we use the average 1990 port share in the baseline model as $F(r)$ in each port city.

Counterfactual simulation of Benchmark 2. In the no-containerization counterfactual simulation of Benchmark 2, we change transshipment cost parameter $\beta$ in the same way as in the counterfactual of the baseline model; offset the relationship between $\log \nu(r)$ and port depth; and increase all $\log \nu(r)$ by a constant $\nu_{C F}$ such that we have the same increase in international trade to world GDP (4.7 pp) as in the baseline model (Section 6.2). We also use the same procedure to obtain $a(r)$ from $\tilde{a}(r)$ (Appendix A.4).

Finally, we solve for the counterfactual equilibrium using an algorithm that consists of three loops embedded in each other. In the innermost loop, we obtain the distribution of population $N(r)$ that solves equation (A.15) for a fixed set of $\aleph_{c}, F(r)$ and Shipping $(r)$ (implying that $\mathbf{E}[T(r, s)]$ are also fixed). We use the average port share in the counterfactual of the baseline model as $F(r)$ in each port city. We follow the same iterative procedure as in Appendix A.4 to solve equation (A.15).

In the middle loop, we solve for the set of country-specific $\aleph_{c}$ such that the sum of city populations equals total country population in each country. We also solve for wages using equation (A.14), which is the same as in the baseline model. We again use the same $F(r)$ in each port city.

In the outermost loop, we iterate on equation (A.17) to obtain equilibrium shipping flows, also

updating $\mathbf{E}[T(r, s)]$ in every step. We again use the same $F(r)$ in each port city. We use the 1990 shipping flows as our initial guess.

\section{A.6 A model with labor used in transshipment}

This section presents a generalization of our baseline model in which the provision of transshipment services may require not only land, but also potentially labor. We show that, as long as the share of labor relative to land in transshipment is sufficiently low, this more general framework delivers predictions on port development and city populations that are extremely similar to the predictions of our baseline model. On the other hand, if the share of labor in transshipment is high, the model's predictions are in contrast with the empirical facts we document in Sections 3 and 5, as we describe below.

We now present the setup of the model with transshipment labor. Assume that the cost of transshipping one unit of a good in port city $r$ equals

$$
\left(\nu(r)+\psi\left(n^{P}(r)^{\gamma_{P}} F(r)^{1-\gamma_{P}}\right)\right) \text { Shipping }(r)^{\lambda}
$$


where $0 \leq \gamma_{P} \leq 1$. That is, $\gamma_{P}$ is labor's share and $1-\gamma_{P}$ is land's share in transshipment services. Our baseline model is a special case in which $\gamma_{P}=0$. The remaining model assumptions are the same as in the baseline model.

We now show how our model predictions - more precisely, the three propositions of Section 4.2 - change in this more general framework. To obtain the first two propositions, note that the first-order conditions to the landlord's problem with respect to $n^{P}(r)$ and $F(r)$ together imply

$$
n^{P}(r)=\frac{\gamma_{P}}{1-\gamma_{P}} \frac{R(r)}{w(r)} F(r)
$$

On the production side, the first-order conditions to the firm's problem imply

$$
n(r)=\frac{\gamma}{1-\gamma} \frac{R(r)}{w(r)}(1-F(r)) .
$$

Adding equations (A.22) and (A.23) yields total demand for labor in the city,

$$
N(r)=\frac{\gamma}{1-\gamma} \frac{R(r)}{w(r)}(1-\tilde{\gamma} F(r))
$$

where $\tilde{\gamma}=\frac{\gamma /(1-\gamma)-\gamma_{P} /\left(1-\gamma_{P}\right)}{\gamma /(1-\gamma)}$. Combining equation (A.24) with equation (A.22), we obtain labor used for transshipment as

$$
n^{P}(r)=\frac{\gamma_{P}}{1-\gamma_{P}} \frac{1-\gamma}{\gamma} N(r) \frac{F(r)}{1-\tilde{\gamma} F(r)}
$$

and hence the landlord's first-order conditions imply

$$
-\psi^{\prime}\left(\left[\frac{\gamma_{P}}{1-\gamma_{P}} \frac{1-\gamma}{\gamma} N(r)\right]^{\gamma_{P}} \frac{F(r)}{(1-\tilde{\gamma} F(r))^{\gamma_{P}}}\right)=\hat{\gamma} \frac{w(r)^{\gamma_{P}} R(r)^{1-\gamma_{P}}}{\text { Shipping }(r)^{1+\lambda}}
$$

where $\hat{\gamma}$ is a constant. Equation (A.25) allows us to state the following two propositions.

Proposition 4. Assume $\gamma_{P} \leq \gamma$. Then land allocated to the port is increasing in the amount of shipping flows (keeping land rents fixed).

Proof. $\gamma_{P} \leq \gamma$ implies $\tilde{\gamma}>0$. As a consequence, the argument inside the function $-\psi^{\prime}$ is increasing in land allocated to the port, $F(r)$. Given the convexity of $\psi$, this means that the left-hand side of equation (A.25) is decreasing in $F(r)$. This, together with the fact that the right-hand side of (A.25) is decreasing in shipping flows Shipping $(r)$, yields the result.

Proposition 5. Assume $\gamma_{P} \leq \gamma$. Then land allocated to the port is decreasing in land rents (keeping the amount of shipping flows fixed). 
Proof. The proof follows the exact same steps as the proof of Proposition 4.

Propositions 4 and 5 are the counterparts of Propositions 1 and 2 of Section 4.2. As the comparison of Propositions 4 and 5 to Propositions 1 and 2 clarifies, the sufficient condition under which the model with transshipment labor yields the same predictions as our baseline model is $\gamma_{P} \leq \gamma$. That is, labor's share in transshipment may be positive but needs to be below labor's share in the production of the city-specific good. This result is intuitive. Higher demand for transshipment, or a lower opportunity cost of transshipment, triggers an expansion of transshipment services in the city. As long as land's share in transshipment is higher than land's share in the rest of the economy, standard Heckscher-Ohlin logic dictates that this expansion is reached through more land used for transshipment and less in the rest of the economy.

If labor's share in transshipment is higher than labor's share in the production of the cityspecific good, the model no longer yields clear-cut predictions on land allocation between the two sectors of the economy. In the extreme case in which land is not used in transshipment at all $\left(\gamma_{P}=1\right)$, port activity naturally does not depend on land rents whatsoever. This is clearly in contrast with our empirical facts documented in Section 3, and in particular, with the result that containerization increased shipping more in low land-rent cities.

To derive the counterpart of Proposition 3, note that land rents in the model with transshipment labor can be obtained from equation (A.24) as

$$
R(r)=\frac{1-\gamma}{\gamma} \frac{w(r) N(r)}{1-\tilde{\gamma} F(r)}
$$

whereas total income in city $r$ is given by

$$
\frac{1}{\gamma} w(r) n(r)=\frac{1}{\gamma} \frac{1-F(r)}{1-\tilde{\gamma} F(r)} w(r) N(r) .
$$

Using these results in the derivation of the equilibrium conditions, we obtain that the population of city $r$ is the solution to the following equation:

$$
\begin{aligned}
N(r)^{[1+\eta \sigma+(1-\gamma-\alpha)(\sigma-1)] \frac{\sigma-1}{2 \sigma-1}}= & \gamma^{\sigma-1} \tilde{a}(r)^{\frac{\sigma(\sigma-1)}{2 \sigma-1}} A(r)^{\frac{(\sigma-1)^{2}}{2 \sigma-1}}(1-\tilde{\gamma} F(r))^{[1+(1-\gamma)(\sigma-1)] \frac{\sigma-1}{2 \sigma-1}} . \\
& (1-F(r))^{-\frac{\sigma-1}{2 \sigma-1}} M A(r)
\end{aligned}
$$


where

$$
\begin{aligned}
M A(r)= & \sum_{s=1}^{S} \tilde{a}(s)^{\frac{(\sigma-1)^{2}}{2 \sigma-1}} A(s)^{\frac{\sigma(\sigma-1)}{2 \sigma-1}}(1-F(s))^{\frac{\sigma-1}{2 \sigma-1}}(1-\tilde{\gamma} F(s))^{[(1-\gamma) \sigma-1] \frac{\sigma-1}{2 \sigma-1}} . \\
& N(s)^{[1-\eta(\sigma-1)-(1-\gamma-\alpha) \sigma] \frac{\sigma-1}{2 \sigma-1}} \mathbf{E}[T(r, s)]^{1-\sigma} .
\end{aligned}
$$

Equation (A.26) allows us to state the following proposition, which is the counterpart of Proposition 3 in Section 4.2.

Proposition 6. If $\gamma_{P}<1$, then an increase in the share of land allocated to the port in city in $r, F(r)$, decreases shipping costs $\mathbf{E}[T(r, s)]$, thus increasing $M A(r)$. Everything else fixed, an increase in $M A(r)$ increases the population of the city (market access effect). Holding $M A(r)$ fixed, if $\gamma_{P} \geq \gamma$, an increase in $F(r)$ draws additional people into the city (crowding-in effect). If $0<\gamma_{P}<\gamma$, an increase in $F(r)$ may trigger either a crowding-in effect or migration out of the city (crowding-out effect), depending on the values of structural parameters $\gamma, \gamma_{P}$ and $\sigma$. If and only if $\gamma_{P}=0$ (our baseline model), the model implies a crowding-out effect irrespectively of the values of structural parameters.

Proof. The results follow directly from equation (A.26).

According to Proposition 6, an expansion of port activity has different implications on city population depending on labor's share in transshipment. Besides the standard market access effect, port development affects city population in two ways. First, it draws people into the transshipment sector as long as labor's share in the sector is different from zero. Second, it decreases the amount of land available for the production of the city-specific good, which induces workers in this sector to leave the city. If labor's share in the transshipment sector is sufficiently high, the first effect always dominates the second one (crowding in). This implies that the population of the city should increase even more than what is implied by the standard market access effect. Such a crowdingin effect, however, is not consistent what we find in the data (Section 5), in particular, with the negative and significant coefficient on shipping once we control for market access.

To sum up, the model presented in this section sheds light on two facts. First, if the share of labor in transshipment is too high, the model with transshipment labor has different implications than our baseline framework. These implications, however, are in clear contrast with the empirical findings of Sections 3 and 5. Second, if the share of labor in transshipment is sufficiently low, the model with transshipment labor is more complex in its structure but delivers predictions that are extremely similar to the predictions of our baseline framework. 


\section{A.7 A model with monopolistic competition in transshipment}

This section presents a version of our baseline model in which landlords providing transshipment services engage in monopolistic competition. This implies that, unlike in our baseline model, port activity involves positive profits. We also show how we take the model with monopolistic competition to the data and how we simulate the same no-containerization counterfactual in it for one of the robustness exercises in Appendix A.8.

We first present the setup of the monopolistic competition model. As in our baseline model, we assume that each city is inhabited by a continuum of landlords. Without loss of generality, we normalize the mass of these landlords to one in each city, and index an individual landlord by $m \in[0,1]$.

Unlike in our baseline model, we assume that transshipment services are differentiated products. Firms shipping through port city $r$ may use the services of any number of landlords $m$ residing in the city. Firms aggregate transshipment services in a CES function with elasticity of substitution $\zeta \in(1, \infty)$ across the services performed for them by the individual landlords. As $\zeta<\infty$, these services are imperfect substitutes. Hence, each firm uses the transshipment service of each landlord in equilibrium. ${ }^{7}$

Landlords are aware that they are the sole provider of their differentiated transshipment service but cannot influence city-wide prices and quantities. Thus, they engage in monopolistic competition, choosing their land allocation, transshipment price and transshipment quantity to maximize their net nominal income. In other words, landlord $m$ in port city $r$ solves the problem

$$
\begin{aligned}
\max _{F_{m}(r), O_{m}(r), \text { Shipping }_{m}(r)}[ & \left.O_{m}(r)-\left(\nu(r)+\psi\left(F_{m}(r)\right)\right) \text { Shipping }(r)^{\lambda}\right] \text { Shipping }_{m}(r) \\
& +R(r)\left(1-F_{m}(r)\right)
\end{aligned}
$$

where $O_{m}(r)$ is the price of transshipment services that landlord $m$ charges, $\nu(r)$ is the exogenous part of transshipment costs, $F_{m}(r)$ is the share of land that the landlord allocates to transshipment, Shipping $(r)$ is the total value of shipments flowing through the port excluding the price of transshipment services, $R(r)$ is the land rent prevailing in the city, and $1-F_{m}(r)$ is the share of land rented out to firms.

As the price elasticity of demand for each landlord's transshipment service is constant at $-\zeta$, each landlord charges a constant markup over her marginal cost in equilibrium:

$$
O_{m}(r)=\frac{\zeta}{\zeta-1}\left(\nu(r)+\psi\left(F_{m}(r)\right)\right) \text { Shipping }(r)^{\lambda}
$$

\footnotetext{
${ }^{7}$ To fix ideas, one may think that one port city landlord provides the cranes, another the storage, and so on. As a result, firms use the services of all landlords, not only one.
} 
As landlords in a given port city are symmetric, we can drop their index and simply write

$$
O(r)=\frac{\zeta}{\zeta-1}(\nu(r)+\psi(F(r))) \text { Shipping }(r)^{\lambda}
$$

from which we get that landlords earn profits on transshipment equal to

$$
\Pi(r)=\frac{1}{\zeta-1}(\nu(r)+\psi(F(r))) \text { Shipping }(r)^{1+\lambda} .
$$

For simplicity, we assume that landlords spend these profits outside our set of cities $S$. This implies that we do not need to take profits into account when calculating demand for goods in the city, or city GDP. This assumption helps us keep the model computationally tractable.

The first-order condition to the landlord's maximization problem with respect to $F_{m}(r)$ implies

$$
-\psi^{\prime}(F(r)) \text { Shipping }(r)^{1+\lambda}-R(r)=0
$$

from which, by rearranging,

$$
-\psi^{\prime}(F(r))=\frac{R(r)}{\text { Shipping }(r)^{1+\lambda}} .
$$

Note that this equation is identical to equation (5) of our baseline model. More generally, as the remaining model assumptions in the monopolistic competition model are the same as those in the baseline model, the only equation that differs between the two frameworks is equation (A.27), which replaces equation (4) in the baseline model. The remaining equilibrium conditions are all identical.

In Section A.8, we conduct a robustness check in which we take the model with monopolistic competition to the data to measure the aggregate and local effects of containerization. Inverting and simulating the monopolistic competition model follows the same steps as described in Appendix A.3 and Appendix A.4, with one exception: we use equation (A.27) instead of equation (4) whenever we calculate transshipment prices.

To do so, we need to choose the value of the markup parameter $\zeta$. Note that, by equation (A.28), transshipment profits are decreasing in $\zeta$. Data on profits of ports are hard to find, especially during our period of interest, but we were able to obtain profit and revenue data for a number of ports from annual reports of port authorities between 1950 and $1990 .{ }^{8}$ In this sample, profits as a percentage of revenue are on average 28\%, with no clear trends over time. Choosing $\zeta=3$, our model predicts an average profit margin of $27 \%$ and a median profit margin of $33 \%$ across ports. Hence, we use

\footnotetext{
${ }^{8}$ We describe these data in Section B.16.
} 
$\zeta=3$ in the inversion and the counterfactual simulation. ${ }^{9}$

\section{A.8 Aggregate and local effects of containerization: robustness}

In Table A.15, we examine the sensitivity of the model-implied aggregate and local effects of containerization to different values of the containerization shock and some alternative modeling choices. We focus on the sensitivity of our five headline findings: the aggregate welfare gains from containerization; the aggregate resource costs; the aggregate specialization gains; the local population effects of shipping; and the reallocation of shipping toward low-rent cities. Row (1) of Table A.15 repeats these five results in our baseline model calibration, while rows (2) to (11) report them for each of our ten robustness exercises.

In the exercises of rows (2) and (3), we use higher and lower values of our transshipment cost parameter $\beta$, respectively. We showed in Section 6.1.2 that our endogenous port development mechanism is stronger under higher values of $\beta$. Thus, it is not surprising that we obtain higher resource costs and specialization gains from containerization, net population effects closer to zero as a result of more crowding-out, and more reallocation of shipping toward low-rent cities in row (2). The opposite is true under the lower $\beta$ of row (3).

In rows (4) and (5), we use alternative values of our counterfactual $\beta$ : one that implies a smaller $(65 \%)$ increase in the mean port share, and one that implies a larger (85\%) increase. As expected, a smaller increase in land use leads to slightly higher welfare gains, lower resource costs and lower specialization gains from containerization.

In row (6), we do not offset the relationship between exogenous transshipment costs and port depth in the counterfactual. As depth no longer plays a role in the model in this case, we cannot estimate the local population effects and the reallocation toward low-rent cities, as estimating these reduced-form coefficients relies on depth as an instrument for shipping changes. Nevertheless, we find aggregate welfare gains, resource costs and specialization gains that are fairly close to our baseline estimates.

In rows (7) and (8), we choose $\nu_{C F}$ to target different ( $30 \%$ and $20 \%$, respectively) changes in the sum of exogenous and endogenous transshipment costs. Unsurprisingly, a larger change in total transshipment costs is associated with higher aggregate gains, resource costs and specialization gains. The opposite is true if we assume that total transshipment costs changed less. The estimated local effects of containerization hardly change, however.

To study how the assumption of perfect competition in transshipment influences our results, we develop a model in which the provision of transshipment services is subject to monopolistic competition in Appendix A.7. The key difference relative to our baseline setup is that transship-

\footnotetext{
${ }^{9}$ We compute the profit margin of port $r$ in the model as $\frac{\Pi(r)-R(r) F(r)}{O(r) \operatorname{Shipping}(r)}$. These margins vary across ports and are in fact negative for a few of them. As these ports operate in the data, we do not let them shut down in the model and assume they are subsidized from the outside economy.
} 
ment activity involves positive profits in this monopolistic competition model. Row (9) reports the aggregate and local effects of containerization in the monopolistic competition model. While the results obviously change to some extent, they remain close to our baseline model, both qualitatively and quantitatively.

Finally, rows (10) and (11) add a uniform $10 \%$ and $20 \%$ change in the elasticity of inland shipping costs to distance, respectively. This amounts to making inland shipping costs higher in the counterfactual, mimicking a decline in inland shipping costs brought about by containerization besides the change in transshipment costs. Obviously, adding an inland shipping cost reduction increases the estimated aggregate gains. However, the resource costs and specialization gains from containerization, as well as the local effects, remain very similar to our baseline model. Overall, we conclude that the estimated aggregate and local effects of containerization are fairly stable across these different model specifications.

\section{B Data}

In this section, we provide additional details about data construction and sources for the variables used in the analysis.

\section{B.1 Lloyd's List shipping data}

We clean the shipping data by manually matching them to the 1953 and 2017 editions of the World Port Index (WPI), which is a widely used reference list of worldwide ports. The initial Lloyd's List sample of 'ports' included ports on navigable rivers such as Budapest, Hungary. We therefore chose to discipline the sample of ports using WPI. We use a historic and current edition of the WPI to ensure we capture both ports that may no longer exist, and ones that only appear later in the period. A different approach would have been to choose a distance threshold from the coast and drop any port located further from the coast than the threshold. This definition, however, is very sensitive to the precision of the coastline shapefile used to calculate distance form the coast, which is why we did not choose this method. Despite filtering the Lloyd's List sample through the WPI, our final sample still contains a handful of ports that are very far inland. In the empirical

analysis, we show that our results are robust to different ways of treating these 'inland ports.' Our base sample consists of Lloyd's List ports that match to at least one of the WPI editions.

\section{B.2 Underwater elevation levels}

We use data on underwater elevation levels from the General Bathymetric Chart of the Oceans $(G E B C O)$. We use the 2014 version of these data. Most observations in the dataset are from shiptrack soundings with interpolation between soundings guided by satellite-derived gravity data. The data are continuously updated with sources from local bathymetry offices and coastal navigation charts. More details on dataset construction can be found at http://www.gebco.net. 


\section{B.3 Saiz proxy for land-rents}

The following sources are used to calculate the Saiz measure for our sample of cities. The coastline shapefile needed to distinguish between land and sea cells is from GSHHG (https://www.soest. hawaii.edu/pwessel/gshhg/). Inland bodies of water and wetlands are from the World Wildlife Fund's Global Lakes and Wetlands Database. ${ }^{10}$ Finally, data on land elevations used to calculate the slope of each cell is from GEBCO's land data, described above.

\section{B.4 Predicted city-level GDP per capita}

Here we provide a more detailed discussion of how we estimate city level GDP per capita for our full sample of cities (port and non-port cities). First, we merge the Canback data with our city list, and construct GDP per capita from the level of GDP and the population data provided by Canback. GDP are reported at purchasing power parity (in 2005 USD). We have estimates from this source for 898 cities in our sample.

We estimate city-level GDP for the full sample by extrapolating the estimated relationship between GDP per capita and nighlight luminosity. We begin by estimating the linear fit of GDP per capita on nightlight luminosity, building on a growing body of evidence suggesting that income can be reasonably approximated using nightlight luminosity data (Donaldson and Storeygard, 2016).

We construct the 'luminosity' of each city in the following way. We take the 199230 arcsecond grid layer from NOAA's National Geophysical Data Center (source: https://ngdc.noaa. gov/products/) as the baseline input, as this is the closest year to 1990 - the year for which we have city income from Canback. We define a cell in this raster to be 'lit up' if its luminosity level is above 25. This threshold defines meaningful levels of economic activity in the cell - as proxied by nightlights. ${ }^{11}$ We then construct a polygon from contiguous cells with luminosity above 25 for each city in our sample. We observe luminosity for 2,294 cities in our dataset. ${ }^{12}$ With these data in hand, we then define a city $i$ 's luminosity, luminosity, to be the sum of all cells' luminosity levels within the polygon. Note that in this summation, we drop any cells identified as 'gas flares' in the source data, as these do not contain meaningful information on economic activity.

For the remaining 342 cities (13\%), we either fail to identify an area polygon assigned to the city (340 cities) or a gas flare completely covers the polygon of the city ( 2 cities). We observe both GDP per capita and luminosity for a subset of 810 cities. For this subset, we estimate the relationship between GDP per capita and luminosity. More precisely, we estimate

\footnotetext{
${ }^{10}$ Link: https://www.worldwildlife.org/pages/global-lakes-and-wetlands-database.

${ }^{11}$ We experimented with different cutoffs and this was the one for which the $R^{2}$ in the regression of income on luminosity was highest.

${ }^{12}$ We have cities with 'missing' luminosity data if we fail to detect any cells with luminosity levels above 25 in the vicinity of the city's geocode.
} 


$$
\ln \left(G D P / \text { capita }_{i}=\beta * \ln \left(\text { luminosity }_{i}\right)+F E_{c}+\epsilon_{i}\right.
$$

where $G D P /$ capita $_{i}$ is city-level GDP per capita as compiled in the Canback Global Income Distribution Database (CGIDD) for the year 1990 which covers 898 cities, and luminosity $y_{i}$ measures the sum of luminosity in the cells in the polygon that defines the area of the city.

Note that most of the papers in this literature estimate the level of GDP within a country, where the level of development is not as widely dispersed as across cities worldwide. To account for these differences and the way in which they affect luminosity, we include country fixed effects $F E_{c}$ in our estimation. However, in order to identify country fixed effects, we need to drop 21 cities that are the only cities with GDP per capita data in their respective country, leaving a sample of 789 cities for the estimation.

The results of this regression are given in column (1) of Table A.17. We then predict GDP per capita for all cities for which we observe luminosity that are also in the set of countries used in this regression. This allows us to predict GDP per capita for a total of 2,289 cities. For the remaining 341 cities, we use the following approximation. For 89 cities, we observe GDP per capita directly, which we use. For 240 cities, we only observe population in 1990, so we use this to predict GDP per capita based on the estimated relationship between GDP per capita and population in 1990 for all cities in our sample for which we observe both measures. This estimated relationship is given in column (2) of Table A.17. Finally, for 18 cities, we only observe population in 1980, so we use the latter to predict GDP per capita for all cities in our sample for which we observe both variables, resulting in the estimated relationship in column (3) of Table A.17.

This procedure yields a city-level estimate for GDP per capita for all 2,636 cities in our dataset.

\section{B.5 Port shares for 1990}

Here, we provide details on the construction of port share data and the sources used. First, it is important to note that historical data on the area occupied by the port are very difficult to find. For example, data on port area are only sporadically and inconsistently reported in Lloyd's Ports of the World, and they are usually not found in ports' annual reports. These are in fact the two sources from which we take the measure for the ports where port area is observed. We also experimented with using satellite images from the 1980s, but the resolution is too low to detect port areas.

We observe data on port area in 1990 for seven cities. These are: Aarhus (Denmark), Helsinki (Finland), Copenhagen (Denmark), Hamburg (Germany), Los Angeles (USA), New Orleans (USA) and Seattle (USA). ${ }^{13}$ Data for the European ports and for the port of Los Angeles are from Lloyd's Ports of the World (1990). We complemented these with data for other U.S. ports where planning maps and annual reports gave information on the land area of the port. In all these cases, we ver-

\footnotetext{
${ }^{13}$ The port area for Los Angeles includes the area occupied by the ports of Los Angeles and Long Beach.
} 
ified or cleaned the data to ensure that a consistent definition of port area was used. In particular, these measures only include the total land (and not sea) area occupied by the port. Data for the remaining U.S. ports are from Port Authority of Seattle (1989) and Port of New Orleans (1984). These documents were shared by the port authorities based on requests we made. For Long Beach, we take port area in 1971 from the port's annual report (Port of Long Beach, 1971) and add additional land acquired from a detailed history of port projects (Riffenburgh, 2012). To construct the port shares, we use the area of land occupied by the city as reported in Wikipedia.

\section{B.6 Area per throughput calculation for the Port of Seattle}

We obtained 'Property Books' that allow us to calculate the area of the Port of Seattle from the Port of Seattle Public Records Office. These volumes contain engineering maps for each parcel of land under the ownership of the port. Each map includes an estimate of the land area. For both years 1961 and 1973, we used only land parcels directly related to port activities. In particular, we excluded the airport and the marina terminal. Data on annual total throughput (in short tons, including both domestic and international sea-borne trade) and the share of containerized cargo were collected from Annual Reports that are archived at the Puget Sound Regional Archives. To smooth out fluctuations in year-to-year capacity utilization, we took the five-year moving-average of throughput.

Table A.18 reports the numbers. While the expansion of traffic during this period was impressive (throughput doubled), the area occupied by the port expanded even more rapidly (increasing almost fourfold), such that area per throughout increased by $90 \%$ during this period. The Annual Reports paint a consistent picture. In the early 1960s, the port acquired vast parcels of land in the Lower Duwamish Industrial Development District. Throughout the latter half of the decade, the port continued to acquire more land in this area and to simultaneously develop the acquired tracts. These were completed in the late 1960s, early 1970s. We illustrate this in Figure A.8 which shows the set of acquired land parcels and an example of a completed container facility.

\section{B.7 Google Earth port area and containerization, modern data}

We compiled data on the area of all ports for a random subset of port cities in our dataset (236 cities, which is $43 \%$ of the full sample), resulting in 252 individual ports. For each port, we hand-coded polygons that contain port activities based on satellite imagines from Google Earth. We used the name tags of buildings as well as visual markers (e.g., stacked containers, ships). We aimed to be conservative in that we only included areas that could clearly be identified as containing port-related activities. As such, we did not include warehouses (as they cannot be unambiguously identified) or highways or railways. A port can have multiple polygons, e.g., in the case of terminals that are not directly connected. Google Earth reports the area (in $\mathrm{km}^{2}$ ) of each polygon, which we aggregate to the level of Geopolis port cities. The average area of a port 
in our data is $3.6 \mathrm{~km}^{2}$ (median: $2 \mathrm{~km}^{2}$ ), with a minimum of $0.03 \mathrm{~km}^{2}$ and a maximum of 30 $\mathrm{km}^{2}$ (Los Angeles, including the Port of Long Beach). The latter occupies $43 \mathrm{~km}^{2}$ according to Wikipedia (https://en.wikipedia.org/wiki/Port_of_Long_Beach and https://en.wikipedia.org/wiki/ Port_of_Los_Angeles), so while our measure most likely underestimates the true size of ports, the measure is arguably in the correct range.

Data on total (in tons) and containerized (in TEUs; twenty-foot equivalent units) volume of cargo handled by each port is taken from the 2009 edition of Le Journal de la Marine Marchande $(J M M)$. We use the average of the reported numbers for 2008 and 2009 in order to maximize the number of observations, as some ports only report data for one of the two years. In order to generate the share of container traffic in total merchandise traffic, we use the average weight per TEU of 12 tons as recommended by the European Sustainable Shipping Forum. ${ }^{14}$

We match the dataset on the area of ports and cargo volume based on the names, countries and geocodes of the ports, resulting in 123 observations.

\section{B.8 Land reclamation}

Data on land reclaimed from the sea are taken from Martín-Antón et al. (2016). The authors compare historical maps to current Google Earth images to examine whether land reclamation has taken place in a city. We matched these data to our sample of port cities. The authors report three measures; i) any land reclamation, ii) coastal land reclamation, iii) coastal and island land reclamation. This contains land reclaimed for any purpose, not just for port activities. In our analysis, we use their coastal land reclamation measure, though the results are essentially the same regardless of the measure used.

The authors systematically examined the coastlines of the world, paying particular attention to South East Asia, the Persian Gulf, Europe and the U.S., where land reclamation has been more extensive. Any systematic measurement error introduced in this way will be accounted for in our specifications that control for continent and coastline fixed effects. Reassuringly, the coefficients of interest do not change substantially with the inclusion of these, suggesting that these issues - if present - are not quantitatively large.

\section{B.9 Country GDP per capita}

Data on country-level GDP per capita are from the Penn World Tables. We take real GDP at constant 2011 prices (USD) and divide by country population reported from the same source. In theory, the data exist for 1950 (our first sample year), but in practice there are many missing observations. For this reason, in robustness checks, we always use the data for 1960. This is observed for many, though not all, countries.

\footnotetext{
${ }^{14}$ Downloaded on March 11, 2021, from https:/ec.europa.eu/clima/sites/clima/files/docs/0108/ 20170517_guidance_cargo_en.pdf.
} 


\section{B.10 Identifying city centroids for within port-city moves}

In Section 3, we discussed evidence that showed that ports had moved further towards the outskirts of the city during our sample period. To conduct this exercise, we use data on ports' geocodes from two editions of the World Port Index: 1953 and 2017. We also need to identify the geocode of each city's centroid. To this end, we use daylight satellite data to identify a city's contiguous built-up area and find the city centroid within this polygon. We closely follow the methodology in Baragwanath, Goldblatt, Hanson, and Khandelwal (2019). In particular, we use an extremely high resolution dataset of daylight satellite data, the Global Human Settlement Built-Up Grid available at $38 \mathrm{~m}$ resolution (source: https://ghsl.jrc.ec.europa.eu/ghs_bu.php). Using this raster and the geocodes of our cities, we construct a polygon for each city consisting of contiguous built-up cells around the geocode. We take the centroid of this polygon to be the centroid of the city.

\section{B.11 Ship size data}

The evolution of ship sizes, illustrated in Figure A.9, is based on data purchased from the Miramar Ship Index (Haworth, 2020), accessible at http://www.miramarshipindex.nz. The Miramar Ship Index is a comprehensive list of all newly built ships and their main characteristics going back to the 19th century. We calculate the average tonnage of all newly built ships in the years 1960, 1990, and 2010, distinguishing between container-ships and non-container ships.

\section{B.12 Ship positions}

We purchased data on the precise geo-location of ships for 100 randomly selected ports in our sample from marinetraffic.com. Data were available for 94 of these 100 ports. The data refer to all stationary (i.e., reporting speed of 0 knots per hour) cargo vessels during the week of November 4 and 10, 2019, at 12:00-13:00 local time, resulting in 17,000 observations. For vessels that report different stationary positions during this one-hour window, we keep the last reported stationary location within the hour. We calculate the geodesic distance of each anchored vessel to the geocode of the port and take the sum across the number of anchored ships within certain distances from the geocode of the port. Table A.19 shows the distribution of ships around the port by decile of port size.

\section{B.13 Nautical maps for dredging dummy variable}

We obtained access to nautical maps of ports around the world from marinetraffic.com, see https: //www.marinetraffic.com/en/online-services/single-services/nautical-charts.

These detailed nautical charts have been constructed based on information from hydrographic organizations of different countries. They provide pilotage information including depth of water at high spatial disaggregation. Dredged channels are demarcated on these maps by a 'safety contour' that distinguishes the channel from the surrounding shallow waters (defined as less than 5 meters). We constructed a binary variable, 'Dredging', that takes the value 1 if a dredged channel is visible 
on the nautical chart in the $3-5 \mathrm{~km}$ buffer ring around the port.

\section{B.14 Port cost data based on Blonigen and Wilson (2008)}

Blonigen and Wilson (2008) estimate port costs as exporter-port fixed effects in a regression of bilateral HS 6-digit product level import charges that control for distance, value, value-to-weight, percentage of containerized traffic between the two ports, trade imbalances, time, product and importer-port fixed effects using U.S. census data for 1991 (see Blonigen and Wilson (2008) for additional details). The exporter fixed effects are all estimated relative to the port costs at Rotterdam. For our purposes, these relative measures need to be scaled to levels. We do this by setting the iceberg trade cost of passing through Rotterdam to be 1.004 . This is based on estimates of revenue from handling one container to be approximately \$140 AUD (Australian Competition and Consumer Commission, 2017, p. 8) and the average value of a container to be 20,000 EUR (Kirchner, 2006, p. 4). ${ }^{15}$

\section{B.15 Data on frost-free days}

We use data from the FAO GAEZ database (http://www.fao.org/nr/gaez/en/) to measure the average the number of frost-free days per year in each city. This database provides the average of this variable during the years between 1961 and 1990 in every cell over a 5 by 5 arc minute grid of the Earth. Using the geocoordinates of each city, we determine the grid cell in which the city is located, and assign the average number of frost-free days in the cell to the city.

\section{B.16 Annual reports for ports}

We were able to acquire annual reports for a number of port authorities in the United States during our sample period, 1950 to 1990, and for a handful of ports worldwide. Some ports have made historical annual reports available online, while for others, we have obtained the reports by contacting the port authorities. We use these reports i) for historical evidence (Section 1), ii) in the case of the Port of Seattle, to measure changes in land per unit of throughput during the period in which they containerized (Section 1), iii) to examine reporting on pollution and disamenities (Section 7), and iv) to calculate profit rates (Section A.7).

As accounting and reporting standards changed across ports and over time, we only kept ports that reported consistent information on profits over time (defined as revenue minus operating expenses and depreciation). These ports are: Houston, Los Angeles, Long Beach, New York/New Jersey, New Orleans, Seattle and Townsville (Australia). We tried to collect at least one observation per port for each decade between 1950 and 1990, and ended up with on average three decadal observations per port. The average profit margin across all observations in our sample is $28 \%$, with no clear time trend. Data sources are as follows;

\footnotetext{
${ }^{15}$ These are industry-level averages as of 2016 (for revenue from container handling) and 2006 (for average value of cargo), and do not refer specifically to data from Rotterdam.
} 
Houston. Port of Houston Authority of Harris County, Texas: 'Comprehensive Annual Financial Report' (various years). Thank you to Dollores Villareal at the Port of Houston for responding to our request and digitizing the data for us.

Los Angeles. Port of Los Angeles Board of Harbor Commissioners: 'Annual Report' (various years). Thank you to Kurt Arendt at the Port of Los Angeles for responding to our request and sharing data.

Long Beach. The Port of Long Beach California: 'Harbor Highlights' (various years). Accessible at https://www.polb.com/port-info/history\#historical-publications.

New York/New Jersey. The Port Authority of New York and New Jersey: 'Annual Report' (various years). These can be accessed online at https://corpinfo.panynj.gov/pages/annual-reports/.

New Orleans. Board of Commissioners of the Port of New Orleans: 'Annual Report Fiscal' (various years). Thank you to Mandi Venderame at the Port of New Orleans for responding to our request and sharing data.

San Francisco. The Port of San Francisco: 'Annual Report', other reports and planning maps from various years. Thank you to Randolph Quezada at the Port of San Francisco for numerous helpful conversations and for sharing scans.

Seattle. The Port of Seattle: 'Annual Report' (various years) and planning maps. Thank you to Midori Okazaki, archivist at Puget Sound Regional Archives, for scanning the files during the COVID-19 lockdown while the archives were closed to the public.

Townsville (Australia). Townsville Harbor Board: 'Report' (various years). Thank you to the Port Authority for responding to our data request.

Appendix p.27 


\section{Tables}

Table A.1: Relationship between containerization and port area

\begin{tabular}{|c|c|c|c|c|c|c|c|}
\hline & \multicolumn{7}{|c|}{$\mathrm{Ln}($ Port area, km2) } \\
\hline & $(1)$ & $(2)$ & (3) & (4) & $(5)$ & $(6)$ & (7) \\
\hline Ln(Container traffic, TEUs) & $\begin{array}{c}0.288 * * * \\
(0.049)\end{array}$ & $\begin{array}{c}0.127 * * * \\
(0.045)\end{array}$ & $\begin{array}{c}0.133 * * * \\
(0.044)\end{array}$ & $\begin{array}{c}0.151 * * * \\
(0.047)\end{array}$ & $\begin{array}{c}0.153 * * * \\
(0.046)\end{array}$ & $\begin{array}{c}0.144 * * * \\
(0.053)\end{array}$ & \\
\hline Ln(Total merchandise traffic, tons) & & $\begin{array}{c}0.375^{* * *} \\
(0.080)\end{array}$ & $\begin{array}{l}0.283^{*} \\
(0.166)\end{array}$ & $\begin{array}{c}0.311 * * * \\
(0.080)\end{array}$ & $\begin{array}{c}0.247 \\
(0.161)\end{array}$ & $\begin{array}{c}0.356 * * * \\
(0.118)\end{array}$ & $\begin{array}{c}0.506 * * * \\
(0.069)\end{array}$ \\
\hline Ln(Non-bulk traffic, tons) & & & $\begin{array}{c}0.014 \\
(0.099)\end{array}$ & & $\begin{array}{c}0.008 \\
(0.096)\end{array}$ & & \\
\hline Ln(Country GDP/capita) & & & & $\begin{array}{c}0.311 * * * \\
(0.108)\end{array}$ & $\begin{array}{c}0.292 * * \\
(0.134)\end{array}$ & & \\
\hline Container traffic share & & & & & & & $\begin{array}{c}0.562 * * * \\
(0.209)\end{array}$ \\
\hline Observations & 123 & 123 & 73 & 122 & 73 & 123 & 123 \\
\hline R-squared & 0.287 & 0.395 & 0.327 & 0.431 & 0.352 & 0.672 & 0.398 \\
\hline$\%$ change & & & & & & & 0.75 \\
\hline Country FEs & $x$ & $x$ & $x$ & $x$ & $x$ & $\checkmark$ & $x$ \\
\hline
\end{tabular}

Notes: 'Container traffic share' is defined as $\frac{\text { container traffic in TEU-s } * 12 \text { tons per TEU }}{\text { total merchandise traffic in tons }}$. Non-bulk traffic is all traffic net of liquid and solid bulk. Container traffic and total merchandise traffic are averaged across 2008 and 2009 in order to maximize the sample size. Country level GDP per capita and non-bulk traffic are for 2009. Data sources: Google Earth and Le Journal de la Marine Marchande. Robust standard errors in parentheses. $* * * \mathrm{p}<0.01, * * \mathrm{p}<0.05, * \mathrm{p}<0.1$. 
Table A.2: Summary statistics

\begin{tabular}{lccc}
\hline \hline & Observations & Mean & Standard Deviation \\
\hline Shipment (annualized) & 2,765 & 2,913 & 7,051 \\
Population (in '000s): All Cities & 12,698 & 386 & 1,086 \\
Population (in '000s): Port Cities & 2,735 & 724 & 1,886 \\
Depth & 553 & 2.19 & 1.49 \\
Saiz & 553 & 0.44 & 0.19 \\
\hline \hline
\end{tabular}

Notes: Shipment reports the annualized flow of shipments across all port city - year pairs (in levels). Population refers to the level of the population of each city-year pair in thousands. Depth and the Saiz Land Rent Proxies are time invariant measures and are defined in the main text.

Table A.3: Relationship between dredging and measured depth

\begin{tabular}{lccc}
\hline \hline & \multicolumn{3}{c}{ Dredging } \\
\cline { 2 - 4 } Independent variables & $(1)$ & $(2)$ & $(3)$ \\
\hline \multirow{2}{*}{ Depth } & $-0.058^{* *}$ & $-0.042^{*}$ & -0.028 \\
& $(0.025)$ & $(0.024)$ & $(0.028)$ \\
\hline Observations & 100 & 100 & 100 \\
R-squared & 0.059 & 0.138 & 0.250 \\
FE & none & continent & coastline \\
\hline \hline
\end{tabular}

Notes: This table tests the extent to which the baseline measure of depth captures naturally endowed depth (as opposed to depth attained by dredging). Dredging is a binary indicator that takes the value of one if nautical maps from marinetraffic.com show the presence of a dredged channel. Depth is the baseline measure of port suitability used in the paper. The sample consists of 100 randomly selected ports from the baseline sample. Robust standard errors in parentheses. ${ }^{* * *} \mathrm{p}<0.01, * * \mathrm{p}<0.05, * \mathrm{p}<0.1$. 
Table A.4: Balancing checks for candidate depth measures

\begin{tabular}{|c|c|c|c|c|c|c|c|c|}
\hline & (1) & (2) & (3) & (4) & (5) & (6) & (7) & (8) \\
\hline Independent variables & $\begin{array}{l}\ln \text { (Shipping } \\
\text { flows 1950) }\end{array}$ & $\begin{array}{c}\ln (\text { Population } \\
1950)\end{array}$ & $\begin{array}{l}\Delta \ln \text { (Shipping } \\
\text { flows) }\end{array}$ & $\begin{array}{c}\Delta \ln \\
\text { (Population) }\end{array}$ & $\begin{array}{l}\ln (\mathrm{GDP} p \mathrm{p} \\
\text { country) }\end{array}$ & Latitude & Longitude & $\begin{array}{c}\text { Saiz land rent } \\
\text { proxy }\end{array}$ \\
\hline \multirow[t]{2}{*}{ Depth } & $-0.2308 * *$ & $-0.1953 * * *$ & -0.0351 & $0.0135^{*}$ & -0.0215 & -0.4541 & 1.7585 & $0.0625 * * *$ \\
\hline & $(0.0955)$ & $(0.0389)$ & $(0.0606)$ & $(0.0076)$ & $(0.0301)$ & $(0.7176)$ & $(2.1507)$ & $(0.0051)$ \\
\hline \multirow[t]{2}{*}{ Residualized depth } & -0.0416 & & -0.0507 & -0.0003 & 0.0065 & 0.3900 & 2.4352 & $0.0587 * * *$ \\
\hline & $(0.0977)$ & & $(0.0636)$ & $(0.0082)$ & $(0.0308)$ & $(0.7160)$ & $(2.1867)$ & $(0.0053)$ \\
\hline Observations & 553 & 553 & 553 & 532 & 472 & 553 & 553 & 553 \\
\hline
\end{tabular}

Notes: This table regresses observables pre-containerization on two candidate measures of port suitability: 'Depth' and 'Residualized depth.' The former is defined as the log of $1+$ the sum of cells deeper than 30 feet within 3-5 kilometers of the port. The latter takes the depth measure and residualizes it on the $\log$ of population in 1950. $\Delta \ln$ (Shipping flows) and $\Delta \ln$ (Population) are the growth rates between 1950 and 1960 for the respective variables. GDP per capita, measured at the country level in 1960, is from the Penn World Tables. Latitude and Longitude are observed at the city level. The 'Saiz land rent proxy' is the measure defined in Saiz (2010). Robust standard errors in parentheses. *** $\mathrm{p}<0.01, * * \mathrm{p}<0.05, * \mathrm{p}<0.1$.

Table A.5: Relationship between coastal land reclamation and the Saiz measure

\begin{tabular}{lcccccc}
\hline \hline & \multicolumn{5}{c}{ Coastal land reclamation (indicator) } \\
\cline { 2 - 7 } Independent variables & $(1)$ & $(2)$ & $(3)$ & $(4)$ & $(5)$ & $(6)$ \\
\hline Saiz & $0.1296^{*}$ & $0.1356^{* *}$ & 0.1146 & & & \\
& $(0.0686)$ & $(0.0678)$ & $(0.0754)$ & & & \\
Depth & & & & 0.0008 & 0.0038 & -0.0003 \\
& & & & $(0.0093)$ & $(0.0096)$ & $(0.0106)$ \\
\hline Observations & 553 & 553 & 553 & 553 & 553 & 553 \\
R-squared & 0.00534 & 0.08521 & 0.13287 & 0.00001 & 0.07991 & 0.12925 \\
FE & none & continent & coastline & none & continent & coastline \\
\hline \hline
\end{tabular}

Notes: Dependent variable is equal to one in case coastal land reclamation was reported, and zero otherwise. Robust standard errors in parentheses. $* * * \mathrm{p}<0.01,{ }^{* *} \mathrm{p}<0.05,{ }^{*} \mathrm{p}<0.1$. 
Table A.6: Robustness to data choices

\begin{tabular}{|c|c|c|c|c|c|c|}
\hline & \multicolumn{6}{|c|}{ Panel A: Depth predicts shipping flows } \\
\hline & \multicolumn{6}{|c|}{$\ln ($ Shipment $)$} \\
\hline & $(1)$ & $(2)$ & (3) & $(4)$ & $(5)$ & (6) \\
\hline & Baseline & Shipment +1 & IHST & Port Cities & Depth $=0$ & $100 \mathrm{~K}$ \\
\hline Depth $\times$ post 1970 & $\begin{array}{c}0.247 * * * \\
(0.059)\end{array}$ & $\begin{array}{c}0.144 * * * \\
(0.029)\end{array}$ & $\begin{array}{c}0.164 * * * \\
(0.034)\end{array}$ & $\begin{array}{c}0.218 * * * \\
(0.060)\end{array}$ & $\begin{array}{c}0.247 * * * \\
(0.059)\end{array}$ & $\begin{array}{c}0.285 * * * \\
(0.071)\end{array}$ \\
\hline Observations & 2765 & 2765 & 2765 & 2640 & 2765 & 1565 \\
\hline R-squared & 0.126 & 0.156 & 0.155 & 0.133 & 0.126 & 0.139 \\
\hline \multirow[t]{4}{*}{ Number of cities } & 553 & 553 & 553 & 528 & 553 & 313 \\
\hline & \multicolumn{6}{|c|}{ Panel B: The local causal effect of shipping on population } \\
\hline & \multicolumn{6}{|c|}{$\ln ($ Population $)$} \\
\hline & (1) & (2) & (3) & (4) & (5) & (6) \\
\hline Independent variables & Baseline & Shipment +1 & IHST & Port Cities & Depth $=0$ & $100 \mathrm{~K}$ \\
\hline $\ln$ (Shipment) & $\begin{array}{c}0.015 \\
(0.049)\end{array}$ & $\begin{array}{c}0.027 \\
(0.086)\end{array}$ & $\begin{array}{c}0.024 \\
(0.076)\end{array}$ & $\begin{array}{c}0.025 \\
(0.053)\end{array}$ & $\begin{array}{c}0.015 \\
(0.049)\end{array}$ & $\begin{array}{c}0.045 \\
(0.052)\end{array}$ \\
\hline Observations & 2734 & 2734 & 2734 & 2609 & 2734 & 1563 \\
\hline R-squared & 0.717 & 0.719 & 0.719 & 0.720 & 0.717 & 0.606 \\
\hline \multirow[t]{4}{*}{ Number of cities } & 552 & 552 & 552 & 527 & 552 & 313 \\
\hline & \multicolumn{6}{|c|}{ Panel C: Containerization increased shipping more in low rent cities } \\
\hline & \multicolumn{6}{|c|}{$\ln ($ Shipment $)$} \\
\hline & (1) & (2) & (3) & (4) & (5) & (6) \\
\hline Independent variables & Baseline & Shipment +1 & IHST & Port Cities & Depth $=0$ & $100 \mathrm{k}$ \\
\hline Depth $\times$ post 1970 & $\begin{array}{c}0.566^{* * *} \\
(0.152)\end{array}$ & $\begin{array}{c}0.318 * * * \\
(0.079)\end{array}$ & $\begin{array}{c}0.368 * * * \\
(0.090)\end{array}$ & $\begin{array}{c}0.583 * * * \\
(0.147)\end{array}$ & $\begin{array}{c}0.566^{* * * *} \\
(0.152)\end{array}$ & $\begin{array}{c}0.348 * * \\
(0.177)\end{array}$ \\
\hline Depth $\times$ Saiz $\times$ post 1970 & $\begin{array}{c}-0.707 * * \\
(0.323)\end{array}$ & $\begin{array}{c}-0.408 * * \\
(0.159)\end{array}$ & $\begin{array}{c}-0.472 * * * \\
(0.183)\end{array}$ & $\begin{array}{c}-0.779 * * \\
(0.315)\end{array}$ & $\begin{array}{c}-0.707 * * \\
(0.323)\end{array}$ & $\begin{array}{l}-0.203 \\
(0.376)\end{array}$ \\
\hline Saiz $\times$ post 1970 & $\begin{array}{c}0.975 \\
(0.804)\end{array}$ & $\begin{array}{c}0.740 * * \\
(0.376)\end{array}$ & $\begin{array}{l}0.814 * \\
(0.436)\end{array}$ & $\begin{array}{c}0.950 \\
(0.802)\end{array}$ & $\begin{array}{c}0.975 \\
(0.804)\end{array}$ & $\begin{array}{c}0.694 \\
(0.963)\end{array}$ \\
\hline Observations & 2765 & 2765 & 2765 & 2640 & 2765 & 1565 \\
\hline R-squared & 0.129 & 0.161 & 0.159 & 0.137 & 0.129 & 0.139 \\
\hline Number of cities & 553 & 553 & 553 & 528 & 553 & 313 \\
\hline
\end{tabular}

Notes: 'Baseline' reports the baseline specification for comparability. Columns (2)-(3) examine robustness to different ways of dealing with zero shipping flows. Column (2) uses $\ln ($ Shipment +1$)$ as dependent variable - that is, we take the raw shipping variable and replace the zeros with ones and then take the natural logarithm. Column (3) uses the inverse hyperbolic sine transformation (IHST) for shipment. Different to the baseline, neither of these transformations annualizes the data. Columns (4) - (5) examine robustness to different ways of dealing with 'inland ports.' Column (4) drops them, reducing the sample size. Column (5) assigns depth equal to zero to these cities. Column (6) uses the subset of cities that already attained 100,000 inhabitants in 1950 to examine the effect of sample selection bias. 'Depth' indicates the port suitability measure interacted with indicators for decades including and after 1970. Standard errors clustered at the city level. *** $\mathrm{p}<0.01, * * \mathrm{p}<0.05, * \mathrm{p}<0.1$. 
Table A.7: The local causal effect of shipping on population - full panel specification

\begin{tabular}{|c|c|c|c|c|c|}
\hline \multirow[b]{2}{*}{ Independent variables } & \multicolumn{5}{|c|}{ Panel Regression } \\
\hline & $\begin{array}{c}\ln (\text { Pop }) \\
(1)\end{array}$ & $\begin{array}{c}\ln \text { (Ship) } \\
(2)\end{array}$ & $\begin{array}{c}\ln (\text { Pop) } \\
(3)\end{array}$ & $\begin{array}{c}\ln (\text { Ship) } \\
(4)\end{array}$ & $\begin{array}{c}\ln (\text { Pop }) \\
(5)\end{array}$ \\
\hline $\ln ($ Shipment $)$ & $\begin{array}{c}0.015 \\
0.035 \\
(0.049) \\
\{0.039\}\end{array}$ & & & & \\
\hline Depth $\times$ post 1970 & & $\begin{array}{c}0.268 * * * \\
0.143 * * * \\
(0.058)\end{array}$ & $\begin{array}{c}0.004 \\
0.005 \\
(0.013)\end{array}$ & & \\
\hline Depth $\times 1960$ & & & & $\begin{array}{l}-0.042 \\
(0.064)\end{array}$ & $\begin{array}{l}-0.003 \\
(0.008)\end{array}$ \\
\hline Depth $\times 1970$ & & & & $\begin{array}{c}0.246 * * * \\
(0.069)\end{array}$ & $\begin{array}{c}0.007 \\
(0.013)\end{array}$ \\
\hline Depth $\times 1980$ & & & & $\begin{array}{c}0.213 * * * \\
(0.079)\end{array}$ & $\begin{array}{l}-0.002 \\
(0.017)\end{array}$ \\
\hline Depth $\times 1990$ & & & & $\begin{array}{c}0.280 * * * \\
(0.086)\end{array}$ & $\begin{array}{c}0.002 \\
(0.020)\end{array}$ \\
\hline Observations & 2734 & 2734 & 2734 & 2734 & 2734 \\
\hline Number of cities & 552 & 552 & 552 & 552 & 552 \\
\hline Year FE & $\checkmark$ & $\checkmark$ & $\checkmark$ & $\checkmark$ & $\checkmark$ \\
\hline City FE & $\checkmark$ & $\checkmark$ & $\checkmark$ & $\checkmark$ & $\checkmark$ \\
\hline Population $1950 \times$ Year & $\checkmark$ & $\checkmark$ & $\checkmark$ & $\checkmark$ & $\checkmark$ \\
\hline Population 1950 & $x$ & $x$ & $\times$ & $x$ & $x$ \\
\hline Specification & 2SLS & FS & $\mathrm{RF}$ & dyn FS & dyn RF \\
\hline KP F-stat & 21.13 & & & & \\
\hline
\end{tabular}

Notes: 'Depth' indicates the port suitability measure. It is interacted with decade dummies or indicator variables for decades including and after 1970, as indicated. Standardized coefficients in italics underneath the baseline coefficients. Notation for specification as follows: 'FS' refers to the first stage, 'RF' to the reduced form, 'dyn FS' to the fully flexible first stage and 'dyn RF' to the fully flexible reduced form. Standard errors clustered at the city level in parentheses, Conley standard errors to adjust for spatial correlation in curly brackets. $* * * \mathrm{p}<0.01, * * \mathrm{p}<0.05, * \mathrm{p}<0.1$ (significance refers to clustered standard errors). 
Table A.8: The local causal effect of shipping on population - robustness

\begin{tabular}{lcccc}
\hline \multirow{2}{*}{ Independent variables } & \multicolumn{4}{c}{$\ln$ (Population) } \\
\cline { 2 - 5 } $\ln$ (Shipment) & 0.015 & -0.071 & 0.018 & -0.015 \\
& $(0.049)$ & $(0.060)$ & $(0.051)$ & $(0.051)$ \\
\hline Observations & 2734 & 2734 & 2734 & 2338 \\
R-squared & 0.717 & 0.759 & 0.717 & 0.756 \\
Number of cities & 552 & 552 & 552 & 471 \\
Year FE & $\checkmark$ & $\checkmark$ & $\checkmark$ & $\checkmark$ \\
City FE & $\checkmark$ & $\checkmark$ & $\checkmark$ & $\checkmark$ \\
Population 1950 $\times$ Year & $\checkmark$ & $\checkmark$ & $\checkmark$ & $\checkmark$ \\
Coastline $\times$ Year FE & $\times$ & $\checkmark$ & $\times$ & $\times$ \\
Saiz $\times$ Year & $\times$ & $\times$ & $\checkmark$ & $\times$ \\
GDP pc (country) $\times$ Year & $\times$ & $\times$ & $\times$ & $\checkmark$ \\
Specification & $2 S L S$ & $2 S L S$ & $2 S L S$ & $2 S L S$ \\
KP F-stat & 21.13 & 13.71 & 16.26 & 19.48 \\
\hline \hline
\end{tabular}

Notes: All specifications are 2SLS, using the depth measure as an instrument for shipping (interacted with a dummy for decades including and after 1970). Standard errors clustered at the city level. $* * * \mathrm{p}<0.01, * *$ $\mathrm{p}<0.05, * \mathrm{p}<0.1$. 
Table A.9: Containerization increased shipping more in low rent cities

\begin{tabular}{lcccc}
\hline \hline & \multicolumn{4}{c}{$\ln ($ Shipment) } \\
\cline { 2 - 5 } Independent variables & $(1)$ & $(2)$ & $(3)$ & $(4)$ \\
\hline Depth $\times$ post 1970 & $0.464^{* * *}$ & $0.566^{* * *}$ & $0.437^{* * *}$ & $0.497^{* * *}$ \\
& $(0.138)$ & $(0.152)$ & $(0.142)$ & $(0.166)$ \\
Depth $\times$ Saiz $\times$ post 1970 & $-0.408^{*}$ & $-0.707^{* *}$ & -0.431 & $-0.586^{*}$ \\
& $(0.220)$ & $(0.323)$ & $(0.308)$ & $(0.331)$ \\
& $\{0.153\}$ & $\{0.237\}$ & & \\
Saiz $\times$ post 1970 & & 0.975 & -0.052 & 1.176 \\
& & $(0.804)$ & $(0.811)$ & $(0.749)$ \\
\hline Observations & 2765 & 2765 & 2765 & 2360 \\
R-squared & 0.128 & 0.129 & 0.250 & 0.143 \\
Number of cities & 553 & 553 & 553 & 472 \\
Year FE & $\checkmark$ & $\checkmark$ & $\checkmark$ & $\checkmark$ \\
City FE & $\checkmark$ & $\checkmark$ & $\checkmark$ & $\checkmark$ \\
Population 1950 $\times$ Year & $\checkmark$ & $\checkmark$ & $\checkmark$ & $\checkmark$ \\
Coastline $\times$ Year FE & $\times$ & $\times$ & $\checkmark$ & $\times$ \\
GDP pc (country) $\times$ Year & $\times$ & $\times$ & $\times$ & $\checkmark$ \\
\hline \hline
\end{tabular}

Notes: 'Depth' indicates the port suitability measure. 'Saiz' is the Saiz land rent proxy defined in Saiz (2010). Each measure is interacted with an indicator for decades including and after 1970. Standard errors clustered at the city level in parentheses. Conley standard errors to adjust for spatial correlation in curly brackets. *** $\mathrm{p}<0.01, * * \mathrm{p}<0.05, * \mathrm{p}<0.1$ (significance refers to clustered standard errors).

Table A.10: Calibration of structural parameters

\begin{tabular}{ll}
\hline \hline Parameter & Target \\
\hline$\alpha=0.06$ & Agglomeration externalities (Ciccone and Hall, 1993) \\
$\gamma=0.84$ & Non-land share in production (Desmet and Rappaport, 2017) \\
$\eta=0.15$ & Migration elasticity (Kennan and Walker, 2011) \\
$\sigma=4$ & Elasticity of substitution across tradables (Bernard et al., 2003) \\
$\theta=203$ & Idiosyncratic shipping cost dispersion (Allen and Arkolakis, 2019) \\
$\lambda=0.074$ & Congestion externalities in ports (Abe and Wilson, 2009) \\
\hline \hline
\end{tabular}




\section{Table A.11: Prediction of population based on the number of frost free days}

\begin{tabular}{|c|c|c|c|c|c|c|c|c|c|}
\hline \multirow[b]{2}{*}{ Independent variables } & \multicolumn{9}{|c|}{$\ln$ (Population) } \\
\hline & (1) & (2) & $\begin{array}{l}\text { Africa } \\
\text { (3) }\end{array}$ & $\begin{array}{c}\text { North America } \\
\text { (4) }\end{array}$ & $\begin{array}{c}\text { Latin America } \\
\text { (5) }\end{array}$ & $\begin{array}{l}\text { Asia } \\
(6)\end{array}$ & $\begin{array}{l}\text { Europe } \\
\text { (7) }\end{array}$ & $\begin{array}{c}\text { Oceania } \\
\text { (8) }\end{array}$ & $\begin{array}{l}\text { USSR } \\
\text { (9) }\end{array}$ \\
\hline Frost Free Days $\times 1960$ & $\begin{array}{c}0.0007 * * * \\
(0.0001)\end{array}$ & $\begin{array}{l}0.0003 * \\
(0.0002)\end{array}$ & $\begin{array}{l}-0.0005 \\
(0.0013)\end{array}$ & $\begin{array}{c}0.0015 * * * \\
(0.0003)\end{array}$ & $\begin{array}{c}0.0008 * * * \\
(0.0002)\end{array}$ & $\begin{array}{l}-0.0001 \\
(0.0002)\end{array}$ & $\begin{array}{l}-0.0001 \\
(0.0001)\end{array}$ & $\begin{array}{c}0.0014 \\
(0.0012)\end{array}$ & $\begin{array}{r}0.0001 \\
(0.0007)\end{array}$ \\
\hline Frost Free Days $\times 1970$ & $\begin{array}{c}0.0017 * * * \\
(0.0001)\end{array}$ & $\begin{array}{c}0.0006^{* * * *} \\
(0.0003)\end{array}$ & $\begin{array}{l}-0.0006 \\
(0.0021)\end{array}$ & $\begin{array}{c}0.0026^{* * * *} \\
(0.0005)\end{array}$ & $\begin{array}{c}0.0013 * * * \\
(0.0003)\end{array}$ & $\begin{array}{c}0.0008 * * * \\
(0.0002)\end{array}$ & $\begin{array}{c}0.0004 * * \\
(0.0002)\end{array}$ & $\begin{array}{c}0.0023 \\
(0.0020)\end{array}$ & $\begin{array}{r}0.0012 \\
(0.0010)\end{array}$ \\
\hline Frost Free Days $\times 1980$ & $\begin{array}{c}0.0028 * * * \\
(0.0001)\end{array}$ & $\begin{array}{c}0.0012 * * * \\
(0.0003)\end{array}$ & $\begin{array}{l}-0.0006 \\
(0.0020)\end{array}$ & $\begin{array}{c}0.0039 * * * \\
(0.0006)\end{array}$ & $\begin{array}{c}0.0017 * * * \\
(0.0004)\end{array}$ & $\begin{array}{l}0.0005^{*} \\
(0.0003)\end{array}$ & $\begin{array}{c}0.0011 * * * \\
(0.0003)\end{array}$ & $\begin{array}{c}0.0036 \\
(0.0027)\end{array}$ & $\begin{array}{r}0.0010 \\
(0.0011)\end{array}$ \\
\hline Frost Free Days $\times 1990$ & $\begin{array}{c}0.0039 * * * \\
(0.0002)\end{array}$ & $\begin{array}{c}0.0013 * * * \\
(0.0004)\end{array}$ & $\begin{array}{l}-0.0009 \\
(0.0026)\end{array}$ & $\begin{array}{c}0.0047 * * * \\
(0.0007)\end{array}$ & $\begin{array}{c}0.0015 * * * \\
(0.0005)\end{array}$ & $\begin{array}{c}0.0014 * * * \\
(0.0003)\end{array}$ & $\begin{array}{c}0.0013 * * * \\
(0.0003)\end{array}$ & $\begin{array}{c}0.0049 \\
(0.0031)\end{array}$ & $\begin{array}{r}0.0011 \\
(0.0012)\end{array}$ \\
\hline Observations & 12368 & 12368 & 1184 & 987 & 1532 & 4784 & 2410 & 104 & 1367 \\
\hline R-squared & 0.729 & 0.839 & 0.798 & 0.686 & 0.852 & 0.756 & 0.556 & 0.647 & 0.762 \\
\hline Number of cities & 2568 & 2568 & 245 & 198 & 308 & 1038 & 482 & 21 & 276 \\
\hline City FE & $\checkmark$ & $\checkmark$ & $\checkmark$ & $\checkmark$ & $\checkmark$ & $\checkmark$ & $\checkmark$ & $\checkmark$ & $\checkmark$ \\
\hline Country year FE & $x$ & $\checkmark$ & $x$ & $x$ & $x$ & $x$ & $x$ & $x$ & $x$ \\
\hline Year FE & $\checkmark$ & $x$ & $\checkmark$ & $\checkmark$ & $\checkmark$ & $\checkmark$ & $\checkmark$ & $\checkmark$ & $\checkmark$ \\
\hline
\end{tabular}

Notes: Column (2), which includes country-year fixed effects, is our preferred specification used for predicting population. Column (1) only controls for year fixed effects. The time pattern in the effect of frost free days on population is similar; however, country-year fixed effects take out some of the explanatory power of temperature and are therefore a more conservative measure. Columns (3) to (9) estimate column (1) for countries in different regions of the world. Reassuringly, the number of frost free days has the strongest effect in North America, where air conditioning is arguably most prevalent, has medium effects in Latin America, Asia, and Europe, and has no detectable effects in Africa, Oceania and USSR, where air conditioning was probably less wide-spread. Frost Free Days indicates the average number of frost free days per year in the city between 1961-1990. Standard errors clustered at the city level in parentheses. $* * * \mathrm{p}<0.01, * * \mathrm{p}<0.05, * \mathrm{p}<0.1$. 
Table A.12: Model-inspired specification: fully flexible first stages

\begin{tabular}{|c|c|c|}
\hline & (1) & (2) \\
\hline Independent variables & $\ln ($ Shipment $)$ & $\ln$ (Market Access) \\
\hline \multirow[t]{2}{*}{ Depth $\times 1960$} & -0.038 & 0.003 \\
\hline & $(0.064)$ & $(0.002)$ \\
\hline \multirow[t]{2}{*}{ Depth $\times 1970$} & $0.251 * * *$ & $0.007 * * *$ \\
\hline & $(0.069)$ & $(0.002)$ \\
\hline \multirow[t]{2}{*}{ Depth $\times 1980$} & $0.226 * * *$ & $0.009 * * *$ \\
\hline & $(0.079)$ & $(0.002)$ \\
\hline \multirow[t]{2}{*}{ Depth $\times 1990$} & $0.290 * * *$ & $0.009 * * *$ \\
\hline & $(0.085)$ & $(0.002)$ \\
\hline \multirow[t]{2}{*}{ Market Access IV } & 7.169 & $1.929 * * *$ \\
\hline & $(5.413)$ & $(0.140)$ \\
\hline Observations & 2696 & 2696 \\
\hline R-squared & 0.125 & 0.728 \\
\hline Number of cities & 544 & 544 \\
\hline Year FE & $\checkmark$ & $\checkmark$ \\
\hline City FE & $\checkmark$ & $\checkmark$ \\
\hline Population $1950 \times$ Year & $\checkmark$ & $\checkmark$ \\
\hline
\end{tabular}

Notes: 'Depth' indicates the port suitability measure. It is interacted with dummy variables for decades in order to examine the time path of when depth started to matter for $\ln$ (Shipment) and $\ln$ (MarketAccess). ' $\ln ($ MarketAccess $)$ ' is the empirical counterpart of the market access term, defined in Section 5. 'Market access IV' is the instrument for the market access term, defined in Section 5. Standard errors clustered at the city level. *** $\mathrm{p}<0.01, * * \mathrm{p}<0.05, *$ $\mathrm{p}<0.1$. 
Table A.13: Model-inspired specification - robustness

\begin{tabular}{|c|c|c|c|c|c|c|c|c|}
\hline \multirow[b]{2}{*}{ Independent variables } & \multicolumn{8}{|c|}{$\ln$ (Population) } \\
\hline & (1) & (2) & (3) & (4) & (5) & (6) & (7) & (8) \\
\hline $\ln ($ Shipment $)$ & $\begin{array}{c}-0.159 * * \\
(0.065)\end{array}$ & $\begin{array}{c}-0.156 * * \\
(0.067)\end{array}$ & $\begin{array}{c}-0.147 * * \\
(0.072)\end{array}$ & $\begin{array}{c}-0.084 * * \\
(0.041)\end{array}$ & $\begin{array}{l}-0.080 \\
(0.058)\end{array}$ & $\begin{array}{c}-0.164 * * \\
(0.074)\end{array}$ & $\begin{array}{c}-0.231 * * * \\
(0.066)\end{array}$ & $\begin{array}{c}-0.215^{* * *} \\
(0.081)\end{array}$ \\
\hline $\ln$ (Market Access) & $\begin{array}{c}7.103 * * * \\
(0.795)\end{array}$ & $\begin{array}{c}6.982 * * * \\
(0.844)\end{array}$ & $\begin{array}{c}6.613 * * * \\
(1.043)\end{array}$ & $\begin{array}{c}0.588 \\
(2.918)\end{array}$ & $\begin{array}{c}7.111 * * * \\
(0.713)\end{array}$ & $\begin{array}{c}5.692 * * * \\
(1.354)\end{array}$ & $\begin{array}{c}10.090 * * * \\
(1.250)\end{array}$ & $\begin{array}{c}9.400 * * * \\
(1.514)\end{array}$ \\
\hline Observations & 2696 & 2696 & 2696 & 2696 & 2696 & 2303 & 2696 & 2696 \\
\hline R-squared & 0.417 & 0.429 & 0.467 & 0.755 & 0.507 & 0.544 & $(1.250)$ & $(1.514)$ \\
\hline Number of cities & 544 & 544 & 544 & 544 & 544 & 464 & 544 & 544 \\
\hline Year FE & $\checkmark$ & $\checkmark$ & $\checkmark$ & $\checkmark$ & $\checkmark$ & $\checkmark$ & $\checkmark$ & $\checkmark$ \\
\hline City FE & $\checkmark$ & $\checkmark$ & $\checkmark$ & $\checkmark$ & $\checkmark$ & $\checkmark$ & $\checkmark$ & $\checkmark$ \\
\hline Population $1950 \times$ Year & $\checkmark$ & $\checkmark$ & $\checkmark$ & $\checkmark$ & $\checkmark$ & $\checkmark$ & $x$ & $x$ \\
\hline Coastline $\times$ Year FE & $x$ & $x$ & $x$ & $\checkmark$ & $x$ & $x$ & $x$ & $x$ \\
\hline Saiz $\times$ Year & $x$ & $x$ & $x$ & $x$ & $\checkmark$ & $x$ & $x$ & $x$ \\
\hline GDP pc (country) $1960 \times$ Year & $x$ & $x$ & $x$ & $x$ & $x$ & $\checkmark$ & $x$ & $x$ \\
\hline Specification & $2 \mathrm{SLS}$ & $2 \mathrm{SLS}$ & 2SLS & 2SLS & 2SLS & 2SLS & 2SLS & 2SLS \\
\hline Drop Cities in Market Access IV & none & $\leq 200$ & $\leq 500$ & none & none & none & none & none \\
\hline Borusyak Hull correction & none & none & none & none & none & none & worldwide & $30^{\circ}$ lat \\
\hline KP F-stat & 9.63 & 9.16 & 7.75 & 4.02 & 8.64 & 8.43 & 12.98 & 8.694 \\
\hline
\end{tabular}

Notes: This table reports the same specification as Table 3, column (2). All specifications are 2SLS. The instruments used are the depth measure and the market access IV as defined in Section 5. Nearby cities are dropped from the market access IV in columns 2-3. 'Drop Cities in Market Access IV' defines the point-to-point distance buffer (in km) for the set of cities to be dropped. Columns 4-6 examine robustness of the results to the inclusion of the same set of controls we added in Section 3. Columns 7 - 8 use Borusyak and Hull (2020) to correct for potential non-random shock exposure in the market access IV by reshuffling the number of frost free days across cities. 'Borusyak Hull correction' specifies how the reshuffling is done. Standard errors clustered at the city level. *** $\mathrm{p}<0.01, * * \mathrm{p}<0.05, * \mathrm{p}<0.1$. 
Table A.14: Heterogeneity of effect of land rents on shipping - model-simulated data

(1)

\begin{tabular}{lc} 
Independent Variables & $\Delta \ln ($ Shipment $)$ \\
\hline Depth & $0.508^{* * *}$ \\
& $(0.087)$ \\
$\ln \left(\right.$ Rent $\left._{C F}\right) \times$ Depth & $-0.022^{* *}$ \\
& $(0.010)$ \\
$\ln \left(\right.$ Rent $\left._{C F}\right)$ & 0.014 \\
& $(0.013)$ \\
\hline Observations & 553 \\
R-squared & 0.508 \\
\hline \hline
\end{tabular}

Notes: 'Depth' (residualized) indicates the port suitability measure. $\ln \left(\right.$ Rent $\left._{C F}\right)$ refers to the logarithm of the counterfactual (precontainerization) land rents. Robust standard errors in parentheses. $* * * \mathrm{p}<0.01, * * \mathrm{p}<0.05$, $* \mathrm{p}<0.1$.

Table A.15: The aggregate welfare effects of containerization - sensitivity analysis

\begin{tabular}{lccccc}
\hline \hline Model & $\begin{array}{c}\text { Welfare effect } \\
(\%)\end{array}$ & $\begin{array}{c}\text { Resource cost } \\
(\mathrm{pp})\end{array}$ & $\begin{array}{c}\text { Specialization } \\
\text { gains }(\mathrm{pp})\end{array}$ & $\begin{array}{c}\text { Local population } \\
\text { effect }\end{array}$ & $\begin{array}{c}\text { Rent } \\
\text { heterogeneity }\end{array}$ \\
\hline 1. Baseline & 3.84 & -0.67 & 0.39 & $0.033(0.052)$ & $-0.073^{* *}(0.032)$ \\
2. $20 \%$ higher $\beta$ in inversion & 3.86 & -0.82 & 0.46 & $0.017(0.053)$ & $-0.076^{* *}(0.032)$ \\
3. $20 \%$ lower $\beta$ in inversion & 3.84 & -0.53 & 0.33 & $0.049(0.051)$ & $-0.068^{* *}(0.032)$ \\
4. Counterfactual $\beta$ implying $65 \%$ increase in port share & 3.88 & -0.65 & 0.38 & $0.025(0.052)$ & $-0.074^{* *}(0.032)$ \\
5. Counterfactual $\beta$ implying $85 \%$ increase in port share & 3.81 & -0.70 & 0.42 & $0.040(0.052)$ & $-0.072^{* *}(0.032)$ \\
6. No depth-dependent change in $\nu(r)$ & 4.20 & -0.75 & 0.44 & $\mathrm{n} / \mathrm{a}$ & $\mathrm{n} / \mathrm{a}$ \\
7. Larger $\nu_{C F}$ : implies 30\% change in total transshipment cost & 4.52 & -0.71 & 0.42 & $0.034(0.055)$ & $-0.068^{* *}(0.033)$ \\
8. Larger $\nu_{C F}$ : implies $20 \%$ change in total transshipment cost & 3.13 & -0.63 & 0.38 & $0.029(0.049)$ & $-0.078^{* *}(0.031)$ \\
9. Monopolistic competition & 4.20 & -0.72 & 0.46 & $0.049(0.058)$ & $-0.076^{* *}(0.034)$ \\
10.Additional $10 \%$ inland cost transport reduction & 5.38 & -0.68 & 0.39 & $0.056(0.051)$ & $-0.081^{* * *}(0.030)$ \\
11.Additional $20 \%$ inland cost transport reduction & 6.86 & -0.69 & 0.40 & $0.076(0.052)$ & $-0.085^{* * *}(0.030)$
\end{tabular}

Notes: Welfare effect refers to the gain in welfare due to containerization in our baseline model. Resource cost refers to the difference in welfare gains between Benchmark 1 (with exogenous and free transshipment cost reductions) and Benchmark 2 (with identical land use across port cities). Specialization gains refer to the difference in welfare gains between the baseline and Benchmark 2. Local population effects report the (standardized) causal effect of shipping on local population, using residualized depth as an IV (note that this is the same as in column 5 of Table 2, except that Table 2 is restricted to the same sample as in the data, whereas this table uses the full sample of 553 port cities). Rent heterogeneity reports the (standardized) coefficient on the interaction of rent and depth on changes in shipping (note that Table A.14 reports the raw coefficients). The latter two coefficients cannot be estimated in model 6 , as depth is not used in that counterfactual. $* * * \mathrm{p}<0.01, * * \mathrm{p}<0.05, * \mathrm{p}<0.1$. 
Table A.16: Maritime Silk Road Counterfactual - country fixed effects

\begin{tabular}{|c|c|c|c|c|c|c|c|c|}
\hline & \multicolumn{4}{|c|}{ Baseline } & \multicolumn{4}{|c|}{ Benchmark 1} \\
\hline & (1) & (2) & (3) & (4) & (5) & (6) & (7) & (8) \\
\hline & $\Delta \ln ($ Shipment $)$ & $\Delta \ln ($ Port cost $)$ & $\Delta \ln$ (Market access) & $\Delta \ln$ (Population) & $\Delta \ln$ (Shipment) & $\Delta \ln ($ Port cost $)$ & $\Delta \ln$ (Market access) & $\Delta \ln$ (Population) \\
\hline \multirow[t]{2}{*}{ Treated port city } & $1.09629 * * *$ & $-0.13053 * * *$ & $0.01604 * * * *$ & $-0.02003^{* *}$ & $0.91013^{* * *}$ & -0.10536 & $0.01290 * * *$ & $0.01584 * * *$ \\
\hline & $(0.10472)$ & $(0.01255)$ & $(0.00277)$ & $(0.00807)$ & $(0.06377)$ & 0 & $(0.00232)$ & $(0.00285)$ \\
\hline \multirow[t]{2}{*}{ Untreated port city in treated country } & $-0.92756^{* * *}$ & 0.00933 & $0.04688^{* * * *}$ & 0.00551 & $-0.86467 * * *$ & 0 & $0.05045^{* * * *}$ & -0.01007 \\
\hline & $(0.03863)$ & $(0.00859)$ & $(0.00595)$ & $(0.00953)$ & $(0.07237)$ & 0 & $(0.00631)$ & $(0.00775)$ \\
\hline \multirow[t]{2}{*}{ Port city in untreated country } & $0.00362 * * *$ & $-0.00006^{*}$ & $-0.00140 * * *$ & -0.00133 & $0.00262^{* * * *}$ & 0 & $-0.00134 * * *$ & $0.00032^{* * * *}$ \\
\hline & $(0.00045)$ & $(0.00003)$ & $(0.00031)$ & $(0.00108)$ & $(0.00020)$ & 0 & $(0.00005)$ & $(0.00007)$ \\
\hline \multirow[t]{2}{*}{ Inland city in treated country } & & & $0.05329 * * *$ & -0.00020 & & & $0.05504 * * *$ & -0.00443 \\
\hline & & & $(0.00482)$ & $(0.00754)$ & & & $(0.00516)$ & $(0.00633)$ \\
\hline \multirow[t]{2}{*}{ Inland city in untreated country } & & & $-0.00192 * * *$ & 0.00009 & & & $-0.00155 * * *$ & 0.00006 \\
\hline & & & $(0.00005)$ & $(0.00006)$ & & & $(0.00005)$ & $(0.00006)$ \\
\hline Observations & 553 & 544 & 2636 & 2636 & 553 & 553 & 2636 & 2636 \\
\hline$R$-squared & 0.639 & 0.380 & 0.942 & 0.178 & 0.924 & 1.000 & 0.979 & 0.282 \\
\hline
\end{tabular}

Table A.17: Relationship between GDP per capita and nightlight luminosity

\begin{tabular}{|c|c|c|c|}
\hline \multirow[b]{2}{*}{ Independent variables } & \multicolumn{3}{|c|}{$\ln ($ GDP per capita) } \\
\hline & (1) & (2) & (3) \\
\hline $\ln$ (Luminosity) & $\begin{array}{c}0.126 * * * \\
(0.014)\end{array}$ & & \\
\hline $\ln$ (Population, 1990) & & $\begin{array}{c}0.107 * * * \\
(0.013)\end{array}$ & \\
\hline $\ln$ (Population, 1980) & & & $\begin{array}{c}0.100 * * * \\
(0.014)\end{array}$ \\
\hline Observations & 789 & 854 & 871 \\
\hline R-squared & 0.926 & 0.923 & 0.921 \\
\hline Country FE & $\checkmark$ & $\checkmark$ & $\checkmark$ \\
\hline
\end{tabular}

Notes: All regressions include country fixed effects. Robust standard errors in parentheses. $* * * \mathrm{p}<0.01, * * \mathrm{p}<0.05, * \mathrm{p}<0.1$. 
Table A.18: Port of Seattle: area per unit of cargo shipped

\begin{tabular}{cccc}
\hline \hline Year & Area & Throughput & Area/Throughput \\
\hline 1961 & $8,651,016$ & $2,022,192$ & 4.28 \\
1973 & $33,547,908$ & $4,135,795$ & 8.11 \\
\hline
\end{tabular}

Notes: Area reported in square feet, throughput in short tons. Data were not available far enough back in time to allow for the calculation of the five-year moving-average for 1961.

Table A.19: Location of stationary ships around the port

\begin{tabular}{lccccccccc}
\hline \hline Port & up to $1 \mathrm{~km}$ & $3 \mathrm{~km}$ & $5 \mathrm{~km}$ & $10 \mathrm{~km}$ & $15 \mathrm{~km}$ & $20 \mathrm{~km}$ & $25 \mathrm{~km}$ & $30 \mathrm{~km}$ & Total \\
\hline All & 11 & 39 & 57 & 76 & 83 & 86 & 89 & 90 & 100 \\
1st decile & 27 & 91 & 100 & 100 & 100 & 100 & 100 & 100 & 100 \\
2nd - 3rd decile & 49 & 81 & 95 & 95 & 95 & 95 & 95 & 95 & 100 \\
4th - 5th decile & 26 & 64 & 88 & 99 & 100 & 100 & 100 & 100 & 100 \\
6th - 7th decile & 21 & 57 & 78 & 96 & 100 & 100 & 100 & 100 & 100 \\
8th - 10th decile & 8 & 33 & 50 & 70 & 79 & 83 & 86 & 88 & 100 \\
\hline \hline
\end{tabular}

Notes: The table shows the location of stationary cargo ships for 94 random ports in our sample. Data were requested for 100 random ports in our sample. Four ports we requested data for had no anchored ships during the time window when data were reported and two ports from the source could not unambiguously be matched to our data. The data are from marinetraffic.com. Deciles shown by row refer to the number of anchored ships in the port. In general, larger ports have stationary ships located farther from the port. 
Table A.20: Prediction of port cost

\begin{tabular}{lc}
\hline \hline & $(1)$ \\
Independent Variables & Port cost \\
\hline $\ln$ (Shipment) & $-0.033 * *$ \\
& $(0.015)$ \\
Constant & $0.444 * * *$ \\
& $(0.145)$ \\
\hline Observations & 72 \\
R-squared & 0.074 \\
\hline \hline
\end{tabular}

Notes: The dependent variable, port cost, is taken from the port efficiency estimation in Blonigen and Wilson (2008) for 1991, available for 72 international port cities in our data (for details, see Appendix B.14). The regressor, $\ln$ (Shipment), refers to our shipping data in 1990. Observations are weighted by the inverse of the squared standard error of the estimated port cost as given by Blonigen and Wilson (2008). Robust standard errors in parentheses. $* * *$ $\mathrm{p}<0.01, * * \mathrm{p}<0.05, * \mathrm{p}<0.1$.

Table A.21: Predicted port cost

\begin{tabular}{cccc}
\hline \hline & $\mathrm{N}$ & mean & standard deviation \\
\hline 1950 & 2145 & 0.345 & 0.105 \\
1960 & 2145 & 0.328 & 0.106 \\
1970 & 2145 & 0.324 & 0.108 \\
1980 & 2145 & 0.317 & 0.105 \\
1990 & 2145 & 0.294 & 0.104 \\
\hline \hline
\end{tabular}

Notes: This table shows summary statistics for the predicted port cost based on the estimation in Table A.20. The 2,145 ports include the 553 ports with population data (Geopolis ports) as well as all other ports from the Lloyd's List data that do not have population data. 


\section{Figures}
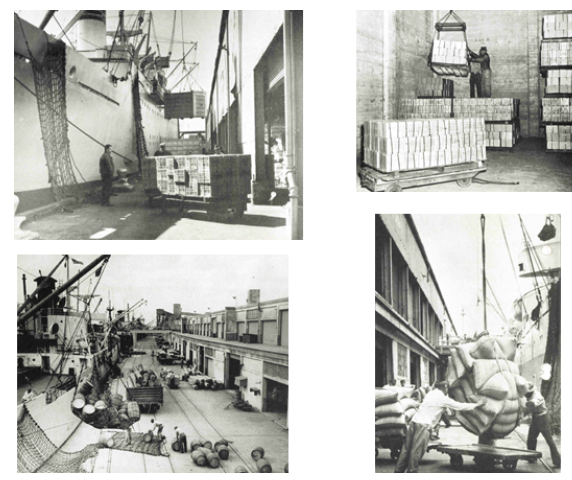

Breakbulk shipping, 1950s
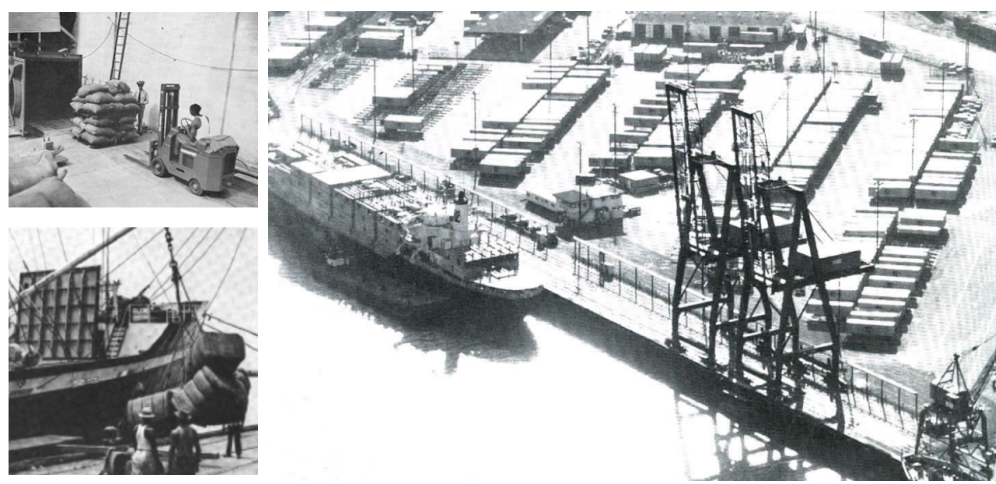

Container shipping, 1967

Figure A.1: Illustration of changes in port technology

Notes: Sources: Annual reports for the Port of Seattle and the Port of New Orleans (1950, 1951, 1952, 1955).

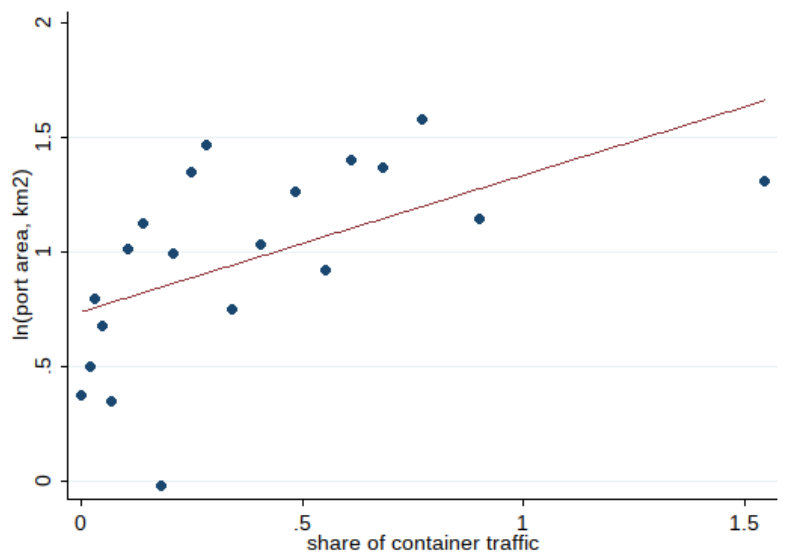

Figure A.2: Relationship between port area and share of container traffic

Notes: The figure shows the correlation between port area and the share of container traffic at the port. The latter is defined as $\frac{\text { container traffic in TEU-s*12 tons per TEU }}{\text { total merchandise traffic in tons }}$. As 12 tons per TEU is an approximation of the weight of containerized cargo, it is possible to get a share of container traffic that is larger than one. 

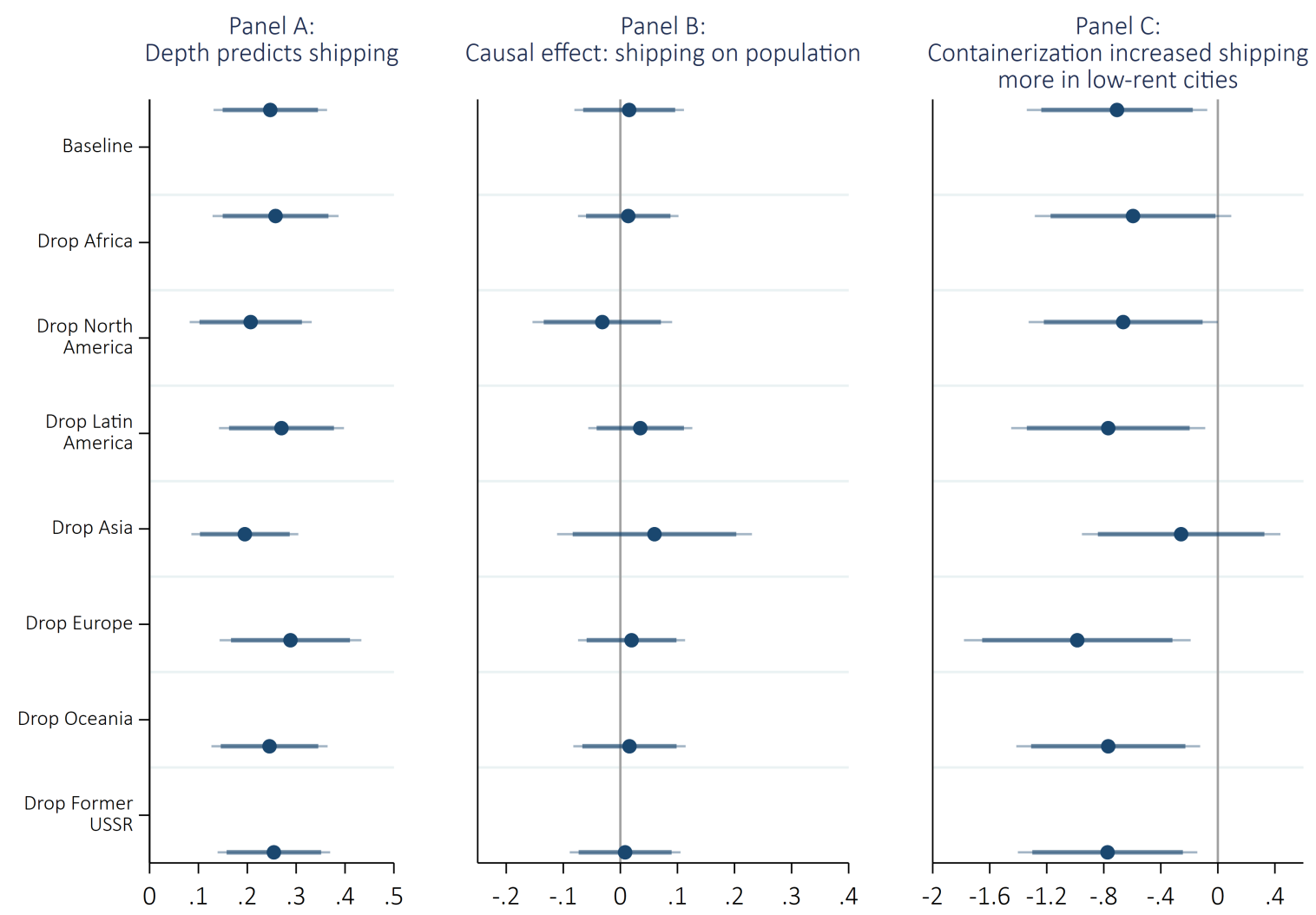

Figure A.3: Dropping continents one at a time

Notes: The plotted coefficients for Panel A are based on the specification in Table 1, column (5). The plotted coefficients for Panel B are based on the specification in Table 2, column (2). The plotted coefficients for Panel C are based on the specification in Table A.9, column (2). 'Baseline' uses the full sample, while the remaining rows drop continents one at a time as labelled. 

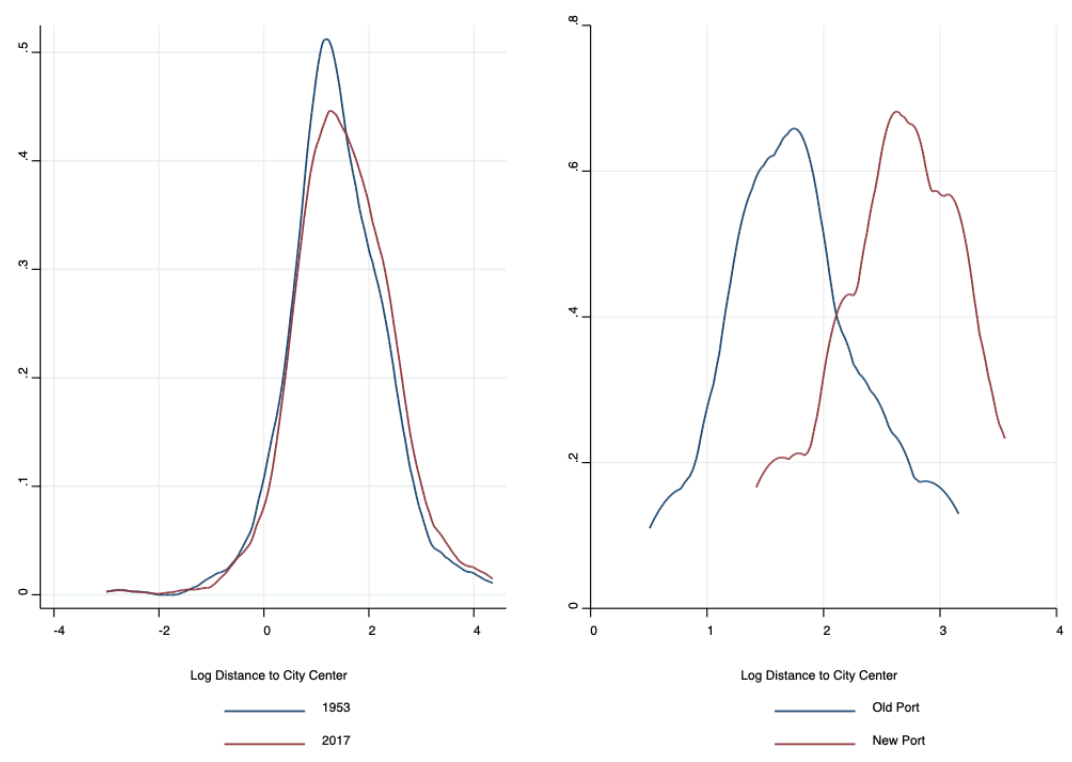

Figure A.4: Location of ports within cities 1953 - 2017

Notes: The figure plots the kernel density of the log distance to the city center for ports in 1953 and 2017. The left panel uses the full sample, the right panel restricts to only those cities where a new port was established after 1953. Data on the geocodes of ports are from the World Port Index. The calculation of city centroids is described in Appendix B.10.

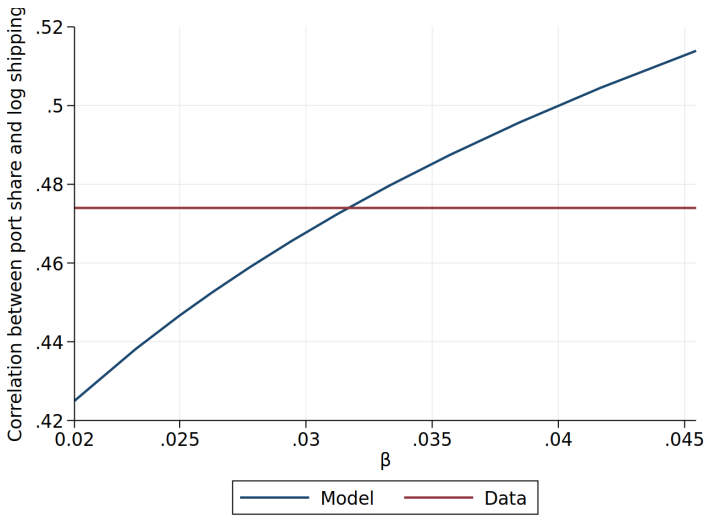

(a) Correlation between port share and shipping as a function of $\beta$

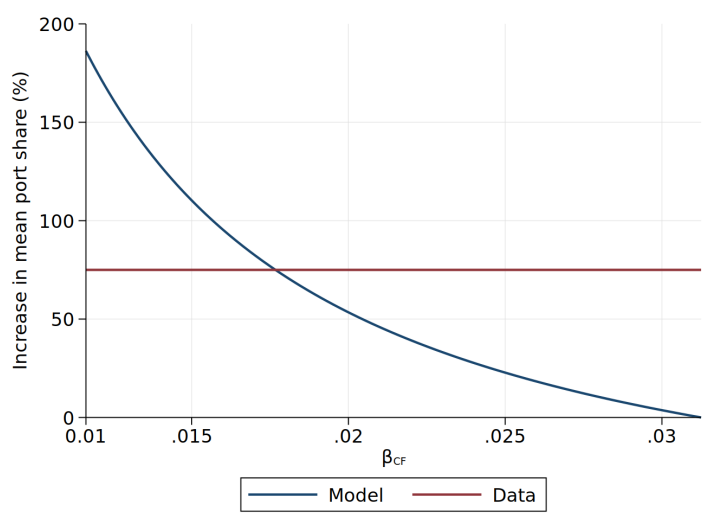

(b) Increase in mean port share as a function of $\beta_{C F}$

Figure A.5: Calibration of transshipment cost parameter $\beta$ in 1990 (left) and in the nocontainerization counterfactual (right)

Notes: The left panel shows the correlation between the port share and log shipping flows in the model as a function of the transshipment cost parameter $\beta$ (blue line). It also shows the value of this correlation based on 7 ports in the data (red line). The right panel shows the increase in mean port share in the model, keeping the non-technological determinants of the port share fixed, as a function of $\beta_{C F}$ (blue line). It also shows the increase in port share induced by containerization in the data (red line). 


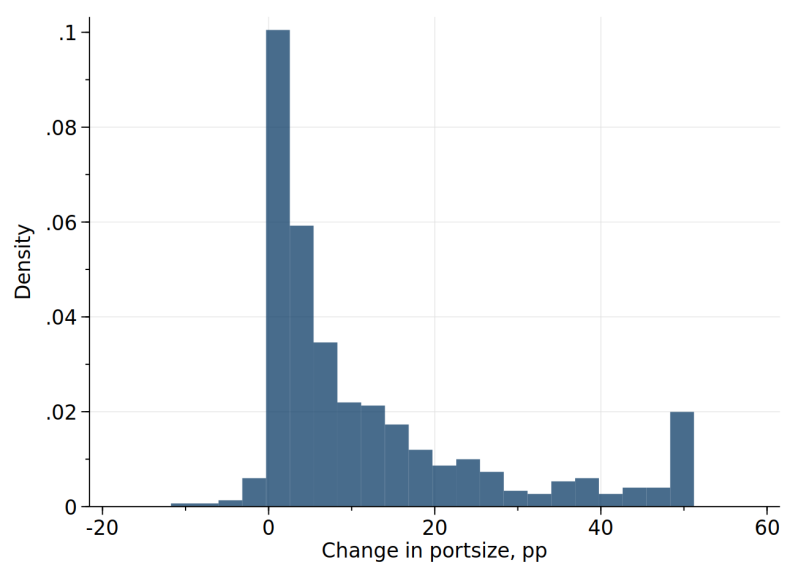

Figure A.6: Histogram of changes in port share between the counterfactual and the 1990 equilibrium, in percentage points

Notes: The figure shows the histogram of the percentage point change in port shares between the modelsimulated counterfactual (pre-containerization) and the 1990 equilibrium (after containerization, also modelsimulated data).

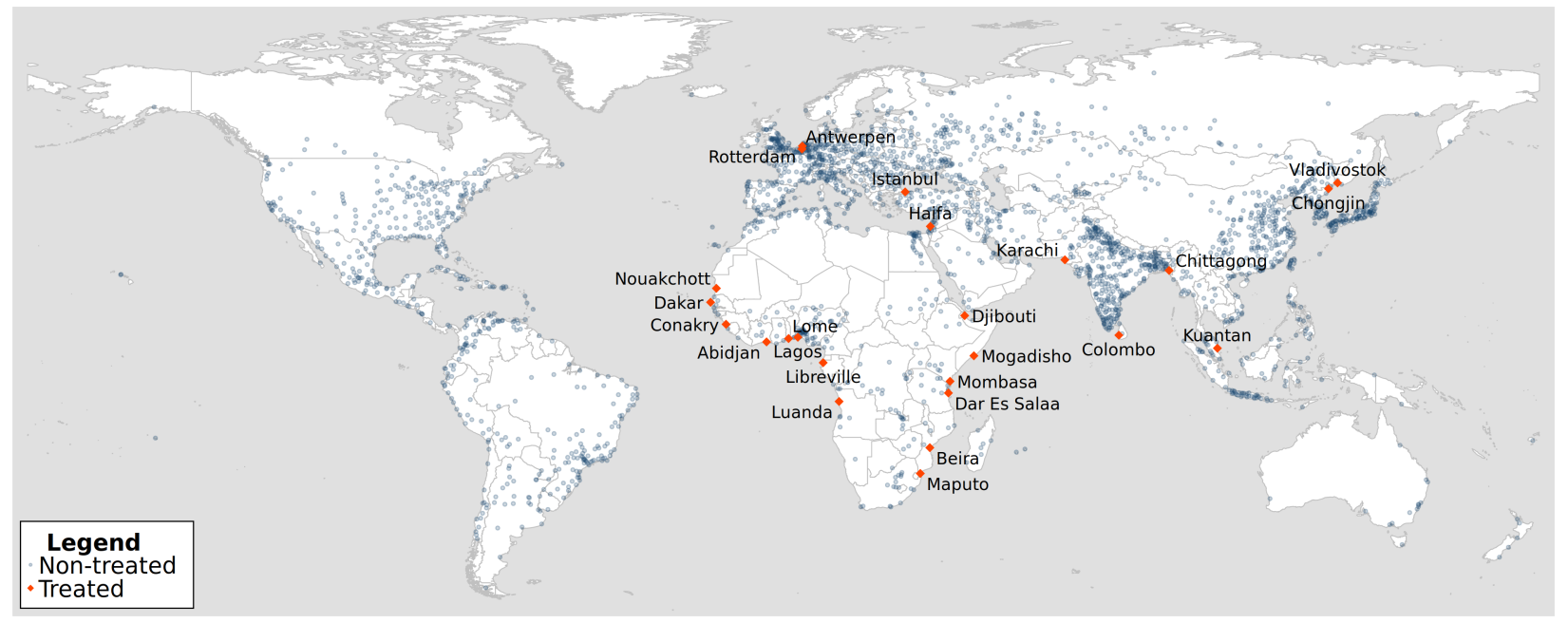

Figure A.7: Maritime Silk Road: targeted ports

Notes: The targeted cities are: Abidjan (Côte d'Ivoire), Antwerpen (Belgium), Beira (Mozambique), Chittagong (Bangladesh), Chongjin (North Korea), Colombo (Sri Lanka), Conakry (Guinea), Dakar (Senegal), Dar Es Salaam (Tanzania), Djibouti (Djibouti), Haifa (Israel), Istanbul (Turkey), Karachi (Pakistan), Kuantan (Malaysia), Lagos (Nigeria), Libreville (Gabon), Lome (Togo), Maputo (Mozambique), Mogadisho (Somalia), Mombasa (Kenya), Nouakchott (Mauritania), Rotterdam (Netherlands) and Vladivostok (Russia). Source: OECD (2018). 


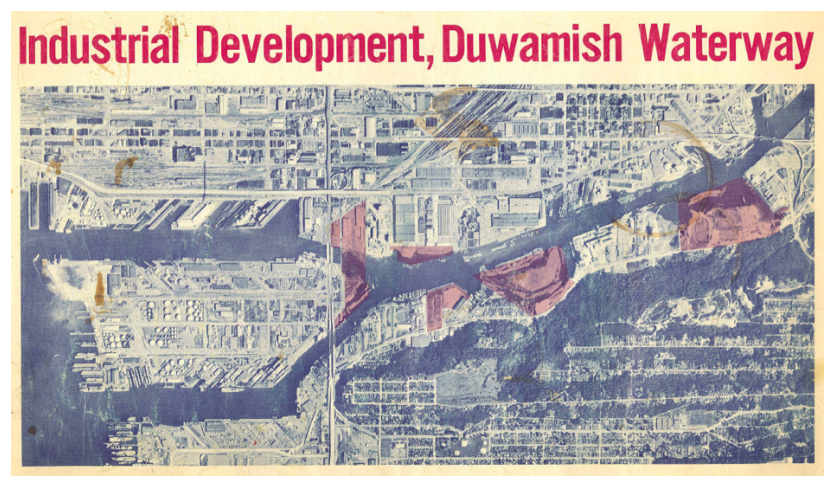

Acquired land parcels (red shading), 1963

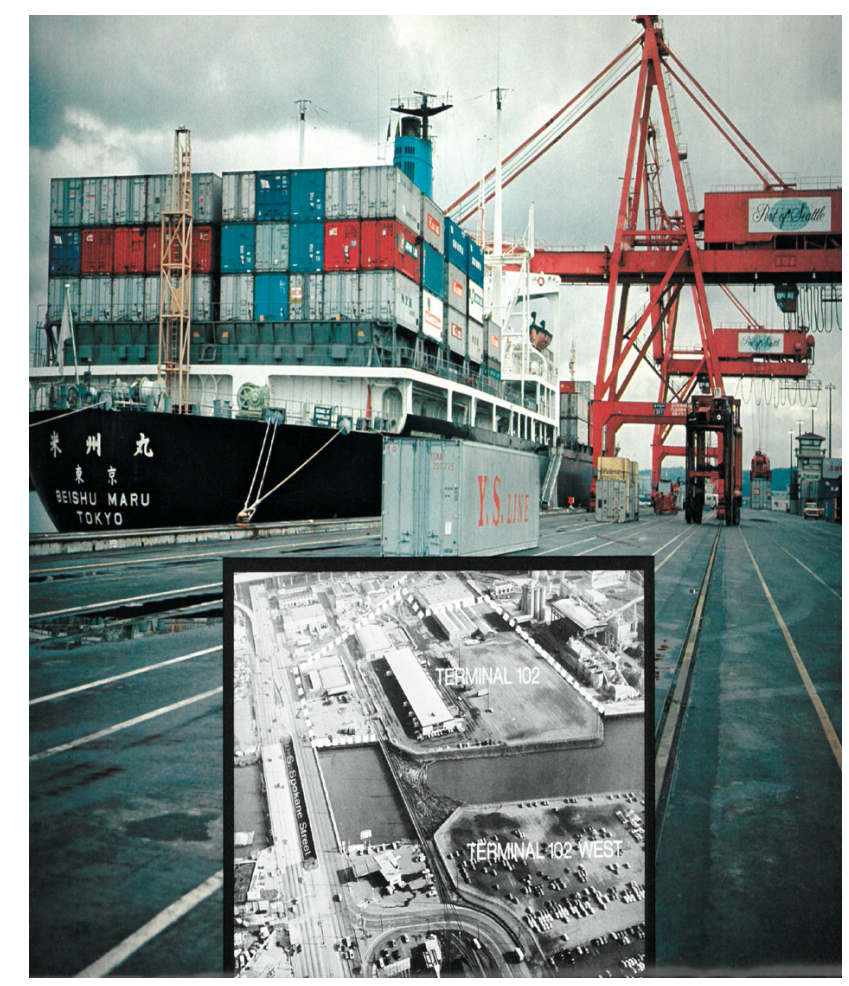

Completed terminal 102, 1970

Figure A.8: Illustration of port development, Seattle

Notes: The two panels illustrate development of the port through the 1960s. The first panel shows the initial set of land parcels acquired by the port along the Duwamish Waterway in the early 1960s. The second shows a container terminal completed in 1970 within this project. Sources: 'Port of Seattle: Industrial Development, Duwamish Waterway' (1963), 'Annual Report of the Port of Seattle’ (1970). 


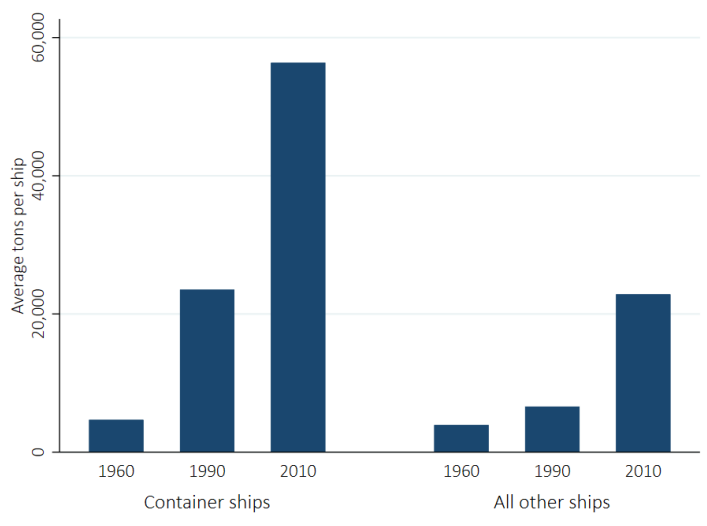

Figure A.9: Development of ship sizes over time, 1960-2010

Notes: The figure illustrates the growth in ship size, as measured in average tons per newly built ship in a given year, for the years 1960, 1990, and 2010, for container-ships and all other ships (i.e., excluding container-ships), respectively. Source: Haworth (2020). 


\section{References}

Abe, K. and J. Wilson (2009). Weathering the Storm: Investing in Port Infrastructure to Lower Trade Costs in East Asia. World Bank.

Allen, T. and C. Arkolakis (2014). Trade and the Topography of the Spatial Economy. Quarterly Journal of Economics 129(3), 1085-1140.

Allen, T. and C. Arkolakis (2019). The Welfare Effects of Transportation Infrastructure Improvements.

Australian Competition and Consumer Commission (2017). Container Stevedoring and Monitoring Report 2016-17. Technical report, ACCC.

Baragwanath, K., R. Goldblatt, G. Hanson, and A. Khandelwal (2019). Detecting Urban Markets with Satellite Imagery: An Application to India. Journal of Urban Economics (103173).

Bernard, A., J. Eaton, J. Jensen, and S. Kortum (2003). Plants and Productivity in International Trade. American Economic Review 93(4), 1268-1290.

Blonigen, B. and W. Wilson (2008). Port Efficiency and Trade Flows. Review of International Economics 16(1), 21-36.

Borusyak, K. and P. Hull (2020). Non-Random Exposure to Exogenous Shocks: Theory and Applications. National Bureau of Economic Research (Working Paper 27845).

Ciccone, A. and R. Hall (1993). Productivity and the Density of Economic Activity. National Bureau of Economic Research (Working Paper 4313).

Desmet, K. and J. Rappaport (2017). The Settlement of the United States, 1800-2000: The Long Transition Towards Gibrat's Law. Journal of Urban Economics 98, 50-68.

Donaldson, D. and A. Storeygard (2016). The View from Above: Applications of Satellite Data in Economics. Journal of Economic Perspectives 30(4), 171-98.

Haworth, R. B. (2020). Miramar ship index.

Kennan, J. and J. Walker (2011). The Effect of Expected Income on Individual Migration Decisions. Econometrica 79(1), 211-251.

Kirchner, M. (2006). Container Vessels and Risk Aggregation: The Cargo Underwriter's View. Technical report, AXA Corporate Solutions.

Lloyd's of London Press (1990). Lloyd's Ports of the World.

Martín-Antón, M., d. C. J. M. Negro, V., J. S. López-Gutiérrez, and M. D. Esteban (2016). Review of coastal land reclamation situation in the world. Journal of Coastal Research 75, $667-671$.

OECD (2018). The Belt and Road Initiative in the Global Trade, Investment, and Finance Landscape. Technical report, OECD Publishing Paris.

Port Authority of Seattle (1989). Seaport Properties Book. Technical report, Port Authority of Seattle.

Port of Long Beach (1971). Harbor Highlights 1971 Report. Technical report, Port Authority of Long Beach.

Port of New Orleans (1984). 88th Annual Report. Technical report, Port of New Orleans Board of Commissioners.

Riffenburgh, R. (2012). A Project History of the Port of Long Beach 1970 to 2010. Technical report, Port of Long Beach.

Saiz, A. (2010). The Geographic Determinants of Housing Supply. Quarterly Journal of Economics 125(3), 1253-1296. 
CENTRE FOR ECONOMIC PERFORMANCE

Recent Discussion Papers

\begin{tabular}{|c|c|c|}
\hline 1733 & $\begin{array}{l}\text { Jonathan Colmer } \\
\text { John Voorheis }\end{array}$ & $\begin{array}{l}\text { The grandkids aren’t alright: the } \\
\text { intergenerational effects of prenatal pollution } \\
\text { exposure }\end{array}$ \\
\hline 1732 & $\begin{array}{l}\text { Kabir Dasgupta } \\
\text { André Diegmann } \\
\text { Tom Kirchmaier } \\
\text { Alexander Plum }\end{array}$ & $\begin{array}{l}\text { Heterogeneity in criminal behavior after child } \\
\text { birth: the role of ethnicity }\end{array}$ \\
\hline 1731 & $\begin{array}{l}\text { Andreas Diemer } \\
\text { Tanner Regan }\end{array}$ & $\begin{array}{l}\text { No inventor is an island: social connectedness } \\
\text { and the geography of knowledge flows in the } \\
\text { US }\end{array}$ \\
\hline 1730 & $\begin{array}{l}\text { Hanming Fang } \\
\text { Chunmian Ge } \\
\text { Hanwei Huang } \\
\text { Hongbin Li }\end{array}$ & $\begin{array}{l}\text { Pandemics, global supply chains, and local } \\
\text { labor demand: evidence from } 100 \text { million } \\
\text { posted jobs in China }\end{array}$ \\
\hline 1729 & $\begin{array}{l}\text { Ria Ivandić } \\
\text { Tom Kirchmaier } \\
\text { Ben Linton }\end{array}$ & $\begin{array}{l}\text { Changing patterns of domestic abuse during } \\
\text { COVID-19 lockdown }\end{array}$ \\
\hline 1728 & $\begin{array}{l}\text { Jonathan Colmer } \\
\text { Ralf Martin } \\
\text { Mirabelle Muûls } \\
\text { Ulrich J. Wagner }\end{array}$ & $\begin{array}{l}\text { Does pricing carbon mitigate climate change? } \\
\text { Firm-level evidence from the European Union } \\
\text { emissions trading scheme }\end{array}$ \\
\hline 1727 & $\begin{array}{l}\text { Tony Beatton } \\
\text { Michael P. Kidd } \\
\text { Matteo Sandi }\end{array}$ & School indiscipline and crime \\
\hline 1726 & $\begin{array}{l}\text { Maximilian v. Ehrlich } \\
\text { Henry G. Overman }\end{array}$ & $\begin{array}{l}\text { Place-based policies and spatial disparities } \\
\text { across European cities }\end{array}$ \\
\hline 1725 & $\begin{array}{l}\text { Gabriel M. Ahlfeldt } \\
\text { Thilo N. H. Albers } \\
\text { Kristian Behrens }\end{array}$ & Prime Locations \\
\hline
\end{tabular}




\begin{tabular}{|c|c|c|}
\hline 1724 & $\begin{array}{l}\text { Benjamin Handel } \\
\text { Jonathan Kolstad } \\
\text { Thomas Minten } \\
\text { Johannes Spinnewijn }\end{array}$ & $\begin{array}{l}\text { The Social Determinants of Choice Quality: } \\
\text { Evidence from Health Insurance in the } \\
\text { Netherlands }\end{array}$ \\
\hline 1723 & $\begin{array}{l}\text { Claudia Hupkau } \\
\text { Barbara Petrongolo }\end{array}$ & $\begin{array}{l}\text { Work, Care and Gender During the Covid-19 } \\
\text { Crisis }\end{array}$ \\
\hline 1722 & $\begin{array}{l}\text { Ross Levine } \\
\text { Yona Rubinstein }\end{array}$ & $\begin{array}{l}\text { Selection Into Entrepreneurship and Self- } \\
\text { Employment }\end{array}$ \\
\hline 1721 & Sandra McNally & $\begin{array}{l}\text { Gender Differences in Tertiary Education: } \\
\text { What Explains STEM Participation? }\end{array}$ \\
\hline 1720 & $\begin{array}{l}\text { Edoardo di Porto } \\
\text { Paolo Naticchioni } \\
\text { Vincenzo Scrutinio }\end{array}$ & $\begin{array}{l}\text { Partial Lockdown and the Spread of Covid- } \\
\text { 19: Lessons From the Italian Case }\end{array}$ \\
\hline 1719 & $\begin{array}{l}\text { Swati Dhingra } \\
\text { Stephen Machin }\end{array}$ & The Crisis and Job Guarantees in Urban India \\
\hline 1718 & Stephen J. Redding & Trade and Geography \\
\hline 1717 & $\begin{array}{l}\text { Arun Advani } \\
\text { Felix Koenig } \\
\text { Lorenzo Pessina } \\
\text { Andy Summers }\end{array}$ & $\begin{array}{l}\text { Importing Inequality: Immigration and the } \\
\text { Top } 1 \text { Percent }\end{array}$ \\
\hline 1716 & $\begin{array}{l}\text { Pol Antràs } \\
\text { Stephen J. Redding } \\
\text { Esteban Rossi-Hansberg }\end{array}$ & Globalization and Pandemics \\
\hline 1715 & $\begin{array}{l}\text { Davin Chor } \\
\text { Kalina Manova } \\
\text { Zhihong Yu }\end{array}$ & $\begin{array}{l}\text { Growing Like China: Firm Performance and } \\
\text { Global Production Line Position }\end{array}$ \\
\hline
\end{tabular}

The Centre for Economic Performance Publications Unit

Tel: +44 (0)2079557673 Email info@cep.lse.ac.uk

Website: http://cep.lse.ac.uk Twitter: @CEP_LSE 